Une déclaration d'un comité consultatif (DCC)

Comité consultatif national de l'immunisation $(\mathrm{CCNI})^{\dagger}$

\title{
DÉCLARATION SUR L'UTILISATION DU VACCIN CONJUGUÉ CONTRE LE PNEUMOCOQUE 13-VALENT CHEZ L'ADULTE (PNEU-C-13)
}

\section{Préambule}

Le Comité consultatif national de l'immunisation (CCNI) donne à l'Agence de la santé publique du Canada (ASPC) des conseils constants et à jour liés à l'immunisation dans les domaines de la médecine, des sciences et de la santé publique. L'ASPC reconnaît que les conseils et les recommandations figurant dans la présente déclaration reposent sur les connaissances scientifiques les plus récentes et diffuse le document à des fins d'information. Les personnes qui administrent le vaccin doivent également connaître le contenu de la monographie de produit pertinente. Les recommandations d'utilisation et les autres renseignements qui figurent dans le présent document peuvent différer du contenu de la monographie de produit du fabricant du vaccin au Canada. Les fabricants ont fait approuver leur vaccin et démontré son innocuité et son efficacité uniquement lorsqu'il est utilisé conformément à la monographie de produit. Les membres du CCNI et les agents de liaison doivent se conformer à la politique de l'ASPC régissant les conflits d'intérêts, notamment déclaré chaque année les conflits d'intérêts possibles.

${ }^{\dagger}$ Membres du CCNI : Dre B. Warshawsky (présidente), Dr I. Gemmill (vice-président), Dre N. Crowcroft, Dre B. Henry, Dre D. Kumar, Dre C. Quach-Thanh, Dre M. Salvadori, Dr B. Seifert, Dre N. Sicard, Dre W. Vaudry, Dr R. Warrington.

Agents de liaison : D ${ }^{r e}$ J. Blake (Société des obstétriciens et gynécologues du Canada), Dr A. Corriveau (Conseil des médecins-hygiénistes en chef), Dre S. Deeks (Association canadienne de santé publique), Dre A. Mawle (U.S. Centers for Disease Control and Prevention), Dre D. Moore (Société canadienne de pédiatrie), Dre A. Pham-Huy (Canadian Association for Immunization Research and Evaluation).

Représentants d'office : Dre M. Carew (Direction générale de la santé des Premières nations et des Inuits, Santé Canada), Lt.-Col. Dr P. Eagan (Groupe des Services de santé des Forces canadiennes, ministère de la Défense nationale), Dre A. Klein (Direction des produits biologiques et des thérapies génétiques, Santé Canada), Dre B. Law (Centre de l'immunisation et des maladies respiratoires infectieuses, Agence de la santé publique du Canada), D'e B. Raymond (Centre de l'immunisation et des maladies respiratoires infectieuses, ASPC/Comité canadien d'immunisation), Dre E. Taylor (Direction des produits de santé commercialisés, Santé Canada), Mme M. St-Laurent (Centre de l'immunisation et des maladies respiratoires infectieuses, Agence de la santé publique du Canada).

'La présente déclaration a été rédigée par $\mathrm{D}^{\mathrm{re}} \mathrm{C}$. Quach-Thanh et $\mathrm{M}^{\mathrm{me}} \mathrm{H}$. Thomas, et approuvée par le CCNI.

Le CCNI tient à remercier la contribution des Lt-Col Dr J. Anderson, Dr J. Brophy, Dr P. DeWals, Dre E. Farzad, Mme M. Helferty, Dre J. Johnstone, Dr J. Kellner, Dre J. Laroche, $D^{r e}$ S. McNeil, Dre H. Morrison, Dre A. Opavsky, Dre S. Rechner, M ${ }^{\text {me }}$ L. Sherrard, Dr G. Tyrrell, Dr P. Van Buynder et Dre V. Senikas. 


\section{Table des matières}

Sommaire de l'information contenue dans la présente déclaration du CCNI

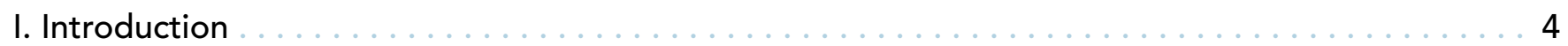

II. Méthodologie . . . . . . . . . . . . . . . . . . . . . . . . . . 4

III. Épidemiologie des infections à pneumocoque au Canada . . . . . . . . . . . . . . . . 4

IV. Vaccin . . . . . . . . . . . . . . . . . . . . . . . 12

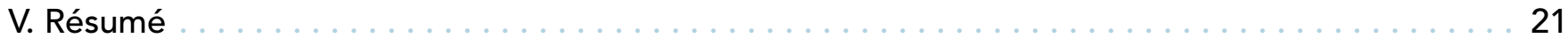

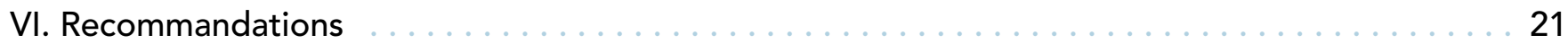

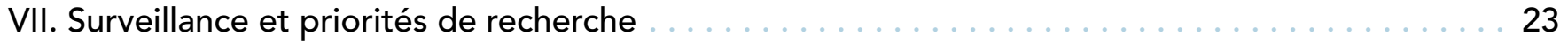

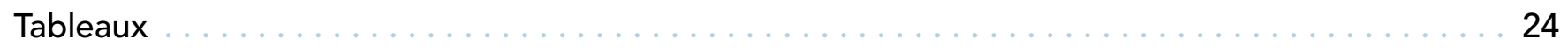

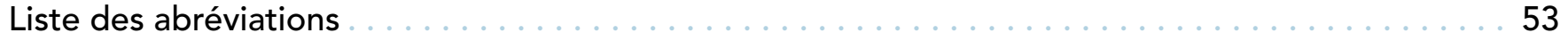

Références . . . . . . . . . . . . . . . . . . . . . . . 54 


\section{Sommaire de l'information contenue dans la présente déclaration du CCNI}

\section{Le tableau suivant résume l'information importante pour les vaccinateurs. Veuillez consulter le reste de la Déclaration pour obtenir plus de précisions.}

\section{Quoi}

\section{Qu'est-ce qu'une infection à pneumocoque?}

Le Streptococcus pneumoniae est une bactérie à Gram positif qui cause des maladies invasives, comme la septicémie, la méningite et la pneumonie. Les symptômes varient selon le site de l'infection. Elle est une cause importante de morbidité et de mortalité chez les enfants, les personnes âgées, les sujets immunodéprimés et les personnes présentant une affection chronique. Pour obtenir de plus amples renseignements, consulter le site Web de l'ASPC (www.phac-aspc.gc.ca/im/vpd-mev/pneumococcal-fra.php)

\section{Qu'est-ce que le vaccin contre le pneumocoque?}

II existe deux formes de vaccins contre le pneumocoque : un vaccin conjugué (PNEU-C-13 et PNEU-C-10) et un vaccin polysaccharidique (PNEU-P-23).

\section{Qui}

\section{Qui devrait recevoir le vaccin?}

La présente déclaration concerne les adultes (18 ans ou plus), et notamment:

1. les adultes ayant reçu une greffe de cellules souches hématopoḯtiques (GCSH);

2. les adultes infectés par le $\mathrm{VIH}$;

3. les adultes immunodéprimés.

Les recommandations relatives aux enfants peuvent être consultées sur le site Web du CCNI (www.phac-aspc.gc.ca/publicat/ccdrrmtc/10vol36/acs-12/index-fra.php)

\section{Comment}

\section{Dose et calendrier}

Dans le cas du vaccin PNEU-C-13, la dose est de 0,5 ml par voie intramusculaire (IM).

Plus particulièrement :

1. chez les adultes ayant reçu une greffe de moelle: administrer trois doses de vaccin PNEU-C-13, en commençant de trois à neuf mois après la greffe. Les doses devraient être administrées à au moins quatre semaines d'intervalle. Il faut ensuite administrer une dose de rappel du vaccin PNEU-P-23 de 12 à 18 mois après la greffe (de 6 à 12 mois après la dernière dose du vaccin PNEU-C-13);

2. chez les adultes infectés par le VIH : administrer une dose de vaccin PNEU-C-13, puis une dose de vaccin PNEU-P-23 après huit semaines. II n'existe aucune donnée indiquant que l'administration d'une dose de rappel du vaccin PNEU-C-13 confère un quelconque avantage. La dose de vaccin PNEU-C-13 devrait être administrée au moins un an après la dernière dose de vaccin PNEU-P-23;

3. chez les adultes immunodéprimés : administrer une dose de vaccin PNEU-C-13, puis une dose de vaccin PNEU-P-23 huit semaines plus tard. II n'existe aucune donnée indiquant que l'administration d'une dose de rappel du vaccin PNEU-C-13 confère un quelconque avantage. La dose de vaccin PNEU-C-13 devrait être administrée au moins un an après la dernière dose de vaccin PNEU-P-23.

\section{Précautions/contre-indications}

Le vaccin PNEU-C-13 est contre-indiqué chez les personnes ayant déjà présenté une réaction anaphylactique à l'un des composants du vaccin, y compris à l'anatoxine diphtérique.

\section{Administration en concomitance}

Il est possible d'administrer le vaccin PNEU-C-13 en concomitance avec d'autres vaccins (en utilisant un autre site d'injection).

\section{Pourquoi}

Les données probantes actuelles appuient l'utilisation du vaccin PNEU-C-13 chez les adultes immunodéprimés, étant donné que ceux-ci présentent un risque accru de contracter une infection invasive à pneumocoque (IIP) et que les vaccins conjugués contre le pneumocoque se sont révélés plus efficaces chez certains groupes de sujets immunodéprimés.

L'infection à pneumocoque peut provoquer de graves infections d'autres types.

La vaccination est le meilleur moyen de prévenir ces infections. 


\section{Introduction}

La présente déclaration vise à compléter les déclarations antérieures sur les vaccins conjugués contre le pneumocoque ${ }^{1-3}$ et à fournir de l'information sur une nouvelle indication qui a été approuvée concernant l'utilisation du vaccin conjugué contre le pneumocoque 13-valent, à savoir PrevnarMD 13 (PNEU-C-13). En janvier 2012, I'utilisation du vaccin PNEU-C-13 a été autorisée chez les adultes de 50 ans ou plus pour prévenir les infections invasives à pneumocoque (IIP), notamment la septicémie, la méningite, la bactériémie et la pneumonie (avec ou sans empyème) avec bactériémie. Lorsqu'on disposera de données supplémentaires sur I'utilisation du vaccin PNEU-C-13 chez l'adulte, le CCNI les examinera et formulera, le cas échéant, de nouvelles directives. Le vaccin polysaccharidique 23-valent (PNEU-P-23) ne sera pas abordé en détail dans la présente déclaration. Les recommandations relatives à son utilisation demeurent inchangées. (www.phac-aspc.gc.ca/publicat/cig-gci/ index-fra.php)

\section{Méthodologie}

Le CCNI a examiné ${ }^{4}$ les éléments tels le fardeau de la maladie et la population cible, l'innocuité, l'immunogénicité, l'efficacité potentielle et réelle du (des) vaccin(s), les calendriers de vaccination et d'autres aspects de la stratégie globale d'immunisation. Suite à une évaluation critique de chacune des études, des tableaux sommaires avec cotes de qualité des preuves utilisant la hiérarchie méthodologique du CCNI (tableaux 6 et 7), des recommandations relatives à l'utilisation des vaccins ont été développées. Le président du groupe de travail a présenté les données probantes et proposé des
La présente déclaration:

- fait la mise à jour de l'épidémiologie des IIP au Canada en ce qui a trait à l'introduction du vaccin PNEU-C-13;

- présente une revue des articles portant sur I'utilisation de vaccins conjugués contre le pneumocoque dans des populations adultes (PNEU-C-7 et PNEU-C-13, lorsque disponibles);

- fournit des recommandations quant à l'utilisation du vaccin conjugué 13-valent chez l'adulte (PNEU-C-13) et à I'utilisation du PNEU-P-23 en plus du PNEU-C-13. Bien que le PNEU-C-13 ait été approuvé pour les adultes âgés de 50 ans et plus, cette déclaration se concentrera sur les adultes (tout âge) avec des conditions à haut risque d'IIP et les adultes en santé de 65 ans et plus à cause du fardeau de la maladie ayant mené à la recommandation d'utiliser le PNEU-P-23 dans ce groupe d'âge.

recommandations au CCNI. Après un examen approfondi des preuves et une consultation des membres lors de réunions du CCNI, le Comité a adopté certaines recommandations. La présente déclaration présente une description des considérations pertinentes, les raisons sous-tendant certaines décisions et les lacunes dans les connaissances. L'ASPC a consigné les renseignements sur ces processus tout au long de la synthèse des connaissances et de l'élaboration des recommandations.

\section{III. Épidemiologie des infections à pneumocoque au Canada}

\section{III.1 DESCRIPTION DE LA MALADIE}

L'infection invasive à pneumocoque (IIP) est une maladie grave causée par la bactérie Streptococcus pneumoniae. Il existe actuellement 92 sérotypes de la bactérie connus à l'échelle mondiale, dont 15 sont à l'origine de la plupart des cas de maladie. Le S. pneumoniae peut se transmettre d'une personne à une autre par des gouttelettes projetées du nez ou de la bouche de la personne infectée lorsqu'elle éternue ou tousse. Les infections à S. pneumoniae sont une cause majeure de morbidité et de mortalité dans le monde. Il est estimé qu'environ un million d'enfants par année meurent d'infection à pneumocoque; la majorité de ces cas surviennent chez de jeunes enfants dans des pays en développement. Dans les pays développés, un lourd fardeau associé à la maladie existe également chez les personnes âgées. Chez les enfants et les adultes, les voies respiratoires supérieures et le rhinopharynx sont souvent colonisés par le S. pneumoniae, sans que cela provoque des symptômes. L'IIP est une infection grave qui survient lorsque la bactérie envahit des sites normalement stériles, comme le système sanguin et le système nerveux central. Les symptômes ou manifestations cliniques dépendent du site de l'infection. L'IlP peut donner lieu à plusieurs syndromes, comme la bactériémie, la méningite et/ou la 
pneumonie (avec ou sans empyème) avec bactériémie. Certains états pathologiques prédisposent les sujets à des complications secondaires à une infection pneumococcique, notamment l'anémie falciforme ou d'autres hémoglobinopathies, l'insuffisance rénale chronique, une hépatopathie chronique, un déficit immunitaire, une asplénie fonctionnelle ou anatomique, des fuites de liquide céphalorachidien, le diabète et l'infection à VIH. Les personnes plus âgées, en particulier celles de 65 ans et plus, courent également un risque accru d'IIP5.

Les données épidémiologiques sur les IIP proviennent de deux sources canadiennes : le Système canadien de surveillance des maladies à déclaration obligatoire (SCSMDO) et le Laboratoire national de microbiologie (LNM).

\section{III.2 DISTRIBUTION DE LA MALADIE}

Depuis que I'IIP est devenue une maladie à déclaration obligatoire au Canada en 2000, le nombre de cas déclarés et les taux d'incidence ont augmenté; ils se sont toutefois stabilisés au cours des cinq dernières années, le taux d'incidence se maintenant à 10 cas pour 100000 habitants (figure 1). L'augmentation des taux d'incidence observée entre 2001 et 2004 était vraisemblablement attribuable, du moins en partie, à un biais de déclaration, le nombre de cas déclarés augmentant à mesure que le système de surveillance passive était mieux connu et compris.

Figure 1. Nombre de cas déclarés d'IIP et taux d'incidence, Canada, 2001-2011

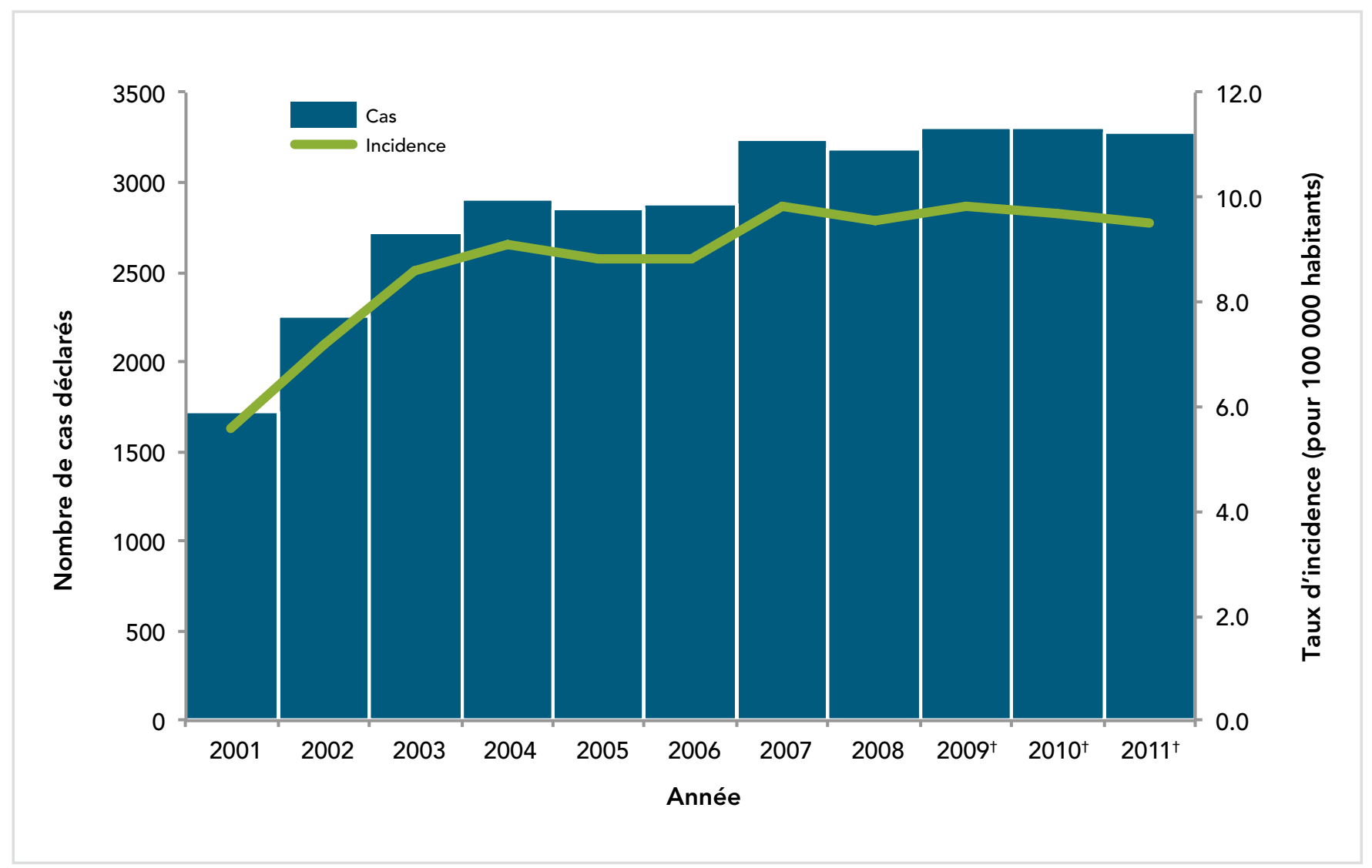

* Données tirées du Système canadien de surveillance des maladies à déclaration obligatoire.

${ }^{\dagger} D^{\prime}$ après des données provisoires. 


\section{III.3 DISTRIBUTION GÉOGRAPHIQUE}

C'est en Ontario et au Québec que l'on observe le plus de cas déclarés, ce qui n'est pas étonnant puisqu'il s'agit de provinces populeuses. Dans les territoires, cependant, le taux d'incidence pour 100000 habitants et la variabilité des résultats sont élevés, vraisemblablement en raison de la petite taille de la population (figure 2, tableaux 1 et 2).
Fait à signaler, on attribue les taux d'incidence élevés observés en Colombie-Britannique (BC), en Alberta (AB), en Saskatchewan (SK) et au Manitoba (MB) aux éclosions importantes dues au sérotype 5 qui sont survenues dans ces provinces de 2006 à 2008. Aucune éclosion n'explique le taux d'incidence élevé observé au Québec.

Figure 2. Nombre moyen de cas et taux d'incidence moyens d'IIP (par 100000 habitants), par province et territoire, Canada, 2007-2011

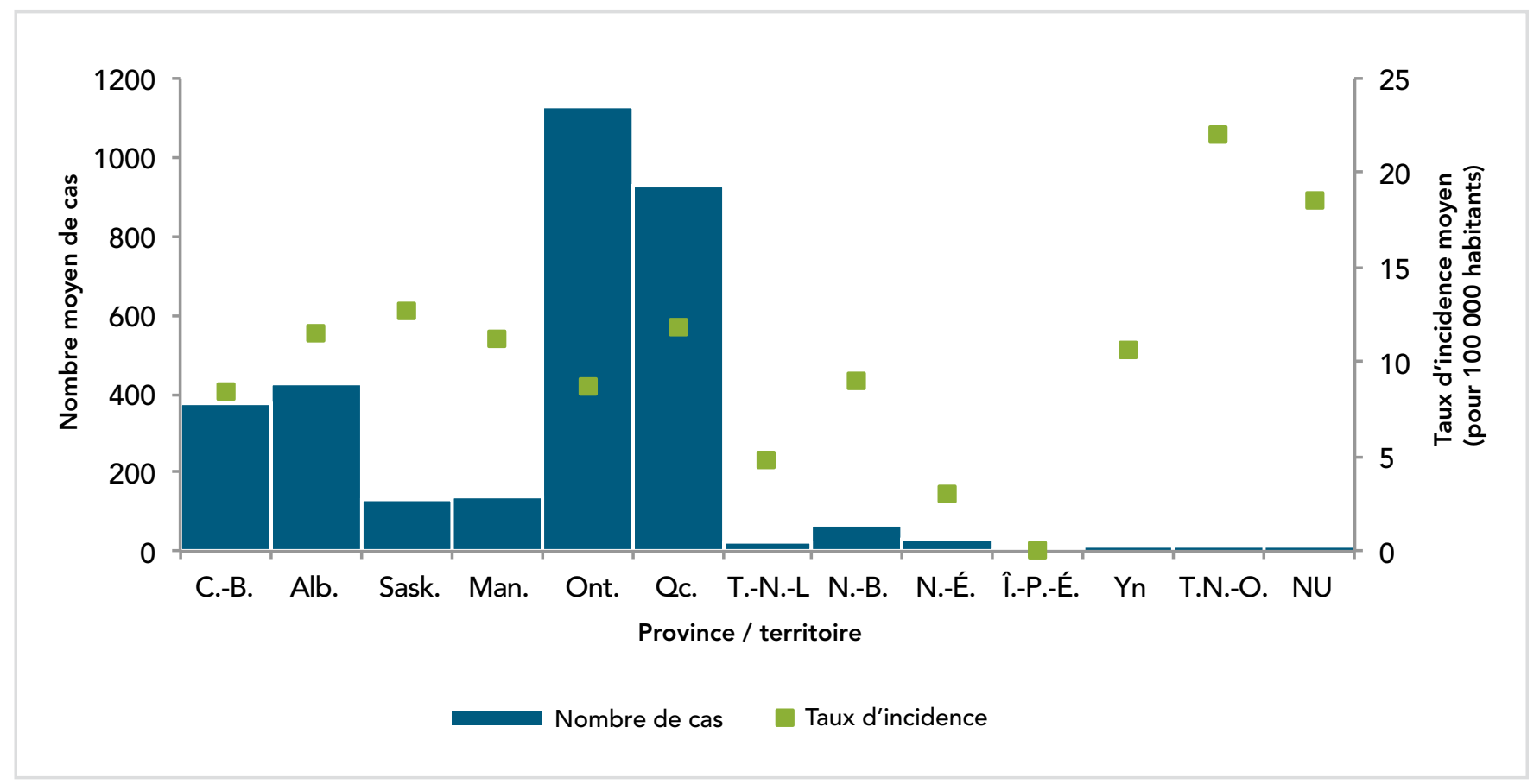

Tableau 1. Nombre de cas déclarés d'IIP, par province/territoire et année, Canada, 2007-2011

\begin{tabular}{|c|c|c|c|c|c|c|c|c|c|c|c|c|c|c|}
\hline \multirow[b]{2}{*}{ Année } & \multicolumn{13}{|c|}{ Province / territoire } & \multirow[b]{2}{*}{ Canada } \\
\hline & C.-B. & Alb. & Sask. & Man. & Ont. & Qc. & T.-N.-L. & N.-B. & N.-É. & Î.-P.-É. & $Y n$ & T.N.-O. & NU & \\
\hline $\begin{array}{c}\text { Moyenne } \\
\text { pour } \\
2001-2006\end{array}$ & 322 & 401 & 76 & 93 & 760 & 833 & 24 & 21 & 14 & 0 & 4 & 5 & 5 & 2557 \\
\hline 2007 & 552 & 601 & 148 & 101 & 941 & 786 & 13 & 47 & 26 & 0 & 2 & 9 & 9 & 3235 \\
\hline 2008 & 402 & 454 & 133 & 145 & 1065 & 877 & 35 & 46 & 14 & 0 & 1 & 7 & 7 & 3186 \\
\hline $2009^{+}$ & 324 & 371 & 112 & 138 & 1224 & 989 & 36 & 75 & 20 & 0 & 7 & 11 & 4 & 3311 \\
\hline $2010^{+}$ & 258 & 340 & 126 & 176 & 1185 & 1066 & 23 & 82 & 35 & 0 & 3 & 10 & 5 & 3309 \\
\hline $2011^{+}$ & 327 & 358 & 134 & 128 & 1235 & 914 & 17 & 89 & 51 & 0 & 5 & 11 & 5 & 3274 \\
\hline $\begin{array}{c}\text { Moyenne } \\
\text { pour } \\
2007-2011\end{array}$ & 373 & 425 & 131 & 138 & 1130 & 926 & 25 & 68 & 29 & 0 & 4 & 10 & 6 & 3263 \\
\hline
\end{tabular}

* Données tirées du Système canadien de surveillance des maladies à déclaration obligatoire.

† D'après des données provisoires. 
Tableau 2. Taux d'incidence d'IIP (par 100000 habitants), par année et province/territoire, Canada, 2007 à 2011

\begin{tabular}{|c|c|c|c|c|c|c|c|c|c|c|c|c|c|c|}
\hline \multirow[b]{2}{*}{ Année } & \multicolumn{13}{|c|}{ Province / territoire } & \multirow[b]{2}{*}{ Canada } \\
\hline & C.-B. & Alb. & Sask. & Man. & Ont. & Qc. & T.-N.-L. & N.-B. & N.-É. & Î.-P.-É. & Yn & T.N.O. & NU & \\
\hline $\begin{array}{c}\text { Moyenne } \\
\text { pour } \\
2001-2006\end{array}$ & 8,05 & 12,04 & 9,95 & 9,52 & 7,33 & 11,43 & 4,71 & 5,63 & 2,22 & 0,07 & 11,81 & 15,84 & 16,84 & 8,81 \\
\hline 2007 & 12,81 & 17,11 & 14,80 & 8,46 & 7,36 & 10,22 & 2,57 & 6,30 & 2,78 & 0,00 & 6,14 & 20,67 & 28,78 & 9,82 \\
\hline 2008 & 9,17 & 12,64 & 13,12 & 12,03 & 8,23 & 11,32 & 6,91 & 6,16 & 1,49 & 0,00 & 3,02 & 16,03 & 22,13 & 9,56 \\
\hline $2009+$ & 7,26 & 10,10 & 10,88 & 11,32 & 9,36 & 12,64 & 7,07 & 10,00 & 2,13 & 0,00 & 20,78 & 25,21 & 12,41 & 9,82 \\
\hline $2010 \dagger$ & 5,70 & 9,14 & 12,07 & 14,26 & 8,96 & 13,48 & 4,50 & 10,89 & 3,70 & 0,00 & 8,68 & 22,82 & 15,23 & 9,70 \\
\hline $2011 \dagger$ & 7,15 & 9,47 & 12,67 & 10,24 & 9,24 & 11,45 & 3,33 & 11,78 & 5,39 & 0,00 & 14,42 & 25,19 & 15,01 & 9,49 \\
\hline $\begin{array}{c}\text { Moyenne } \\
\text { pour } \\
2007-2011\end{array}$ & 8,37 & 11,62 & 12,69 & 11,27 & 8,64 & 11,83 & 4,88 & 9,04 & 3,10 & 0,00 & 10,68 & 21,98 & 18,60 & 9,68 \\
\hline
\end{tabular}

* Données tirées du Système canadien de surveillance des maladies à déclaration obligatoire.

†'après des données provisoires.

Le vaccin PNEU-C-7 a été intégré aux programmes de vaccination pédiatrique de l'ensemble des provinces et des territoires en 2006, et le vaccin PNEU-C-13, en 2011. La figure 3 montre le taux d'incidence moyen d'IIP par province et territoire, avant et après l'introduction du vaccin PNEU-C-7.

Figure 3. Taux d'incidence annuel moyen d'IIP par province et territoire - pour tous les groupes d'âge (par 100000 habitants), avant et après l'introduction du vaccin PNEU-C-7, Canada, 2001-2011

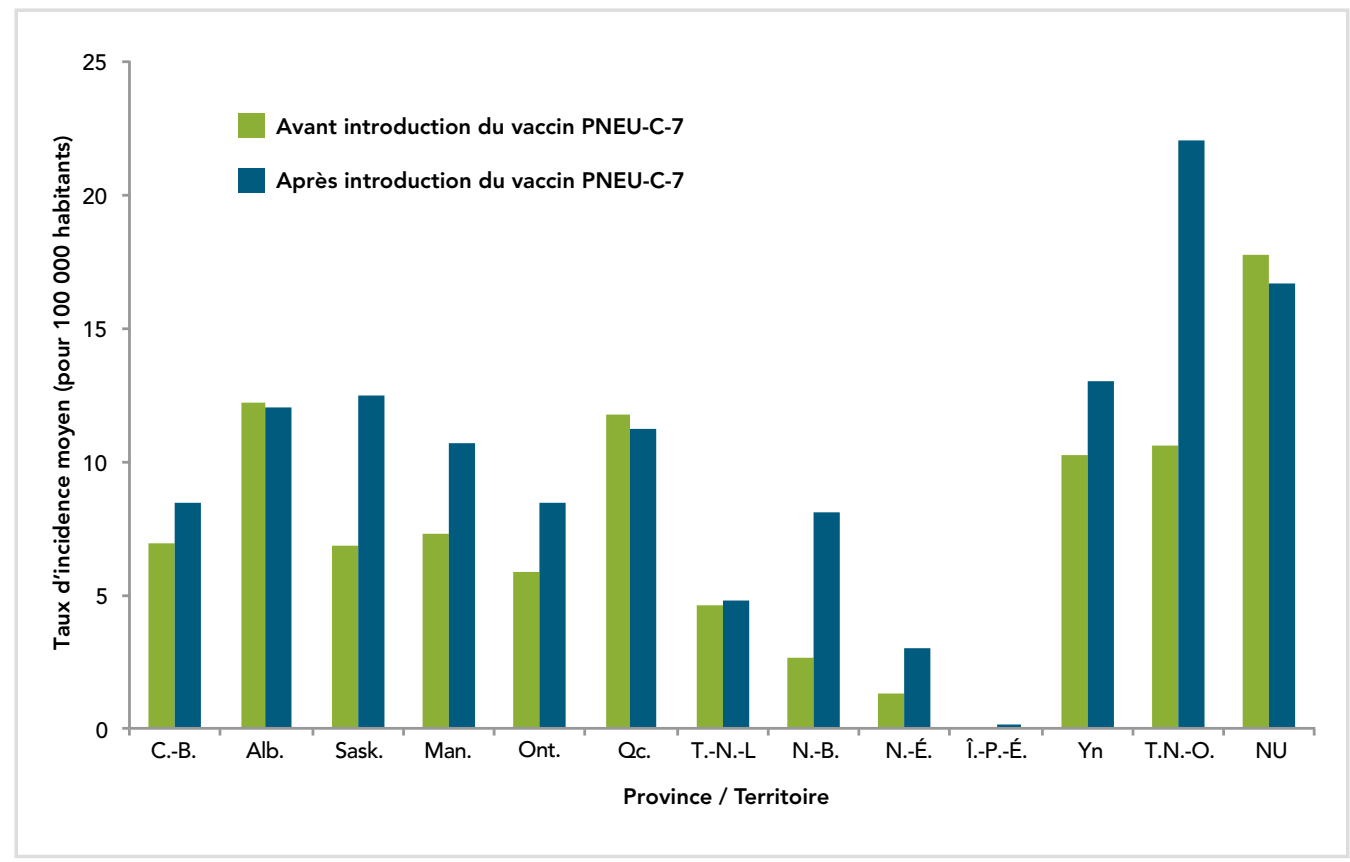

\begin{tabular}{|c|c|}
\hline P/T & $\begin{array}{c}\text { Année } \\
\text { d'introduction } \\
\text { du VCP7 }\end{array}$ \\
\hline C.-B. & 2003 \\
\hline Alb. & 2002 \\
\hline Sask. & 2005 \\
\hline Man. & 2004 \\
\hline Ont. & 2005 \\
\hline Qc. & 2004 \\
\hline T.-N.-L & 2005 \\
\hline N.-B. & 2005 \\
\hline N.-É. & 2005 \\
\hline î.-P.-É. & 2005 \\
\hline Yn & 2005 \\
\hline T.N.-O. & 2006 \\
\hline NU & 2002 \\
\hline
\end{tabular}

* Données tirées du Système canadien de surveillance des maladies à déclaration obligatoire (données provisoires de 2009-2011).

** L'année de mise en œuvre du programme est incluse dans la période « avant introduction ». Les données étaient disponibles de 2001 à 2011 pour l'ensemble des provinces et territoires. 


\section{III.4 RÉPARTITION PAR ÂGE}

Les données sur les IIP par groupe d'âge révèlent que, jusqu'en 2005, les enfants de moins de cinq ans étaient les plus touchés (figure 4). Le vaccin PNEU-C-7 a été intégré aux programmes de vaccination de l'ensemble des provinces et des territoires en 2006, et les données nationales semblent indiquer que l'introduction du vaccin
PNEU-C-7 a entraîné une diminution du taux d'incidence chez les enfants de moins de cinq ans. Bien que l'on ait observé une augmentation du taux d'incidence d'IIP de 2006 à 2008, ce taux était toujours inférieur à ceux enregistrés avant l'introduction du vaccin. On a observé une augmentation stable du taux d'incidence chez les adultes de 60 ans ou plus depuis 2006.

Figure 4. Taux d'incidence d'IIP chez les moins de 20 ans, par groupe d'âge et année, Canada, 2001-2011

Introduction du VCP7 Sask., Ont.

N.-B., N.-É.,

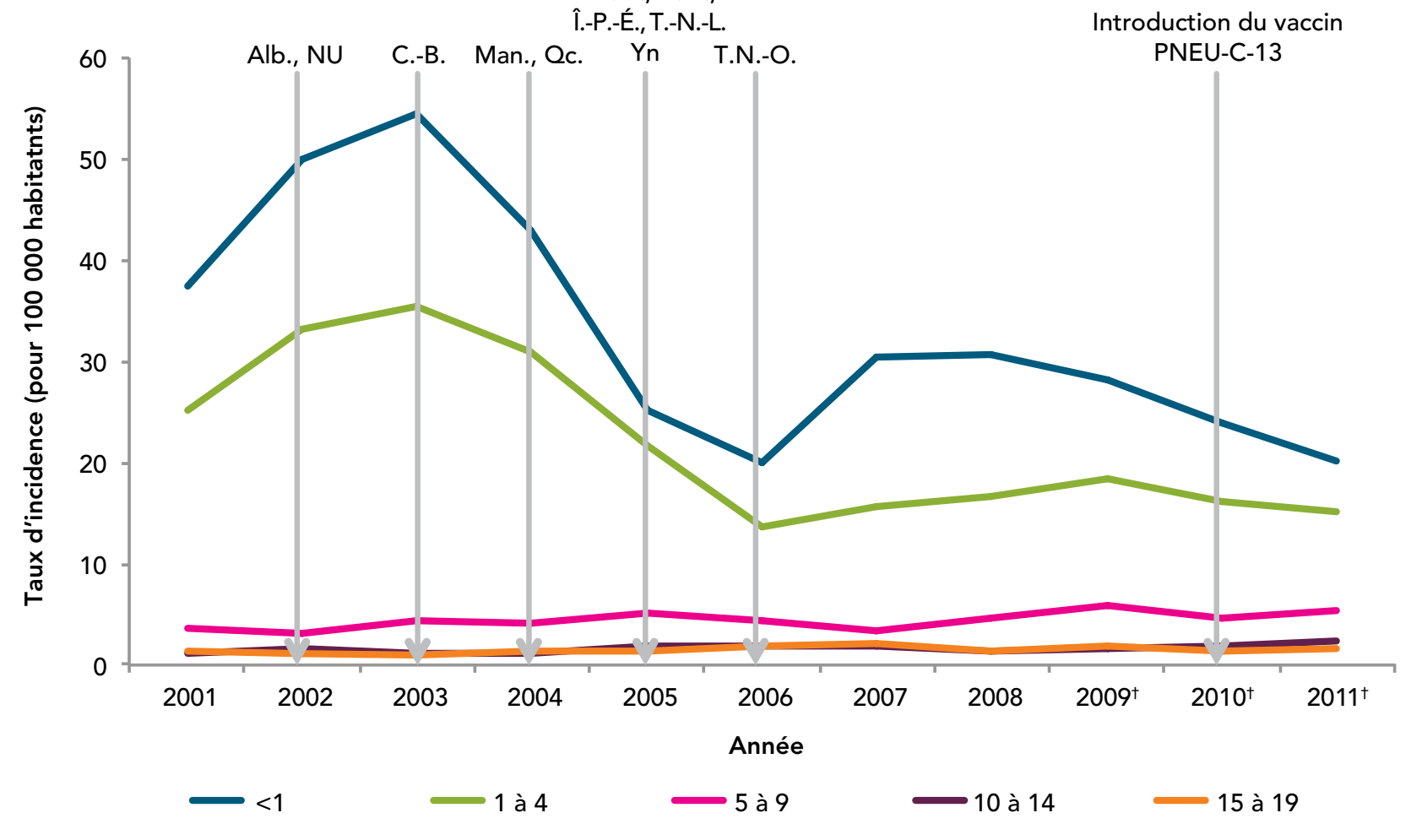

* Données tirées du Système canadien de surveillance des maladies à déclaration obligatoire.

† D'après des données provisoires.

Note: Certaines provinces et territoires canadiens avaient introduit le PNEU-C-10 dans leur programme en 2009.

Les taux d'incidence d'IIP chez l'adulte semblent augmenter en fonction de l'âge, les personnes de 60 ans ou plus étant les plus touchées (figure 5). Les taux d'incidence chez les personnes plus âgées ont augmenté dans le temps dans la quasi-totalité des groupes d'âge, la hausse la plus marquée étant survenue chez les 40 à 59 ans et les 60 ans ou plus. 
Figure 5. Taux d'incidence d'IlP chez les 20 ans ou plus, par groupe d'âge et année, Canada, 2001-2011

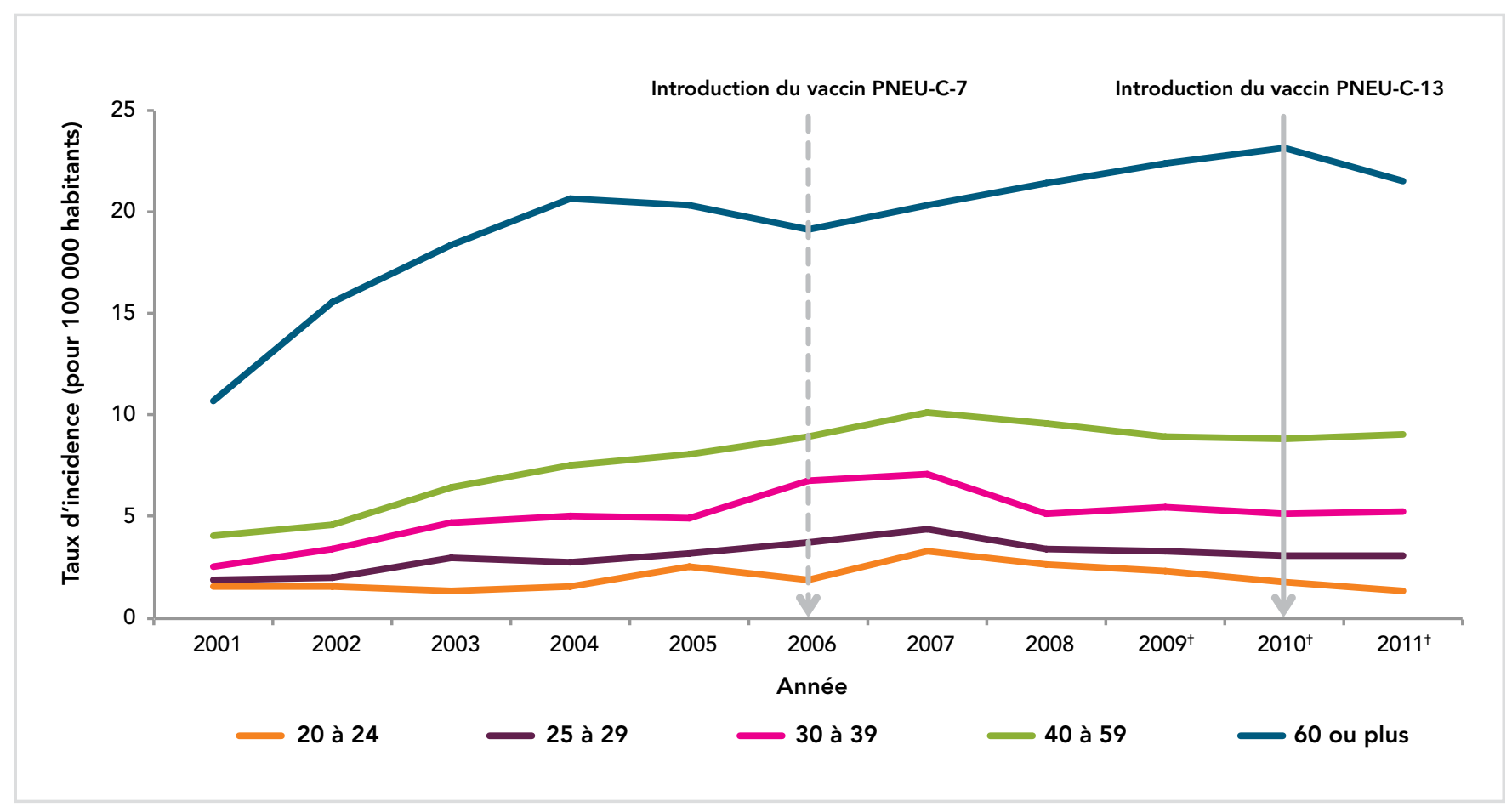

* Données tirées du Système canadien de surveillance des maladies à déclaration obligatoire.

${ }^{\dagger}$ D'après des données provisoires.

Tableau 3. Nombre de cas déclarés d'IIP, par groupe d'âge et année, Canada, 2001-2011

\begin{tabular}{|c|c|c|c|c|c|c|c|c|c|c|}
\hline \multirow[b]{2}{*}{ Année } & \multicolumn{10}{|c|}{ Groupes d'âge } \\
\hline & $<1$ & 1 à 4 & 5 à 9 & 10 à 14 & 15 à 19 & 20 à 24 & 25 à 29 & 30 à 39 & 40 à 59 & $\begin{array}{l}60 \text { ou } \\
\text { plus }\end{array}$ \\
\hline 2001 & 124 & 359 & 72 & 24 & 30 & 33 & 39 & 124 & 358 & 558 \\
\hline 2002 & 164 & 465 & 62 & 33 & 25 & 34 & 42 & 166 & 421 & 828 \\
\hline 2003 & 180 & 490 & 85 & 25 & 21 & 30 & 63 & 223 & 602 & 1002 \\
\hline 2004 & 145 & 425 & 80 & 25 & 28 & 36 & 60 & 230 & 713 & 1161 \\
\hline 2005 & 85 & 296 & 97 & 38 & 28 & 58 & 69 & 223 & 784 & 1171 \\
\hline 2006 & 70 & 188 & 81 & 38 & 40 & 44 & 82 & 303 & 887 & 1133 \\
\hline 2007 & 110 & 221 & 62 & 40 & 48 & 75 & 99 & 319 & 1008 & 1252 \\
\hline 2008 & 114 & 237 & 81 & 29 & 30 & 61 & 79 & 234 & 957 & 1364 \\
\hline $2009+$ & 107 & 271 & 104 & 31 & 41 & 54 & 78 & 252 & 897 & 1475 \\
\hline $2010+$ & 92 & 242 & 83 & 36 & 29 & 42 & 73 & 235 & 900 & 1573 \\
\hline $2011 \dagger$ & 78 & 233 & 96 & 46 & 36 & 32 & 74 & 246 & 921 & 1511 \\
\hline
\end{tabular}

* Données tirées du Système canadien de surveillance des maladies à déclaration obligatoire.

${ }^{\dagger} \mathrm{D}$ 'après des données provisoires. 
Tableau 4. Taux d'incidence (par 100000 habitants) d'IIP par groupe d'âge et année, Canada, 2001-2011

\begin{tabular}{|c|c|c|c|c|c|c|c|c|c|c|}
\hline \multirow[b]{2}{*}{ Année } & \multicolumn{10}{|c|}{ Groupe d'âge } \\
\hline & $<1$ & 1 à 4 & 5 à 9 & 10 à 14 & 15 à 19 & 20 à 24 & 25 à 29 & 30 à 39 & 40 à 59 & $\begin{array}{l}60 \text { ou } \\
\text { plus }\end{array}$ \\
\hline 2001 & 37,37 & 25,17 & 3,57 & 1,15 & 1,42 & 1,57 & 1,88 & 2,54 & 4,08 & 10,71 \\
\hline 2002 & 50,00 & 33,24 & 3,12 & 1,56 & 1,18 & 1,59 & 2,02 & 3,45 & 4,66 & 15,53 \\
\hline 2003 & 54,51 & 35,55 & 4,36 & 1,17 & 0,99 & 1,38 & 3,00 & 4,74 & 6,49 & 18,33 \\
\hline 2004 & 42,90 & 31,04 & 4,20 & 1,17 & 1,31 & 1,63 & 2,83 & 5,00 & 7,50 & 20,70 \\
\hline 2005 & 25,06 & 21,60 & 5,20 & 1,79 & 1,29 & 2,60 & 3,21 & 4,92 & 8,08 & 20,36 \\
\hline 2006 & 19,99 & 13,58 & 4,44 & 1,81 & 1,81 & 1,95 & 3,75 & 6,74 & 9,00 & 19,11 \\
\hline 2007 & 30,54 & 15,75 & 3,44 & 1,95 & 2,14 & 3,30 & 4,44 & 7,09 & 10,16 & 20,37 \\
\hline 2008 & 30,56 & 16,56 & 4,52 & 1,44 & 1,33 & 2,67 & 3,45 & 5,17 & 9,58 & 21,43 \\
\hline $2009+$ & 28,16 & 18,51 & 5,78 & 1,57 & 1,82 & 2,33 & 3,32 & 5,53 & 8,92 & 22,43 \\
\hline $2010+$ & 24,03 & 16,10 & 4,60 & 1,86 & 1,30 & 1,78 & 3,05 & 5,11 & 8,89 & 23,15 \\
\hline $2011 \dagger$ & 20,26 & 15,17 & 5,26 & 2,42 & 1,64 & 1,33 & 3,06 & 5,30 & 9,06 & 21,55 \\
\hline
\end{tabular}

* Données tirées du Système canadien de surveillance des maladies à déclaration obligatoire.

${ }^{\dagger}$ D'après des données provisoires.

Données sur les pathologies sous-jacentes non disponibles.

\section{III.5 DISTRIBUTION DES SÉROTYPES ASSOCIÉS AUX IIP AU CANADA}

Le vaccin PNEU-C-7 contient les sérotypes 4, 6B, 9V, 14, 18C, $19 \mathrm{~F}$ et 23F; le vaccin PNEU-C-13 contient, en plus des sérotypes inclus dans le PNEU-C-7, les sérotypes 1, 3, 5, 6A, 7F et 19A; et le vaccin PNEU-P-23 contient, en plus des sérotypes inclus dans le PNEU-C-13, les sérotypes 2, 8, 9N, 10A, 11A, 12F, $15 B, 17 F, 20,22 F$ et 33F, mais le PNEU-P-23 ne contient pas le sérotype $6 \mathrm{~A}$.

À l'échelle canadienne, la surveillance en laboratoire des sérotypes associés aux IIP s'effectue par l'entremise d'un système passif à participation volontaire : les souches sont envoyées au Laboratoire national de microbiologie (LNM), qui offre des services de diagnostic de référence. Ce système de surveillance passive est toutefois limité par les différences en matière de déclaration qui existent entre les provinces et les territoires; par la variabilité de la taille d'échantillonnage dans les petites administrations, où l'on se trouve à avoir de faibles nombres de cas mais de fortes proportions relatives; et par la disponibilité de souches bactériennes à envoyer pour fins d'analyse.

D'après les souches envoyées au LNM par les provinces et les territoires et d'après l'information additionnelle sur le sérotypage fournie par le Laboratoire de santé publique du Québec (LSPQ) et le Toronto Invasive Bacterial Disease Network (TIBDN), les sérotypes prédominants au Canada en 2011 étaient les sérotypes 19A, 7F et 3 (tous trois présents dans le vaccin PNEU-C-13 et le vaccin PNEU-P-23, mais non dans le vaccin PNEU-C-7), le sérotype 22F (présent dans le vaccin PNEU-P-23) et le sérotype 6C (présent dans aucun vaccin); ensemble, ces sérotypes représentaient $51 \%(n=1252)$ des souches analysées associées à une IIP au Canada (figure 6). Le sérotype 19A demeure le sérotype prédominant en 2011 dans les isolats provenant des $<2$ ans $(23 \%, n=38)$, des 2 à 4 ans (41\%, n= 59), des 50 à 64 ans $(16 \%, n=108)$ et des $\geq 65$ ans $(14 \%, n=126)$, tandis que le sérotype $7 F$ demeure prédominant chez les 5 à 14 ans $(28 \%, n=39)$ et les 15 à 49 ans (21\%, n=134). Le sérotype 3 est relativement fréquent chez les 2 à 4 ans, les 50 à 64 ans et les $\geq 65$ ans, représentant respectivement $11 \%(n=16), 8 \%(n=57)$ et $11 \%(n=99)$ des isolats dans ces groupes d'âge. Le sérotype 22F tend à être relativement fréquent chez les personnes plus âgées, à savoir les 15 à 49 ans $(7 \%, n=46)$, les 50 à 64 ans $(6 \%, n=43)$ et les $\geq 65$ ans ( $10 \%, n=90)$, tandis que le sérotype $6 \mathrm{C}$ est fréquent chez les $\geq 65$ ans, représentant $7 \%(n=60)$ des isolats analysés. La proportion de sérotypes contenus dans le vaccin PNEU-C-13 a diminué de 2010 à 2011 chez les < 2 ans : elle était de $63 \%(n=118)$ en 2010 et de $43 \%(n=70)$ en 2011. La proportion de sérotypes contenus dans le vaccin PNEU-P-23 est demeurée relativement constante dans tous les groupes d'âge au cours des deux ans (figures 7 à 9) ${ }^{6-8}$. 
Figure 6. Distribution régionale des sérotypes de S. pneumoniae au Canada, 2011

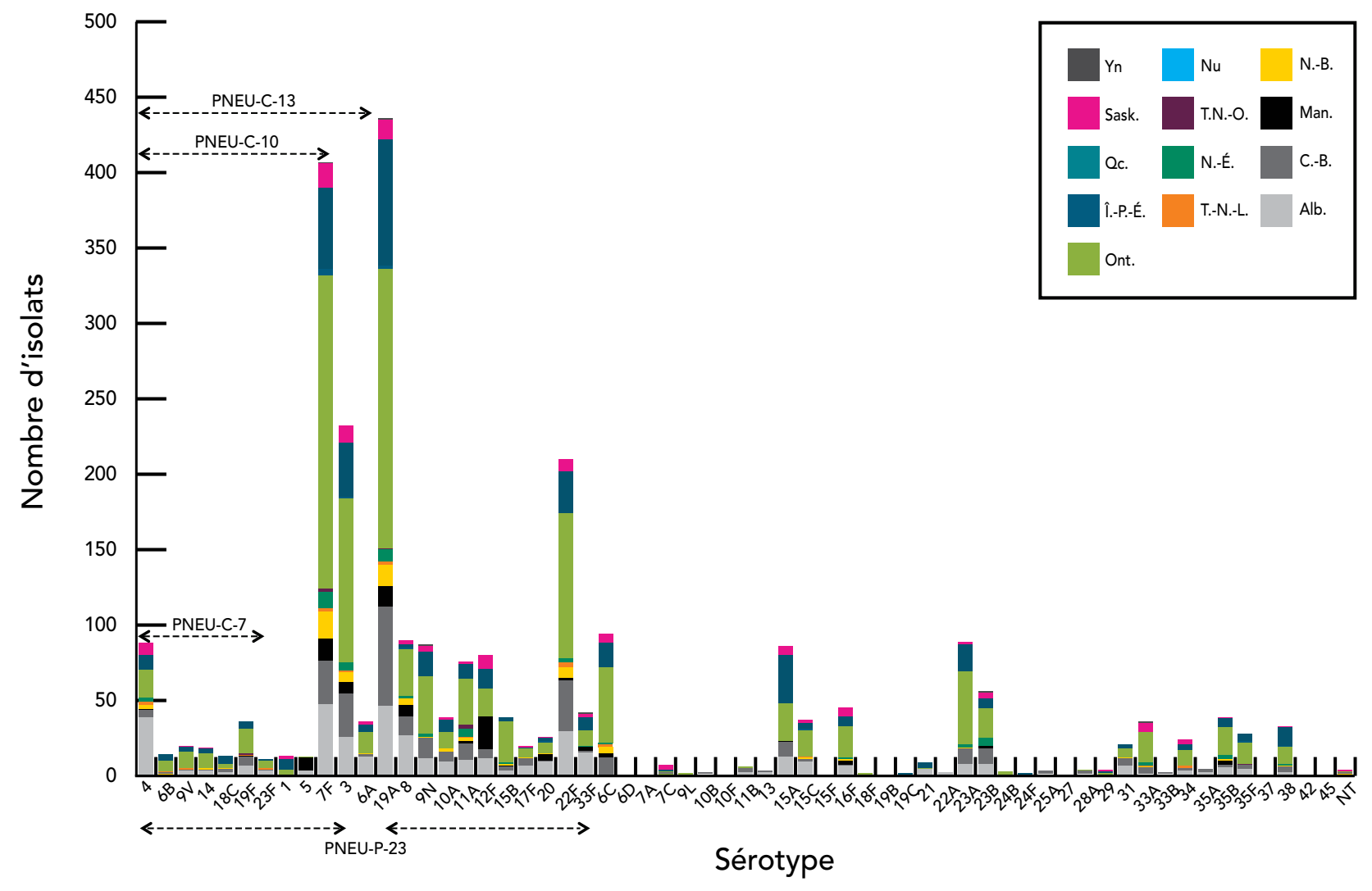

Figure 7. Proportion des sérotypes contenus dans le vaccin PNEU-C-7 par groupe d'âge, 2010-2011

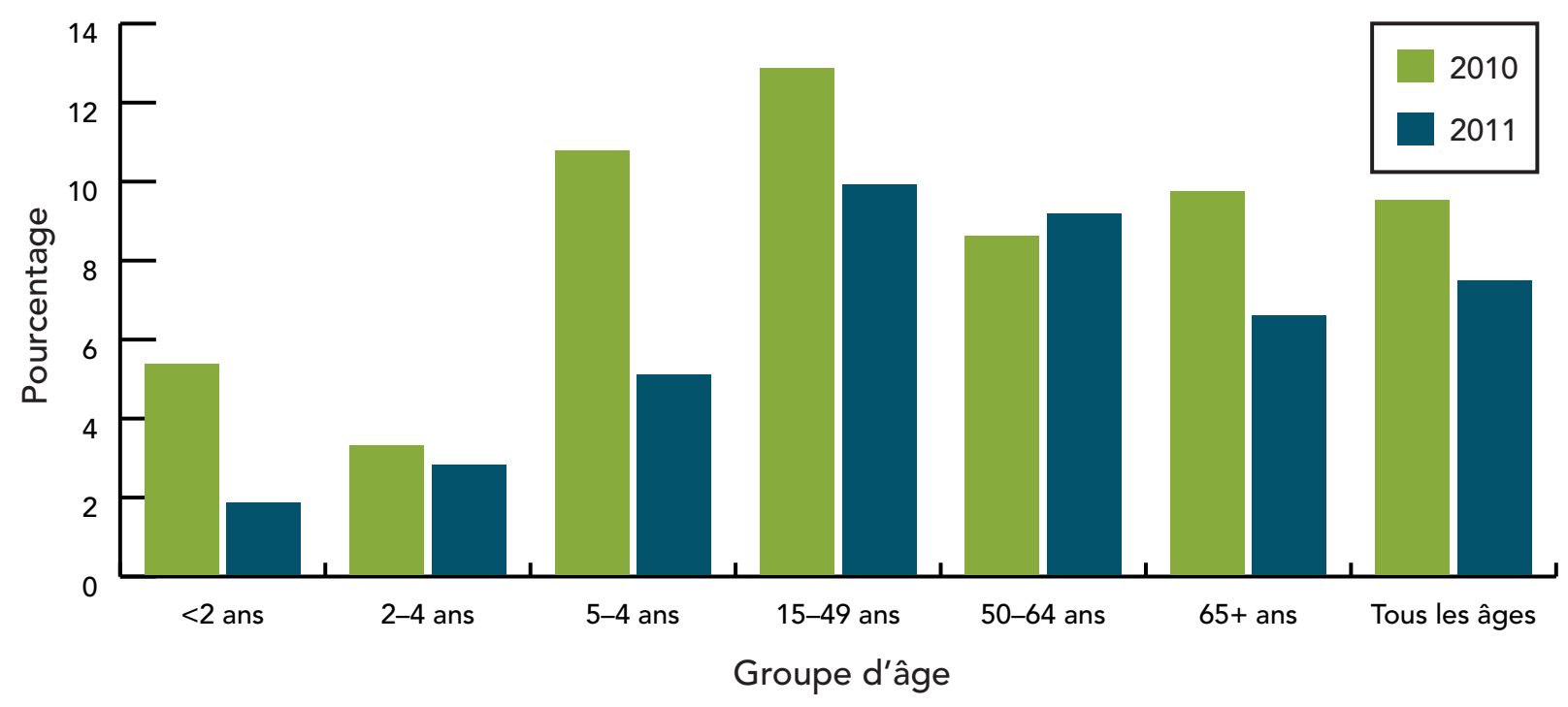


Figure 8. Proportion des sérotypes contenus dans le vaccin PNEU-C-13 par groupe d'âge, 2010-2011

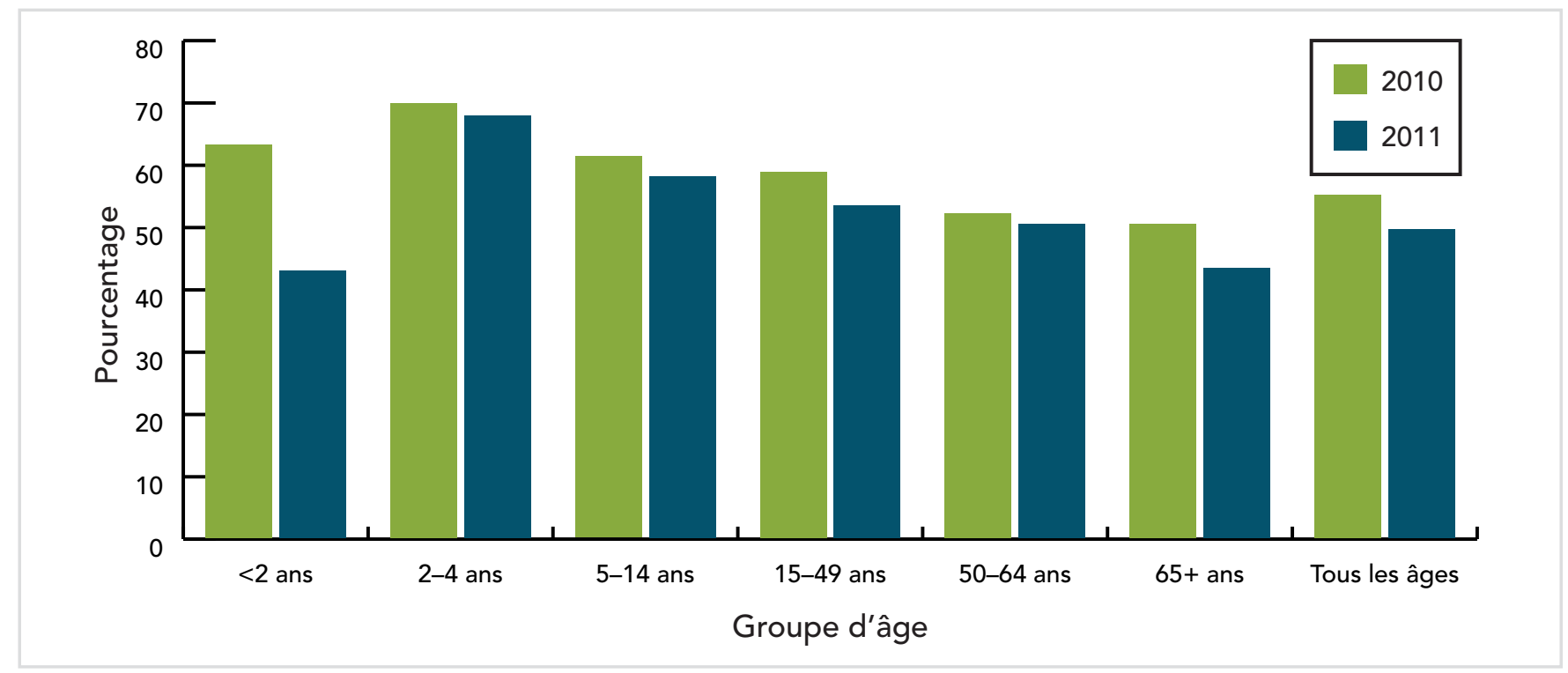

Figure 9. Proportion des sérotypes contenus dans le vaccin PNEU-P-23 par groupe d'âge, 2010-2011

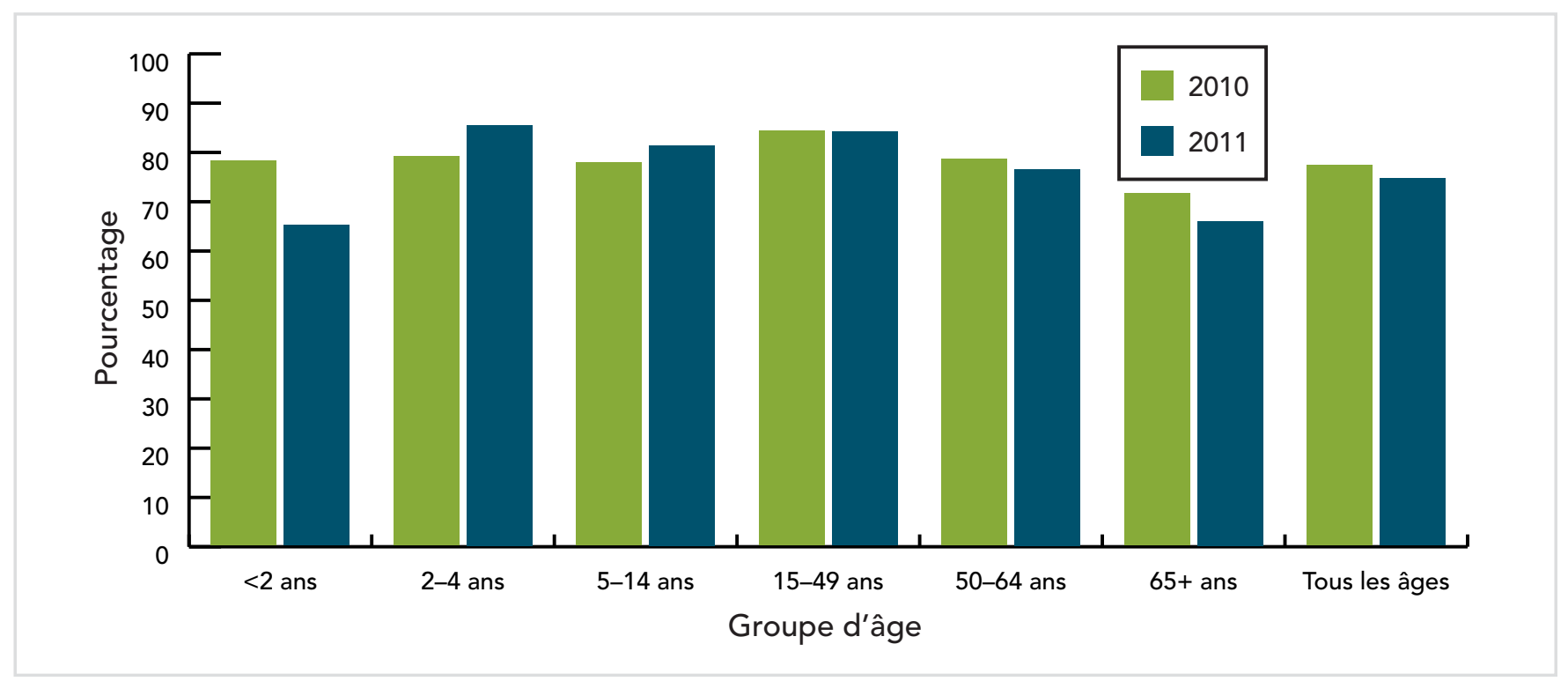

\section{Vaccin}

\section{IV.1 PRÉPARATION(S) AUTORISÉES AU CANADA}

Deux formes de vaccin anti-pneumococcique sont présentement disponibles au Canada : un vaccin conjugué (PNEU-C-13 et PNEU-C-10) et un vaccin polysaccharidique (PNEU-P-23).

Prevnar13 $\mathrm{MD}$, un vaccin antipneumococcique conjugué, est une solution stérile contenant des antigènes capsulaires polysaccharidiques de 13 sérotypes de la bactérie Streptococcus pneumoniae (1, 3, 4, 5, 6A, 6B, 7F, 9V, 14, 18C, 19A, 19F et 23F). Les polysaccharides sont conjugués séparément à une protéine diphtérique porteuse (CRM 197$)$ avant leur combinaison pour former un vaccin multivalent. La protéine porteuse $\mathrm{CRM}_{197}$ est adsorbée sur du phosphate d'aluminium en tant qu'adjuvant. Chaque dose de $0,5 \mathrm{ml}$ de vaccin contient $4,4 \mu \mathrm{g}$ de polysaccharide $6 \mathrm{~B}$ et $2,2 \mu \mathrm{g}$ des polysaccharides de chacun des autres sérotypes. 
Le vaccin PNEU-C-13 est analogue au vaccin PNEU-C-7, mais contient six sérotypes supplémentaires, une modification de la conjugaison du sérotype 19F afin d'en accroître la stabilité, 0,02 \% de polysorbate (Tween) 80 (un expédient) ainsi qu'un tampon succinate. Le bouchon de la seringue ne contient pas de latex.

Le vaccin PNEU-C-13 est commercialisé sous la forme d'une seringue unidose préremplie contenant $0,5 \mathrm{ml}$ de vaccin.

\section{IV.2 EFFICACITÉ POTENTIELLE - DIRECTE ET INDIRECTE (TABLEAU 1)}

\section{Se reporter au tableau 1 pour une description détaillée des études}

On ne dispose actuellement d'aucune donnée sur l'efficacité potentielle du vaccin PNEU-C-13 pour quelque indication que ce soit chez l'adulte. Des données sur l'efficacité potentielle du vaccin PNEU-C-13 pour la prévention de la pneumonie d'origine communautaire (POC) chez les adultes de 65 ans ou plus devraient être disponibles dans les prochaines années. Un examen approfondi de la littérature n'a révélé aucune étude sur l'efficacité potentielle du vaccin PNEU-C-7 ou PNEU-C-10 chez des adultes en bonne santé. Une étude de l'efficacité potentielle menée auprès d'adultes séropositifs pour le VIH a été trouvée et est résumée ci-après.

Le vaccin PNEU-C-7 présente une bonne efficacité potentielle chez les participants positifs pour le VIH. French et coll. ont réparti aléatoirement 439 Malawites positifs pour le VIH qui s'étaient remis d'une IIP confirmée dans des groupes recevant deux doses du vaccin PNEU-C-7 ou un placebo. Le critère de jugement utilisé était un nouvel épisode d'IIP, dû à I'un des sérotypes présents dans le vaccin, ou dû au sérotype 6A en raison de la possibilité d'une protection croisée. L'efficacité potentielle ajustée de deux doses du vaccin PNEU-C-7 par rapport au placebo était de $69 \%$ (IC à $95 \% 16$ à 89) 9 .

\section{IV.3 EFFICACITÉ RÉELLE (TABLEAU 1)}

On ne dispose actuellement d'aucune donnée sur l'efficacité du vaccin PNEU-C-13 chez l'adulte. Les seules études d'efficacité réelle existantes ont été menées avec le vaccin PNEU-P-23 auprès d'adultes séropositifs pour le VIH et auprès de personnes âgées; les résultats sont résumés ci-après.

\section{Adultes séropositifs pour le VIH}

Même avec des soins et des traitements appropriés, les IIP demeurent une affection sérieuse touchant les personnes vivant avec le VIH et le Sida (PVVIH). Siemieniuk et coll. ont récemment publié une étude canadienne dans laquelle ils décrivent 68 cas d'IIP survenus entre 2000 et 2010 parmi 1946 PVVIH adultes vivant dans le Sud de l'Alberta. Dans cette étude, le taux d'incidence non-ajusté était de 342/100 000 années-personnes. Dans l'ensemble, 429 (22 \%) PVIH n'avaient jamais reçu le vaccin PNEU-P-23. Chez les personnes vaccinées, $34 \%$ avaient reçu au moins deux doses de vaccin PNEU-P-23. L'administration du vaccin PNEU-P-23 était associée à une diminution du taux d'incidence d'IIP causées par les sérotypes vaccinaux (720 vs 189/100 000 personnes-années avant la vaccination et après la vaccination respectivement; $p<0,0001$ ) et pour l'ensemble des sérotypes (768 vs 244/100 000 personnes-années; $p<0,001$ ). La charge virale, ajustée pour la numération des lymphocytes CD4, était un prédicteur indépendant d'IIP chez les sujets vaccinés. Le rapport de cote $(R C)$ ajusté pour le risque d'IIP était de 2,3 (IC à $95 \% 1,0$ à 5,4) pour les patients ayant reçu le vaccin PNEU-P-23 au moins une fois tous les cinq ans par rapport à ceux qui l'avaient reçu moins souvent, ce qui illustre à quel point l'efficacité réelle du vaccin PNEU-P-23 est limitée dans cette population, comme l'ont également indiqué d'autres chercheurs10. Bien que $78 \%$ de la population ait été vaccinée, $74 \%$ des cas d'IIP étaient causés par un sérotype présent dans le vaccin PNEU-P-23; ces cas étaient répartis comme suit : $66 \%$ des sérotypes détectés chez les personnes déjà immunisées étaient des sérotypes inclus dans le PNEU-P-23 contre $86 \%$ des sérotypes détectés chez les personnes qui n'avaient pas été immunisées antérieurement.

Des études antérieures ont révélé le caractère sous-optimal de l'efficacité réelle du vaccin PNEU-P-23 chez les WIH dans divers contextes. Dans le cadre d'une étude cas-témoins, Breiman et coll. ont observé une efficacité réelle ajustée du vaccin PNEU-P-23 de 49 \% (IC à $95 \% 12$ à 70). Dans cette étude, la race jouait un rôle important dans l'efficacité réelle du vaccin : I'efficacité réelle ajustée était de $74 \%$ (IC à $95 \%$ 8 à $93 \%$ ) chez les personnes de race blanche et de $8 \%$ (IC à $95 \%$-112 à $60 \%$ ) chez les personnes de race noire ${ }^{11}$. Dans une étude d'observation prospective menée auprès de 507 WIH (305 avaient reçu et 203 n'avaient pas reçu le vaccin PNEU-P-23), Hung et coll. rapportent un RC ajusté ( $R C a$ ) de 0,22 (IC à $95 \%$ 0,02 à 2,56) pour la bactériémie à pneumocoque, ce qui donne une efficacité réelle de $78 \%$ (IC à $95 \%$-156 à 98), de même qu'un RCa de 0,09 (IC à $95 \%$ $0,01$ à 0,74$)$ pour l'ensemble des infections à pneumocoque, ce qui donne une efficacité réelle de $91 \%$ (IC à $95 \% 26$ à 99)12. French et coll. ont réparti aléatoirement 1392 adultes ougandais infectés par le VIH dans des groupes devant recevoir le vaccin PNEU-P-23 ( $n=697$ ) ou un placebo; ils ont fait état d'un rapport de risque (RR) de 1,48 (IC à $95 \%$ 
0,7 à 3,3) pour un premier épisode d'IIP, d'un RR de 2,14 (IC à $95 \% 0,86$ à 5,31) pour une IIP due à un sérotype vaccinal, d'un RR de 2,02 (IC à $95 \%$ 1,19 à 3,45) pour une pneumonie de tout type, et d'un RR de 1,46 (IC à $95 \% 0,73$ à 2,91) pour une infection pneumococcique de tout type. Les auteurs ont donc conclu que le vaccin PNEU-P-23 était incapable de protéger les $\mathrm{VIH}$ des infections à pneumocoque ${ }^{13}$.

\section{Personnes âgées}

Vila-Corcoles et coll. ont étudié l'efficacité réelle du vaccin PNEU-P-23 chez des adultes de 65 ans ou plus dans une étude de cohorte prospective ( $n=4986$ sujets non vaccinés et $\mathrm{n}=6255$ sujets vaccinés avant l'inscription à l'étude). L'efficacité réelle ajustée du vaccin en ce qui concerne la prévention des hospitalisations liées à une pneumonie était de $19 \%$ (IC à $95 \%$-30 à $49 \%$ ). L'efficacité réelle du vaccin était de $15 \%$ (IC à $95 \% 31$ à $44 \%$ ) contre les pneumonies, toutes causes confondues, de $72 \%$ (IC à $95 \% 20$ à $91 \%$ ) contre les décès par pneumonie et de $33 \%$ (IC à $95 \% 17$ à $46 \%$ ) contre la mortalité, toutes causes confondues ${ }^{14}$. Dans une deuxième étude, menée auprès de 11241 adultes de 65 ans ou plus ayant reçu le vaccin PNEU-P-23, Vila-Corcoles et coll. ont montré que l'efficacité réelle ajustée du vaccin contre les IIP associées à un sérotype vaccinal était de $39 \%$ (IC à $95 \% 176$ à $87 \%$ ). L'efficacité réelle pour la prévention de la pneumonie à pneumocoque était de $45 \%$ (IC à $95 \%$ 12 à $66 \%$ ), celle concernant la prévention des hospitalisations liées à une pneumonie était de $26 \%$ (IC à $95 \% 8$ à $41 \%$ ) et celle concernant la prévention des pneumonies de tout type était de $21 \%$ (IC à $95 \% 2$ à $36 \%$ ). Après stratification en fonction du statut vaccinal contre la grippe, les auteurs ont signalé une efficacité réelle de $35 \%$ (IC à $95 \% 1$ à $57 \%$ ) du vaccin PNEU-P-23 concernant la réduction du risque d'hospitalisation liée à une pneumonie chez des sujets non vaccinés contre la grippe ${ }^{15}$.

Mooney et coll. se sont également penchés sur l'efficacité réelle du vaccin PNEU-P-23 pour la prévention des IIP chez les adultes de 65 ans ou plus en Écosse au moyen d'une étude de cohorte rétrospective. L'efficacité réelle ajustée (excluant les patients à risque élevé) était de 61,7\% (IC à $95 \%$ 45,1 à $73,2 \%$ ), ce qui donne un nombre de sujets à vacciner de 5206 (IC à 95 \% 4388 à 7 122). L'efficacité réelle ajustée chez les adultes de 65 à 74 ans, excluant les patients à risque élevé, était de $54,4 \%$ (IC à $95 \%$ 20,1 à $74 \%$ ), et elle était de $68,8 \%$ (IC à $95 \% 52,0$ à 79,8\%) chez les adultes de 75 ans ou plus ${ }^{16}$.

Melegaro et coll. ont publié une méta-analyse de l'efficacité réelle du vaccin PNEU-P-23. Les estimations regroupées de l'efficacité réelle contre la pneumonie à pneumocoque (excluant les groupes à risque élevé), réalisées à l'aide de modèles à effets aléatoires, étaient de $16 \%$ (IC à $95 \%$-50 à $50 \%)$; lorsque les groupes à risque élevé étaient inclus, I'efficacité réelle était de -20\% (IC à $95 \%$-92 à $25 \%$ ). L'estimation groupée de l'efficacité réelle contre les IIP dans la population générale de personnes âgées était de $65 \%$ (IC à $95 \%-42$ à $92 \%$ ), et chez les groupes à risque élevé, elle était de $20 \%$ (IC à $95 \%-187$ à $78 \%)^{17}$. Cette méta-analyse indique que le vaccin PNEU-P-23 avait une efficacité réelle très limitée chez les personnes âgées.

\section{IV.4 IMMUNOGÉNICITÉ (TABLEAU 1)}

Les groupes à risque élevé suivants ont été examinés séparément: greffés (organe solide, et cellules souches hématopoïétiques), les sujets séropositifs pour le VIH et les personnes âgées (de 65 ans ou plus).

\section{Greffés}

\section{A) Greffés d'organes solides}

Kumar et coll. ont publié un essai comparatif randomisé (ECR), avec placebo, mené auprès de 130 participants qui avaient subi une greffe du foie au moins trois mois avant l'inscription à l'étude et, s'ils avaient déjà reçu le vaccin PNEU-P-23, I'avaient reçu au moins cinq ans avant l'inscription à l'étude. Soixante-cinq participants ont été répartis aléatoirement dans des groupes pour recevoir un placebo puis le vaccin PNEU-P-23 huit semaines plus tard, ou le vaccin PNEU-C-7 puis le vaccin PNEU-P-23 huit semaines plus tard. II n'y avait aucune différence de proportion en ce qui concerne les patients qui avaient déjà reçu le vaccin PNEU-P-23 (8 \% dans le groupe placebo et $14 \%$ dans le groupe PNEU-C-7, $p=0,17$ ), les patients qui recevaient de la prednisone $(p=0,09)$ ou les patients qui avaient déjà reçu un traitement par sérum antilymphocytaire $(p=0,06)$. II n'y avait aucune différence dans la proportion de greffés qui avaient répondu à au moins un sérotype après 16 semaines $(85,7 \%$ vs $91,2 \%$ dans le groupe placebo et le groupe PNEU-C-7, respectivement) ou dans le nombre moyen de sérotypes associés à une réponse $(3,7 \pm 2,3$ vs 4,4 $\pm 2,2$ dans le groupe placebo et le groupe PNEU-C-7, respectivement). II n'y avait aucune différence dans le titre moyen géométrique (TMG - niveau d'anticorps) spécifique au sérotype, 16 semaines après l'administration de la première dose de vaccin ni dans l'activité opsonophagocytaire (OPA - reconnue comme 
la meilleure mesure fonctionnelle puisqu'elle représente le principal mécanisme de défense de l'hôte contre l'infection à pneumocoque ${ }^{18}$ ) lorsqu'on comparait le groupe placebo et le groupe PNEU-C-7, chacun suivi du PNEU-P-23 ${ }^{19}$.

Kumar et coll. ont également publié un ECR à double insu mené auprès de 60 participants ayant subi une transplantation rénale de trois mois à trois ans avant l'inscription à l'étude. Les patients qui avaient subi une splénectomie ou qui avaient reçu le vaccin PNEU-P-23 au cours des cinq dernières années étaient exclus. La majorité des participants recevaient encore de la cyclosporine, des corticostéroïdes ou du mofétilmycophénolate (MMF) au moment de la vaccination. Dans chacun des groupes, 30 participants ont été aléatoirement reçus soit le vaccin PNEU-P-23 ou le vaccin PNEU-C-7. Les caractéristiques de base dans les deux groupes étaient similaires. Dans les deux groupes, il n'y avait aucune différence statistiquement significative dans l'augmentation moyenne des TMG spécifiques au sérotype après huit semaines par rapport aux valeurs de référence pour cinq des 7 sérotypes (4, 6B, 14, 18C, 19F). L'augmentation des TMG était plus importante après I'administration du vaccin PNEU-C-7 qu'après celle du vaccin PNEU-P-23 pour le sérotype 23F, et le taux de réponse semblait être meilleur dans le cas du sérotype $9(p=0,09)$. La proportion de patients ayant répondu (augmentation d'au moins un facteur de 2 des titres ELISA par rapport aux valeurs de référence, avec un titre absolu d'au moins $1 \mu \mathrm{g} / \mathrm{ml}$ ) à au moins un sérotype était similaire dans les deux groupes ( $73,3 \%$ vs $53,3 \%$ dans le groupe PNEU-C-7 et le groupe PNEU-P-23, respectivement; $p=0,11)$. Le nombre médian de sérotypes associés à une réponse était de 2,5 (PNEU-C-7) et de 1,0 (PNEU-P-23); $p=0,069$. II n'y avait aucune différence entre les groupes en ce qui concerne le facteur d'augmentation des titres mesurés par I'OPA : une OPA contre un des sérotypes a été observée chez $80 \%$ des participants après I'administration du vaccin PNEU-C-7 et chez $83,3 \%$ des participants après l'administration du vaccin PNEU-P-2320. Un suivi effectué trois ans plus tard (PNEU-C-7 [ $n=23$ ] ou PNEU-P-23 [ $n=24]$ ) a révélé qu'il n'y avait aucune différence quant à la proportion de participants ayant maintenu une réponse spécifique au sérotype après trois ans pour l'ensemble des sept sérotypes. Les TMG globaux après trois ans avaient chuté considérablement pour six des sept sérotypes en comparaison aux titres mesurés après huit semaines, sauf dans le cas du sérotype 19F (aucune différence).

Toutefois, les titres après trois ans étaient nettement plus élevés dans les deux groupes que les titres mesurés avant la vaccination pour tous les sérotypes sauf le 14. Le taux de diminution du TMG était semblable dans les deux groupes ${ }^{21}$.

Tobudic et coll. ${ }^{22}$ ont mené une étude comparative randomisée à simple insu dans le but de déterminer I'utilité d'une dose initiale du vaccin PNEU-C-7 ou du vaccin PNEU-P-23 avant I'administration d'une dose de rappel du vaccin PNEU-P-23 une année plus tard chez des adultes ayant subi une transplantation rénale. La transplantation avait eu lieu au moins six mois avant l'inscription à l'étude. Les critères d'exclusion étaient les suivants : splénectomie, vaccination contre le pneumocoque au cours des cinq années précédant l'inscription à l'étude, traitement visant à prévenir le rejet d'une allogreffe, IGIV au cours des six semaines précédentes, maladie fébrile aiguë dans les deux semaines précédentes. Au total, 80 participants ont aléatoirement reçu le vaccin PNEU-C-7 ou le vaccin PNEU-P-23 puis une dose de rappel du vaccin PNEU-P-23 un an plus tard. Ces groupes ont été comparés entre eux puis avec le groupe initial, qui n'avait reçu que le vaccin PNEU-P-23. Les paramètres mesurés étaient une augmentation d'un facteur de 2 de la concentration d'anticorps par rapport aux valeurs de référence et une valeur absolue $>1 \mu \mathrm{g} / \mathrm{ml}$ après la vaccination. Dans le groupe PNEU-C-7, 77,1 \% des sujets avaient présenté une réponse à au moins un sérotype, comparativement à 93,1\% dans le groupe PNEU-P-23 $(p=0,046)$. Après l'administration de la dose de rappel (vaccin PNEU-P-23) un an plus tard, la réponse à au moins un sérotype était de $87,5 \%$ dans le groupe PNEU-C-7/PNEU-P-23 et de 87,1\% dans le groupe PNEU-P-23/PNEU-P-23. Le nombre médian de sérotypes associés à une réponse n'était pas statistiquement différent entre les deux groupes. À la lumière de ces résultats, les auteurs ont conclu que l'administration d'une seule dose de vaccin PNEU-P-23 devrait demeurer la norme chez les patients adultes ayant subi une transplantation rénale.

\section{B) Greffés de cellules souches hématopoïétiques (GCSH)}

Cordonnier et coll. ont publié un ECR multicentrique mené auprès de $158 \mathrm{GCSH}$ allogéniques répartis aléatoirement dans des groupes pour recevoir le 
vaccin PNEU-C-7 3, 4 et 5 mois après la GCSH puis le vaccin PNEU-P-23 (groupe d'administration précoce; $n=75) 12$ mois après la GCSH, ou le vaccin PNEU-C-7 9, 10 et 11 mois après la GCSH puis le vaccin PNEU-P-23 18 mois après la GCSH (groupe d'administration tardive; $n=83$ ). Les caractéristiques de base étaient semblables dans les deux groupes, mais il y avait une différence significative en ce qui concerne la proportion de participants présentant des titres d'anticorps $\geq 0,15 \mu \mathrm{g} / \mathrm{ml}$ contre l'ensemble des sept sérotypes avant l'administration du vaccin PNEU-C-7 (44\% dans le groupe d'administration précoce vs $9 \%$ dans le groupe d'administration tardive; $p<0,001$ ). Un mois après l'administration de la troisième dose de vaccin PNEU-C-7, $79 \%$ et $82 \%$ des participants présentaient des titres d'anticorps $\geq 0,15 \mu \mathrm{g} / \mathrm{ml}$ contre l'ensemble des sept sérotypes, et $56 \%$ vs $54 \%$ présentaient une réponse à l'ensemble des sept sérotypes (TMG $\geq 0,5 \mu \mathrm{g} / \mathrm{ml}$ ) dans le groupe d'administration précoce et le groupe d'administration tardive, respectivement. Vingt-quatre mois après la GCSH, $59 \%$ vs $83 \%(p=0,013)$ des participants présentaient des titres d'anticorps $\geq 0,15 \mu \mathrm{g} / \mathrm{ml}$ contre l'ensemble des sept sérotypes, et $34 \%$ vs $55 \%$ présentaient une réponse à l'ensemble des sept sérotypes (TMG $\geq 0,5 \mu \mathrm{g} / \mathrm{ml}$ ) dans le groupe d'administration précoce et le groupe d'administration tardive, respectivement. Un mois après l'administration de la troisième dose du vaccin PNEU-C-7, il n'y avait aucune différence concernant les TMG contre les sérotypes dans les deux groupes. Cependant, 24 mois après la GCSH, les TMG étaient significativement plus faibles contre tous les sérotypes, sauf pour le 23F, dans le groupe d'administration précoce ${ }^{23}$.

Molrine et coll. ont étudié l'immunisation des donneurs dans le cadre d'un ECR mené auprès de receveurs de GCSH allogéniques. Certains donneurs ont reçu le vaccin PNEU-C-7 10 jours avant le don de cellules souches, et d'autres, non. Tous les receveurs se sont vus administrer le vaccin PNEU-C-7 3, 6 et 12 mois après la GCSH. Les donneurs de 30 receveurs de GCSH avaient été immunisés, les donneurs de 35 autres receveurs n'avaient pas été immunisés, et 31 receveurs n'étaient pas évaluables (21 sont décédés peu avant ou peu après la greffe, 5 ont été exclus avant la greffe, 2 ont été exclus pour avoir violé le protocole expérimental, et 3 avaient subi une rechute). II n'y avait aucune différence entre les deux groupes quant à la proportion de receveurs ayant un TMG $\geq 0,5 \mu \mathrm{g} / \mathrm{ml} 3,12$ et 13 mois après la GCSH. Les différences entre les TMG des greffés étaient considérablement plus élevées 6 et à 12 mois post-greffe pour les sérotypes 6B, 9V, 18C, 19F et $23 \mathrm{~F}$ lorsque le donneur était immunisé. En dépit de difficultés d'interprétation, les chercheurs ont comparé les concentrations de TMG après I'administration du vaccin PNEU-C-7 dans cette étude avec les résultats obtenus lors d'une étude antérieure chez des receveurs de GCSH allogéniques à qui on avait administré le vaccin PNEU-P-23 12 mois après la greffe. On a constaté que les concentrations de TMG étaient significativement plus élevées pour les sept sérotypes communs aux deux vaccins avec le vaccin PNEU-C-7 plutôt qu'avec le vaccin PNEU-P-2324.

Kumar et coll. ont réparti aléatoirement 64 paires donneur-receveur de GCSH allogénique (32 paires par groupe) dans des groupes devant recevoir le vaccin PNEU-P-23 ou le vaccin PNEU-C-7 : les donneurs avaient été vaccinés au moins deux semaines avant le don des cellules souches, et les receveurs de GCSH se sont vu administrer une dose du vaccin six mois après la GCSH. Les caractéristiques de base étaient semblables dans les deux groupes (donneurs et receveurs). Deux semaines après la vaccination, il n'y avait pas de différence entre les deux groupes en ce qui concerne les TMG des donneurs. Six mois après la GCSH, les TMG étaient semblables pour les sept sérotypes, sauf le 6B (plus élevé après le vaccin PNEU-C-7). Douze mois après la GCSH, les TMG étaient plus élevés après le vaccin PNEU-C-7 pour les sérotypes 14 et $18 \mathrm{C}$. Une réponse à au moins un sérotype $(\geq 0,35 \mu \mathrm{g} / \mathrm{ml})$ a été observée chez $38,1 \%$ et $0 \%$ des receveurs de GCSH après le vaccin PNEU-C-7 et le vaccin PNEU-P-23 six mois après la GCSH, respectivement $(p=0,003)$. Douze mois après la $\mathrm{GCSH}$, la proportion de sujets présentant une réponse était de $90,8 \%$ vs $55,6 \%$ dans le groupe PNEU-C-7 vs le groupe PNEU-P-23, respectivement $(p=0,02)^{25}$. 


\section{Participants séropositifs pour le VIH}

Feikin et coll. ont réparti aléatoirement $90 \mathrm{PVIH}$ (numération des CD4 d'au moins 200 cellules/ $\mu$ l) dans des groupes recevant deux doses d'une association de placebo, vaccin PNEU-C-7 et vaccin PNEU-P-23. II y avait 67 patients évaluables. Les participants ayant reçu le vaccin PNEU-C-7 tendaient à présenter une meilleure réponse que ceux ayant reçu le vaccin PNEU-P-23 pour trois des cinq sérotypes à l'étude $(23 F, 4,9 V)$. Toutefois, la seconde dose de vaccin n'a entraîné aucun bénéfice additionnel: après la seconde dose, la concentration moyenne géométrique (CMG) était équivalente chez les participants ayant reçu les vaccins PNEU-C-7/PNEU-C-7 ou PNEU-C-7/PNEU-P-23. Les titres d'OPA étaient significativement meilleurs après le vaccin PNEU-C-7 qu'après le vaccin PNEU-P-23 pour les cinq sérotypes à l'étude. Une fois de plus, la seconde dose n'a provoqué aucune augmentation des titres d'OPA ${ }^{26}$.

Penaranda et coll. ont réparti aléatoirement $220 \mathrm{PVVIH}$ (CD4 : 200 à 500 cellules/ul, charge virale < 5 log copies/ml) dans des groupes devant recevoir les vaccins PNEU-C-7/ PNEU-P-23 ou le vaccin PNEU-P-23 ( $n=110$ dans chaque groupe). Les caractéristiques de base étaient semblables dans les deux groupes, et une forte proportion des patients recevait un traitement antirétroviral hautement actif (HAART) (98\% et $91 \%$ ). II n'y avait aucune différence statistique dans la proportion de sujets ayant présenté une réponse après huit semaines (augmentation d'un facteur de 2 des lgG et titre minimum de $1 \mu \mathrm{g} / \mathrm{ml}$ ) et il n'y avait aucune différence quant à l'avidité des $\operatorname{lgG} 27$.

Crum-Cianflone et coll. ont réparti aléatoirement des patients de la façon suivante : $131 \mathrm{PVVIH}$ dans un groupe devant être revacciné avec le vaccin PNEU-C-7 et 73 patients PVIH dans un groupe devant être revacciné avec le vaccin PNEU-P-23 de trois à huit ans après la dernière dose du vaccin PNEU-P-23. Vingt-cinq participants négatifs pour le VIH qui n'avaient pas été vaccinés auparavant ont reçu le vaccin PNEU-C-7. Le nombre médian de lymphocytes CD4 était de 533 et de 513 cellules $/ \mathrm{mm} 3$ dans le groupe PNEU-C-7 et le groupe PNEU-P-23, respectivement. Les participants du groupe PNEU-C-7 étaient plus nombreux à suivre un traitement HAART ( $84,7 \%$ vs $56 \%$ ). La proportion de sujets ayant présenté une augmentation d'un facteur de 2 du titre des IgG au jour 60 pour deux des quatre sérotypes $(4,9 \mathrm{~V}$, $14,19 F)$ était plus élevée dans le groupe revacciné avec le vaccin PNEU-C-7 (57 \%) que dans celui revacciné avec le vaccin PNEU-P-23 (36\%); $p=0,004$. La proportion de sujets négatifs pour le $\mathrm{VIH}$ ayant présenté une réponse était de $88 \%$. Le RC (ajusté en fonction de la numération des lymphocytes CD4, de l'âge, de l'ethnicité, d'une pneumonie antérieure, du traitement HAART lors de la vaccination et de la charge virale du $\mathrm{VIH}$ ) associé à une réponse à deux sérotypes sur quatre chez les patients infectés par le VIH était de 2,6 (IC à $95 \% 1,4$ à 5,0 ) lorsqu'on comparait le groupe PNEU-C-7 et le groupe PNEU-P-2328.

Lesprit et coll. ont réparti aléatoirement $212 \mathrm{PVVIH}$ (CD4 : 200 à 500 cellules/ $\mu$ l) dans des groupes recevant les vaccins PNEU-C-7/PNEU-P-23 $(n=106)$ ou le vaccin PNEU-P-23 seul. Les titres de base en ce qui concerne les IgG, de même que les caractéristiques de base, étaient semblables dans les deux groupes. Quatre semaines après l'administration de la dernière dose de vaccin, les titres d'lgG étaient semblables dans les deux groupes; la réponse observée était toutefois meilleure après l'administration des vaccins PNEU-C-7/PNEU-P-23 dans le cas des sérotypes 18C et 23F. À la semaine 24, les titres d'lgG étaient plus élevés dans le groupe PNEU-C-7/PNEU-P-23 pour quatre des sept sérotypes. La proportion de sujets présentant une réponse (augmentation d'un facteur de 2 du titre d'lgG et titre minimum de $1 \mathrm{mg} / \mathrm{L}$ ) à cinq des sept sérotypes était plus élevée dans le groupe PNEU-C-7/PNEU-P-23 (59\%) que dans le groupe n'ayant reçu que le vaccin PNEU-P-23 (40\%); $p=0,005$. On a observé le même phénomène après 24 semaines : $30 \%$ des sujets avaient présenté une réponse à cinq des sept sérotypes dans le groupe PNEU-C-7/PNEU-P-23, et seulement $10 \%$ dans le groupe PNEU-P-23, respectivement $(p=0,003)^{29}$.

\section{Personnes âgées}

Deux études multicentriques ont porté sur l'immunogénicité associée à l'administration concomitante du vaccin trivalent contre l'influenza (VTI) et du vaccin PNEU-C-13 chez des participants en bonne santé n'ayant jamais reçu de vaccin contre le pneumocoque âgés de 50 à 59 ans (étude américaine) ${ }^{30}$ et de 65 ans ou plus (étude européenne) ${ }^{31}$. Dans ces études, les auteurs ont comparé l'administration des vaccins PNEU-C-13/VTI suivie, un mois plus tard, par I'administration d'un placebo et l'administration du VTI avec un placebo suivie, un mois plus tard, par le vaccin PNEU-C-13. Aucune comparaison n'a été effectuée avec le vaccin PNEU-P-23. Schwarz et coll. ont rapporté que les CMG pour 13 sérotypes se situaient entre 1,08 (sérotype 3) et $11,93(19 \mathrm{~A}) \mu \mathrm{g} / \mathrm{ml}$ dans le groupe d'administration concomitante et entre 1,15 (3) et 17,10 (19A) $\mu \mathrm{g} / \mathrm{ml}$ lorsque le vaccin PNEU-C-13 était administré seul; les ratios des CMG (administration concomitante/PNEU-C-13 seul) étaient $<1,0$, et outre le sérotype $19 F$, tous ont atteint le critère de non-infériorité prédéterminé. La réponse au VTI était similaire dans les deux groupes ${ }^{31}$. De même, Frenck et coll. ont fait état de CMG se situant entre 1,15 (sérotype 3) et $16,80(19 \mathrm{~A}) \mu \mathrm{g} / \mathrm{ml}$ dans le groupe d'administration 
concomitante et entre 1,46 (3) et 18,84 (19A) $\mu \mathrm{g} / \mathrm{ml}$ lorsque le vaccin PNEU-C-13 était administré seul. Les CMG mesurées par l'OPA se situaient entre 61 (sérotype 3) et 2421 (6B) dans le groupe d'administration concomitante et entre 78 (3) et 3215 (6B) lorsque le vaccin PNEU-C-13 était administré seul. Bien que, dans cette étude, les ratios des CMG aient tous été $<1$, tous les sérotypes ont atteint le critère de non-infériorité. En ce qui concerne les ratios des TMG mesurés par l'OPA, bien qu'ils aient aussi tous été $<1$, 5 des 13 sérotypes $(1,5,7 F, 9 \mathrm{~V}$ et 19F) n'ont pas atteint le critère de non-infériorité (limite inférieure de I'IC à $95 \%<0,5)^{30}$

Jackson et coll. ont réparti aléatoirement des adultes en bonne santé de 70 à 79 ans qui avaient reçu le vaccin PNEU-P-23 lorsqu'ils avaient 65 ans ou plus (au moins cinq ans avant l'étude) dans des groupes recevant une dose du vaccin PNEU-P-23 ou du vaccin PNEU-C-7, à raison de 0,5, 1 ou $2 \mathrm{ml}$. Les titres mesurés après la vaccination étaient significativement plus élevés chez les sujets ayant reçu la dose de $2 \mathrm{ml}$ par rapport à ceux ayant reçu la dose de $0,5 \mathrm{ml}$ pour trois des sept sérotypes (6B, 9V, 23F) et significativement plus élevés chez les sujets ayant reçu les doses de $1 \mathrm{ml}$ et de $2 \mathrm{ml}$ que chez ceux ayant reçu la dose de $0,5 \mathrm{ml}$ pour les sérotypes $18 \mathrm{C}$ et 19. Un an après la vaccination, les CMG associées à tous les sérotypes étaient semblables aux titres mesurés avant la vaccination, pour tous les vaccins et pour toutes les doses. II n'y avait aucune différence significative de la CMG entre le vaccin PNEU-C-7 (0,5 ml) et le vaccin PNEU-P-23; toutefois, après ajustement en fonction de la CMG de base, deux sérotypes répondaient au critère d'immunogénicité supérieure dans le groupe PNEU-C-7. Les TMG mesurés par I'OPA étaient considérablement plus élevés après le vaccin PNEU-C-7 $(0,5 \mathrm{ml})$ qu'après le vaccin PNEU-P-23 pour les sérotypes $9 \mathrm{~V}$ et 23F. Cependant, il n'y avait aucune différence significative entre les TMG mesurés par l'OPA un an après la vaccination ${ }^{32}$

De Roux et coll. ont réparti aléatoirement 219 adultes de 70 ans ou plus dans des groupes devant recevoir une première dose de vaccin PNEU-C-7 $(n=110)$ ou de vaccin PNEU-P-23 ( $n=109$ ) suivi un an plus du vaccin PNEU-C-7 (PNEU-C-7/ PNEU-C-7) ou PNEU-P-23 (PNEU-C-7/PNEU-P-23) pour les patients ayant d'abord reçu le vaccin PNEU-C-7, et le vaccin PNEU-C-7 (PNEU-P-23/PNEU-C-7) pour les patients ayant d'abord reçu le vaccin PNEU-P-23. Les titres d'lgG spécifiques étaient significativement plus élevés un mois après la première dose de vaccin PNEU-C-7 par rapport au vaccin PNEU-P-23. Les titres étaient considérablement plus faibles après un mois chez les sujets ayant reçu le vaccin PNEU-P-23 puis, un an plus tard, le vaccin PNEU-C-7 par rapport aux sujets ayant reçu une seule dose du vaccin PNEU-C-7. Aucun avantage additionnel n'a été observé après l'administration d'une seconde dose de vaccin PNEU-C-7 un an après l'administration d'une première dose de vaccin PNEU-C-7. Les TMG mesurés par l'OPA suivaient les mêmes tendances que les titres des $\operatorname{lgG}^{33}$.

Miernyk et coll. ont réparti aléatoirement des Autochtones de l'Alaska de 55 à 70 ans qui n'avaient jamais reçu de vaccin contre le pneumocoque en trois groupes devant recevoir le vaccin PNEU-P-23 $(n=28)$, le vaccin PNEU-C-7 suivi du PNEU-P-23 deux mois plus tard $(n=29)$, ou le vaccin PNEU-C-7 suivi du vaccin PNEU-P-23 six mois plus tard $(n=29)$. Les caractéristiques de base des trois groupes étaient semblables. On a observé une augmentation significative des CMG pour tous les sérotypes vaccinaux par rapport aux valeurs de base dans les trois groupes (PNEU-P-23 [1 groupe] et PNEU-C-7 [2 groupes]), et l'augmentation était semblable dans les trois groupes, sauf en ce qui concerne le sérotype 1, qui était plus élevé après le vaccin PNEU-P-23. Deux mois après la dernière dose, il n'y avait aucune différence entre les trois groupes relativement aux CMG associées à tous les sérotypes. Les titres mesurés par l'OPA un mois après la première dose et deux mois après la dernière dose étaient semblables dans les trois groupes ${ }^{34}$.

Goldblatt et coll. ont réparti aléatoirement des patients de 50 à 80 ans qui n'avaient pas reçu de vaccin contre le pneumocoque au cours des cinq dernières années dans des groupes devant recevoir le vaccin PNEU-C-7 suivi du PNEU-C-7 six mois plus tard ( $n=133$ ); le vaccin PNEU-C-7 suivi du PNEU-P-23 six mois plus tard $(n=171)$, le vaccin PNEU-P-23 seul ( $n=159$ ) ou le vaccin PNEU-C-7 seul $(n=136)$. Un mois après I'administration du vaccin PNEU-C-7 ou du vaccin PNEU-P-23, les CMG des sérotypes 4, 9 et 23F étaient plus élevées avec le vaccin PNEU-C-7; cependant, un an après la vaccination, il n'y avait plus de différence significative entre les deux groupes pour six des sept sérotypes (la CMG du sérotype 23F était plus élevée avec le vaccin PNEU-C-7). Un mois après la seconde dose, il n'y avait plus de différence sur le plan des CMG pour six des sept sérotypes (la CMG du sérotype 19F était plus élevée après les vaccins PNEU-C-7/PNEU-P-23 qu'après les vaccins PNEU-C-7/PNEU-C-7). Un an après I'administration des vaccins PNEU-C-7/PNEU-C-7 vs PNEU-P-23, la proportion de sujets présentant des concentrations d'anticorps $>1 \mu \mathrm{g} / \mathrm{ml}$ n'était pas différente35.

Schenkein et coll. ont sélectionné aléatoirement 45 adultes de $<45$ ans et 58 adultes de 65 ans ou plus pour leur administrer le vaccin PNEU-P-23. II n'y avait aucune différence entre les deux groupes de sujets en ce qui concerne la CMG. On a toutefois démontré une activité 
anticorps (titres d'opsonisation) significativement plus importante contre tous les sérotypes chez les sujets plus jeunes ${ }^{36}$.

Musher et coll. ont réparti aléatoirement des adultes de 50 à 65 ans et de 65 ans ou plus qui avaient déjà reçu le vaccin PNEU-P-23 (pas de minimum d'intervalle entre la dose antérieure du vaccin PNEU-P-23 et l'inscription à l'étude) ou non en deux groupes devant recevoir le vaccin PNEU-P-23 ou un placebo. Les chercheurs ont indiqué qu'il n'y avait aucune différence significative, à 30 jours et à 60 jours, entre les groupes qui recevaient le vaccin pour la première fois et le groupe revacciné en ce qui concerne les titres d'IgG pour tous les sérotypes, sauf pour les sérotypes 8 et 14 dans le groupe des 65 ans et plus et pour le sérotype 14 dans le groupe des 50 à 65 ans $^{37}$.

\section{IV.5 ADMINISTRATION DU VACCIN ET CALENDRIER}

La dose du vaccin PNEU-C-13 chez l'adulte est une injection de $0,5 \mathrm{ml}$ par voie IM, laquelle devrait être suivie d'une dose de vaccin PNEU-P-23 deux mois plus tard dans le cas des patients à risque élevé d'IIP. Les greffés de cellules souches hématopoïétiques devraient recevoir une première série de trois doses de vaccin PNEU-C-13 administrées à un intervalle minimum de 4 semaines. Le moment exact auquel la série vaccinale devrait être amorcée sera à déterminer au cas par cas, en consultation avec un hémato-oncologue. Selon les articles publiés sur le sujet, la première série peut être amorcée de trois à neuf mois après la greffe. Cette série primaire devrait être suivie d'une injection de rappel du vaccin PNEU-P-23, administrée 6 à 12 mois plus tard.

\section{IV.6 ÉPREUVES SÉROLOGIOUES}

II n'y a aucune indication relativement à la réalisation d'épreuves sérologiques systématiques avant ou après l'immunisation.

\section{IV.7 EXIGENCES EN MATIÈRE D'ENTREPOSAGE}

Le vaccin doit être réfrigéré à une température de $2^{\circ} \mathrm{C}$ à $8{ }^{\circ} \mathrm{C}$. $\mathrm{S}^{\prime} \mathrm{il}$ est soumis à des températures inférieures au point de congélation, le vaccin doit être jeté. En cas de rupture temporaire de la chaîne de froid, la stabilité du vaccin PNEU-C-13 est assurée jusqu'à $40^{\circ} \mathrm{C}$ pendant un maximum de quatre jours ${ }^{38}$. Les praticiens devraient toutefois se conformer aux normes provinciales usuelles pour déterminer la viabilité du vaccin en cas de rupture de la chaîne de froid.

\section{IV.8 ADMINISTRATION EN CONCOMITANCE AVEC D'AUTRES VACCINS}

Dans la population adulte, le vaccin PNEU-C-13 a été administré en concomitance avec le VTI uniquement ${ }^{30,31}$, et la réponse immunitaire au VTI semble similaire que le VTI ait été administré seul ou en concomitance avec le vaccin PNEU-C-13. Dans la plupart des cas, les titres spécifiques d'anticorps n'étaient pas différents lorsque le vaccin PNEU-C-13 était administré seul ou en concomitance. Une étude a révélé une diminution des TMG mesurés par I'OPA lorsque le vaccin PNEU-C-13 était administré en concomitance avec le VTI, mais les implications cliniques de cette observation ne sont pas claires.

Le vaccin PNEU-C-13 a été étudié en administration concomitante avec un certain nombre d'antigènes utilisés dans le cadre d'un calendrier vaccinal pédiatrique canadien, et il n'y a eu aucun effet négatif sur l'immunogénicité ou le profil d'innocuité du vaccin. Les antigènes en question sont notamment ceux de la diphtérie, du tétanos, de la coqueluche (acellulaire), de l'Haemophilus influenzae de type b, de la poliomyélite (inactivé), de I'hépatite $B$, du méningocoques du sérogroupe $\mathrm{C}$, de la rougeole, des oreillons, de la rubéole et de la varicelle39. Comme le veulent les recommandations générales en matière de vaccination, il faut administrer le vaccin PNEU-C-13 en utilisant un site d'injection distinct de ceux utilisés pour les vaccins administrés en concomitance, en employant une seringue et une aiguille différentes.

\section{IV.9 ÉVÈNEMENTS INDÉSIRABLES}

Le vaccin PNEU-C-13 a été administré à 2276 adultes de 50 ans ou plus dans deux études distinctes. Au total, 943 d'entre eux ont reçu le vaccin PNEU-C-13 seul : 453 âgés de 50-59 ans et 470 âgés de 65 ans et plus. Parmi ces participants, 607/926 (66\%) ont signalé une réaction localisée, le plus souvent de la douleur au site d'injection (chez $587 / 923$ participants, soit $64 \%$ ). Des effets indésirables systémiques (de tous types) ont été signalés chez 562/912 (62\%) participants, les plus fréquents étant la fatigue (305/795; $38 \%)$, les céphalées $(283 / 787 ; 36 \%)$ et les myalgies d'apparition récente (312/798; $39 \%)$. Une fièvre (de $38^{\circ} \mathrm{C}$ ou plus) a été signalée chez 21/663 (3\%) des participants ${ }^{30,31}$. 
L'innocuité a été évaluée dans six essais cliniques (parmi lesquels figurent les deux essais décrits précédemment ${ }^{38}$ : le vaccin PNEU-C-13 a été administré à 5667 adultes; 2616 adultes avaient entre 50 et 64 ans, et 3051 adultes avaient 65 ans ou plus. Parmi les sujets ayant reçu le vaccin PNEU-C-13, 1916 adultes avaient déjà reçu le vaccin PNEU-P-23 au moins trois ans plus tôt, et 3751 adultes n'avaient jamais reçu le vaccin PNEU-P-23. Les résultats obtenus figurent ci-après.

\section{Réactions locales ${ }^{38}$}

Chez les adultes de 50 à 59 ans n'ayant jamais reçu le vaccin PNEU-P-23, l'événement indésirable le plus fréquent était une douleur au site d'injection $(88,8 \%)$, mais celle-ci était légère dans la majorité des cas (85,9\%). Les autres événements locaux indésirables étaient une limitation de l'amplitude des mouvements du bras $(40,7 \%$ - légère dans la plupart des cas), un œdème $(21,7 \%)$ et des rougeurs (15,8\%). Chez les adultes de 60 à 64 ans n'ayant jamais reçu le vaccin PNEU-P-23, 80,1 \% et 69,2\% des participants (deux études différentes) ont éprouvé de la douleur, ce qui était plus important qu'après le vaccin PNEU-P-23 (73,4 \% et 58,3\%). La douleur était principalement de faible intensité. Les participants ont fait état d'une limitation de I'amplitude des mouvements du bras dans $28,5 \%$ et $23,5 \%$ des cas (moins fréquemment qu'après le PNEU-P-23), de rougeurs dans $20,2 \%$ et $12,2 \%$ des cas, et d'un œdème dans $19,3 \%$ et $10 \%$ des cas. Chez les adultes de 68 ans ou plus ayant déjà reçu le vaccin PNEU-P-23, 51 \% ont éprouvé de la douleur, 16,2 \% présentaient une limitation de l'amplitude des mouvements du bras, 14,3\% présentaient des rougeurs et $12,8 \%$ avaient signalé un œdème. Chez les adultes de 70 ans ou plus ayant déjà reçu le vaccin PNEU-P-23, 51,7 \% ont éprouvé de la douleur, 10,5\% présentaient une limitation de l'amplitude des mouvements du bras, $10,8 \%$ présentaient des rougeurs et $10,4 \%$ ont signalé un œdème, ce qui était considérablement moins important qu'après le vaccin PNEU-P-23 en ce qui concerne la limitation de l'amplitude des mouvements du bras $(27,6 \%)$, les rougeurs $(22,2 \%)$ et l'œdème $(23,1 \%)$.

\section{Événements systémiques ${ }^{38}$}

Chez les adultes de 50 à 59 ans n'ayant jamais reçu le vaccin PNEU-P-23, les événements les plus fréquents étaient les céphalées $(65,9 \%)$, puis la fatigue $(63,3 \%)$, la myalgie (61,8\%), l'arthralgie (31,5\%), I'anorexie (25,3\%), les frissons (19,6\%) et les éruptions cutanées (14,2\%).

Dans les deux études menées auprès d'adultes de 60 à 64 ans qui n'avaient jamais reçu le vaccin PNEU-P-23, 63,2 \% et 50,5\% des sujets ont éprouvé de la fatigue, $54 \%$ et $49,7 \%$ ont eu des céphalées, $56,2 \%$ et $46,9 \%$ ont décrit des symptômes de myalgie, $24,4 \%$ et $15,5 \%$ présentaient une arthralgie, $23,5 \%$ et $19,9 \%$ avaient des frissons, et $16,5 \%$ et $8,6 \%$ présentaient des éruptions cutanées. Dans une des études, la proportion d'événements indésirables déclarés après le vaccin PNEU-C-13 n'était pas différente de la proportion d'événements indésirables déclarés après le vaccin PNEU-P-23. Dans la deuxième étude, I'arthralgie (23,8 \%) et l'anorexie (23\%) étaient signalées plus souvent après le vaccin PNEU-P-23 qu'après le vaccin PNEU-C-13.

Chez les adultes de 68 ans ou plus ayant déjà reçu le vaccin PNEU-P-23, les événements indésirables suivants ont été signalés par les sujets selon la proportion indiquée entre parenthèses : fatigue (34,4\%), céphalées $(26,1 \%)$, myalgie $(25,3 \%)$, diarrhée (14,5\%), arthralgie (12,8\%), anorexie $(11,2 \%)$, éruptions cutanées $(8,4 \%)$ et frissons (7,5\%). Chez les adultes de 70 ans ou plus ayant déjà reçu le vaccin PNEU-P-23, les événements indésirables suivants ont été signalés : myalgie (36,8 \%), fatigue (34\%), céphalées $(23,7 \%)$, arthralgie (12,6\%), anorexie (10,4\%), frissons (7,9\%) et éruptions cutanées (7,3\%). Les événements indésirables sollicités suivants étaient considérablement plus fréquents après le vaccin PNEU-P-23 dans la même étude : fatigue (43,3\%), myalgie $(44,7 \%)$ et éruptions cutanées (16,4\%). La fièvre (de tout type) a été signalée par 1,1\% à 4,2\% des participants après le vaccin PNEU-C-13, et par $1,1 \%$ à $2,3 \%$ des participants après le vaccin PNEU-P-23. Dans la plupart des cas, la fièvre était caractérisée par une température de $38^{\circ} \mathrm{C}$ à $38,5^{\circ} \mathrm{C}$. 


\section{IV.10 CONTRE-INDICATIONS ET PRÉCAUTIONS}

Le vaccin PNEU-C-13 est contre-indiqué chez les personnes ayant des antécédents de réaction anaphylactique à un composant du vaccin, y compris l'anatoxine diphtérique.

\section{Résumé}

Les données passées en revue révèlent que la réponse immunitaire induite par les vaccins conjugués contre le pneumocoque est meilleure que celle provoquée par le vaccin PNEU-P-23 chez les adultes ayant reçu une GCSH. Dans le cas des greffés d'organes solides, les données ne sont pas aussi probantes. L'efficacité réelle du vaccin PNEU-P-23 chez les personnes vivant avec le VIH et le Sida est, au mieux, faible, mais elle est le plus souvent insuffisante pour que I'on puisse parler d'un véritable effet protecteur; le vaccin PNEU-C-7, toutefois, confère une meilleure protection. Aucune étude de l'efficacité potentielle ou de l'efficacité réelle des vaccins conjugués contre le pneumocoque n'a été menée chez les personnes âgées. Par ailleurs, les résultats découlant des études d'immunogénicité où l'on a comparé I'utilisation du vaccin PNEU-C-7 et celle du vaccin PNEU-P-23 ont fait état de titres d'anticorps semblables un an après I'administration de ces vaccins en ce qui a trait aux sept sérotypes communs. Du reste, on ne dispose pas actuellement d'études sur l'immunogénicité comparant l'utilisation du vaccin PNEU-C-13 et celle du vaccin PNEU-P-23 chez les personnes âgées; ni de corrélats de la protection définis qui permettraient d'interpréter les données d'immunogénicité dans ce segment de la population.

\section{Recommandations}

Il est à noter que les provinces et les territoires doivent examiner les facteurs économiques et les autres facteurs programmatiques/opérationnels locaux lorsqu'ils envisagent d'inclure les recommandations suivantes aux programmes d'immunisation subventionnés par l'État.

Les recommandations suivantes seront réexaminées et mises à jour lorsque de nouvelles données seront disponibles.

\section{Recommandation 1}

Le CCNI a conclu qu'il existait des données probantes suffisantes pour recommander l'utilisation du vaccin PNEU-C-13 chez les greffés de cellules souches hématopoïétiques (GCSH), compte tenu de la meilleure immunogénicité associée aux vaccins conjugués contre le pneumocoque dans cette population par rapport au vaccin PNEU-P-23. Les GCSH devraient recevoir une série vaccinale primaire de trois doses de vaccin PNEU-C-13, trois à neuf mois après la greffe, après consultation avec un spécialiste en greffe. Les trois doses de la série primaire devraient être administrées à au moins quatre semaines d'intervalle et être suivies par une dose de rappel du vaccin PNEU-P-23 de 12 à 18 mois après la greffe ( 6 à 12 mois après la dernière dose du vaccin PNEU-C-13). (Recommandation du CCNI de catégorie $A$ )

\section{Recommandation 2}

Le CCNI a conclu qu'il existait des données probantes suffisantes pour recommander I'utilisation du vaccin PNEU-C-13 chez les patients positifs pour le VIH, compte tenu des meilleures efficacités potentielle et réelle associées au vaccin conjugué contre le pneumocoque (PNEU-C-7) dans cette population. Les sujets positifs pour le VIH devraient recevoir une dose de vaccin PNEU-C-13, puis une dose de vaccin PNEU-P-23 huit semaines plus tard. Pour I'heure, aucune donnée probante $n$ 'indique que l'administration d'une dose de rappel du vaccin PNEU-C-13 confère un quelconque avantage. (Recommandation du CCNI de catégorie A)

La plupart des études publiées excluaient les participants qui avaient reçu une dose de vaccin PNEU-P-23 dans les cinq années précédant l'inscription à l'étude. Par conséquent, on ignore quel serait l'intervalle minimum à respecter entre la dernière dose de vaccin PNEU-P-23 reçue et le vaccin PNEU-C-13. Cependant, vu la possibilité d'une diminution des titres d'anticorps après l'administration du vaccin PNEU-P-23, vu la gravité de I'IIP chez les sujets immunodéprimés et vu les avantages associés au vaccin PNEU-C-13 dans cette population de patients, le CCNI recommande $d^{\prime}$ administrer le vaccin PNEU-C-13 au moins un an après la dernière dose de vaccin PNEU-P-23 (avis d'experts).

L'administration d'une dose de rappel à vie de PNEU-P-23 est recommandée pour les individus à haut risque d'IIP, entre autres les personnes vivant avec le VIH. Ceux ayant préalablement été vaccinés avec le PNEU-P-23 et qui nécessiteraient une dose supplémentaire de PNEU-P-23 devraient la recevoir au moins 8 semaines après la dose de PNEU-C-13 et au moins 5 ans après la dose la plus récente de PNEU-P-23 (avis d'experts). 


\section{Recommandation 3}

Le CCNI a conclu qu'il existait des données probantes acceptables pour recommander I'utilisation du vaccin PNEU-C-13 chez les sujets immunodéprimés dont l'état est dû à l'une ou l'autre des raisons suivantes :

- asplénie (anatomique ou fonctionnelle);

- anémie falciforme ou autre hémoglobinopathie;

- déficit immunitaire congénital de tout type, touchant notamment l'immunité à médiation humorale (lymphocytes B) ou à médiation cellulaire (lymphocytes T), le système du complément (déficit en properdine ou en facteur D), ou l'activité phagocytaire;

- traitement immunosuppresseur comprenant l'utilisation de corticostéroïdes pendant une longue période, chimiothérapie, radiothérapie, traitement antirejet, biothérapie et autres immunosuppresseurs non-biologiques pour maladies inflammatoires rhumatologiques et autres.

- néoplasies malignes incluant la leucémie et le lymphome;

- greffe d'organe solide ou de cellules des îlots pancréatiques (candidat ou receveur).

Ces patients immunodéprimés devraient recevoir une dose de vaccin PNEU-C-13 suivie d'une dose de vaccin PNEU-P-23 huit semaines plus tard. On ne dispose actuellement d'aucune donnée indiquant que l'administration d'une dose de rappel de vaccin PNEU-C-13 offre un quelconque avantage.

(Recommandation du CCNI de catégorie B)

Les études publiées excluaient les participants qui avaient reçu une dose de vaccin PNEU-P-23 dans les cinq années précédant l'inscription à l'étude. Par conséquent, on ignore quel serait l'intervalle minimum à respecter entre la dernière dose de vaccin PNEU-P-23 reçue et le vaccin PNEU-C-13. Cependant, vu la possibilité d'une diminution des titres d'anticorps après l'administration du vaccin PNEU-P-23, vu la gravité de I'IIP chez les sujets immunodéprimés et vu les avantages associés au vaccin PNEU-C-13 dans cette population de patients, le CCNI recommande d'administrer le vaccin PNEU-C-13 au moins un an après la dernière dose du vaccin PNEU-P-23 (avis d'experts).

L'administration d'une dose de rappel à vie de PNEU-P-23 est recommandée pour les individus à haut risque d'IIP, entre autres les personnes avec asplénie anatomique ou fonctionnelle, anémie falciforme, ou toute immunosuppression causée par une maladie ou un traitement, incluant les greffes d'organes solides. Les individus appartenant à ces groupes à haut risque, ayant préalablement été vaccinés avec le PNEU-P-23 et qui nécessiteraient une dose supplémentaire de PNEU-P-23 devraient la recevoir au moins 8 semaines après la dose de PNEU-C-13 et au moins 5 ans après la dose la plus récente de PNEU-P-23 (avis d'experts).

II n'existe actuellement aucune étude portant sur l'ensemble des pathologies ou situations précédentes. Cependant, d'après les données dont on dispose sur les personnes ayant subi une greffe d'organe solide, la portée de la recommandation est élargie de façon à englober d'autres sujets immunodéprimés.

\section{Recommandation 4}

Le CCNI a conclu qu'il existait des données probantes insuffisantes pour recommander l'utilisation du vaccin PNEU-C-13 chez les patients présentant une affection chronique non associée à une immunodépression (voir la liste ci-dessous). Cependant, d'autres facteurs peuvent influer sur la prise de décisions. Les recommandations relatives à l'administration du vaccin PNEU-P-23 demeurent inchangées. (Recommandation du CCNI de catégorie I)

Les affections chroniques non associées à une immunodépression dont il est question sont les suivantes:

- fuite chronique de liquide céphalorachidien;

- implant cochléaire;

- atteinte neurologique chronique pouvant affecter la clairance des sécrétions orales;

- cardiopathie ou pneumopathie chronique;

- diabète sucré;

- néphropathie chronique, y compris le syndrome néphrotique;

- hépatopathie chronique (y compris l'hépatite $B$ et I'hépatite $C$, ainsi qu'une cirrhose du foie, quelle qu'en soit la cause).

\section{Recommandation 5}

Le CCNI a conclu qu'il existait des données probantes insuffisantes pour recommander l'utilisation du vaccin PNEU-C-13 chez les adultes en bonne santé de 65 ans ou plus. Cependant, d'autres facteurs peuvent influer sur la prise de décisions. Les recommandations relatives à I'administration du vaccin PNEU-P-23 demeurent inchangées. (Recommandation du CCNI de catégorie I)

Comme on ne dispose pas de l'information critique suivante, le CCNI ne peut recommander l'utilisation du vaccin PNEU-C-13 chez des sujets en bonne santé de 65 ans ou plus :

1. données sur l'efficacité potentielle ou réelle du vaccin PNEU-C-13 - en comparaison avec un placebo et, idéalement, avec le vaccin PNEU-P-23 - relativement à la prévention de I'IIP dans cette population; 
2. données sur l'efficacité potentielle ou réelle du vaccin PNEU-C-13 - en comparaison avec un placebo et, idéalement, avec le vaccin PNEU-P-23 - relativement à la prévention de la POC dans cette population;

3. corrélats de protection qui permettraient d'interpréter les données d'immunogénicité dont on dispose actuellement pour le vaccin PNEU-C-13;

4. protection indirecte des adultes contre les IIP causées par les sérotypes inclus dans le PNEU-C-13 attribuable au programme d'immunisation des nourrissons et des enfants avec le vaccin PNEU-C-13.

\section{Surveillance et priorités de recherche}

L'épidémiologie des infections invasives à pneumocoque est en changement au Canada et ailleurs dans le monde, à la fois en raison de l'utilisation de vaccins contre le pneumocoque, mais également indépendamment de celle-ci. D'autres changements sont prévus en raison de I'utilisation du vaccin PNEU-C-13 dans le cadre des programmes de vaccination systématique des enfants. Il est essentiel d'effectuer une surveillance à l'échelle nationale pour détecter ces changements au fil du temps. La prise de décisions optimales concernant l'utilisation de vaccins contre le pneumocoque demande une surveillance continuelle des taux d'IIP spécifique à chaque sérotype ainsi que des taux d'autres syndromes causés par le pneumocoque, une estimation spécifique au sérotype de l'efficacité potentielle des différents vaccins et une évaluation continue de l'efficacité réelle et du coûtefficacité des divers calendriers de vaccination dans le temps.

Les activités de surveillance et de recherche qui visent à répondre aux questions en suspens suivantes sont particulièrement encouragées :

- Quelles sont l'efficacité potentielle et l'efficacité réelle du vaccin PNEU-C-13 chez l'adulte en ce qui concerne la prévention des IIP ou de la POC, par rapport au vaccin PNEU-P-23?
- Quelles sont les répercussions de l'utilisation de vaccins conjugués contre le pneumocoque sur les IIP chez les adultes de 65 ans ou plus, en particulier pour ce qui concerne les sérotypes en cause?

- En ce qui concerne le vaccin PNEU-C-13, quelles en sont l'efficacité potentielle et l'efficacité réelle par sérotype?

- Quelles concentrations d'anticorps ou d'autres marqueurs immunologiques sont le plus fortement corrélées avec une protection contre les IIP, la pneumonie à pneumocoque, l'otite moyenne aiguë et le portage rhinopharyngé?

- Le remplacement des sérotypes annulera-t-il les avantages associés à l'utilisation de vaccins conjugués contre le pneumocoque chez les enfants?

- Quels sont les déterminants de la protection indirecte conférée aux adultes par l'administration de vaccins aux enfants?

- Quels facteurs, autres que l'immunisation, modifient la fréquence des cas de maladie attribuables aux différents sérotypes au fil du temps?

- Chez l'adulte, le fait d'avoir reçu le vaccin PNEU-P-23 a-t-il une incidence sur l'efficacité réelle du vaccin PNEU-C-13?

- Une dose de rappel du vaccin PNEU-C-13 ou du vaccin PNEU-P-23 est-elle nécessaire chez l'adulte? 


\section{Tableaux}

Tableau 5 - Sommaire des données à la base des recommandations du CCNI

\begin{tabular}{|c|c|c|c|c|c|c|}
\hline \multicolumn{7}{|c|}{ Données sur l'efficacité potentielle } \\
\hline \multicolumn{5}{|c|}{ DÉTAIL DE L'ÉTUDE } & \multicolumn{2}{|c|}{ SOMMAIRE } \\
\hline Étude & Vaccin & Devis de l'étude & Participants & $\begin{array}{l}\text { Résumé des principales constatations } \\
\text { sous forme de texte ou de données }\end{array}$ & $\begin{array}{l}\text { Niveau de } \\
\text { preuve }\end{array}$ & Qualité \\
\hline $\begin{array}{l}\text { French, } \\
2010(9)\end{array}$ & $\begin{array}{l}\text { PNEU-C-7 vs } \\
\text { placebo } \\
\text { Patients } \\
\text { recrutés de } \\
\text { I'hôpital } \\
\text { central } \\
\text { Queen } \\
\text { Elizabeth au } \\
\text { Malawi }\end{array}$ & $\begin{array}{l}\text { Essai comparatif } \\
\text { randomisé, à } \\
\text { double insu } \\
\text { Durée du suivi : } \\
\text { févr. } 2003 \text { - oct. } 2007 \\
\text { (médiane : 1,2 an) } \\
\text { Adolescents et } \\
\text { adultes VIH+ } \\
\text { rétablis d'un premier } \\
\text { épisode de IIP }\end{array}$ & $\begin{array}{l}496 \text { patients, } \\
\text { dont } 439 \text { étaient } \\
\text { VIH+, ont été } \\
\text { sélectionnés } \\
\text { aléatoirement de } \\
\text { manière à } \\
\text { recevoir deux } \\
\text { doses de vaccin } \\
\text { ou de placebo à } \\
\text { quatre semaines } \\
\text { d'intervalle } \\
\text { Groupe recevant } \\
\text { le vaccin } \\
\mathrm{N}=248, \text { âge } \\
\text { Suivi complet } \\
\text { disponible pour } \\
239 \text { patients } \\
\text { VIH+ }\end{array}$ & $\begin{array}{l}\text { Paramètre : Nouvel épisode de IIP dû à } \\
\text { I'un des sérotypes du vaccin }+6 \mathrm{~A} \text { (compte } \\
\text { tenu d'une éventuelle protection croisée) } \\
\text { Paramètre principal (1er épisode de IIP } \\
\text { dû à un sérotype du vaccin ou 6A) - IDT : } \\
\text { RR (ajusté) }=0,31(0,11-0,84) \\
\text { ERV (ajustée) }=0,69(0,16-0,89) \\
\text { Selon le protocole : } \\
\text { RR (ajusté) }=0,26(0,08-0,78)\end{array}$ & Niveau I & Bonne \\
\hline \multicolumn{7}{|c|}{ Données sur l'efficacité réelle } \\
\hline \multicolumn{5}{|c|}{ DÉTAIL DE L'ÉTUDE } & \multicolumn{2}{|c|}{ SOMMAIRE } \\
\hline Étude & Vaccin & Devis de l'étude & Participants & $\begin{array}{l}\text { Résumé des principales constatations } \\
\text { sous forme de texte ou de données }\end{array}$ & $\begin{array}{l}\text { Niveau de } \\
\text { preuve }\end{array}$ & Qualité \\
\hline $\begin{array}{l}\text { Breiman, } \\
2000(11)\end{array}$ & $\begin{array}{l}\text { PNEU-P-23 } \\
\text { Dose : n.d. } \\
\text { Voie : n.d. } \\
\text { Calendrier: } \\
\text { n.d. }\end{array}$ & $\begin{array}{l}\text { Étude cas-témoins } \\
\text { rétrospective } \\
\text { Durée de l'étude : } \\
\text { févr. } 1992 \text { - } \\
\text { avril } 1995 \\
\text { Détermination du } \\
\text { statut vaccinal: } \\
\text { communication } \\
\text { avec les médecins } \\
\text { et obtention des } \\
\text { dossiers de } \\
\text { vaccination }\end{array}$ & $\begin{array}{l}\text { N = 503 } \\
\text { Cas : } 176 \text { adultes } \\
\text { infectés par le } \\
\text { VIH hospitalisés } \\
\text { pour une IIP } \\
\text { Témoins = } 327 \\
\text { adultes infectés } \\
\text { par le VIH } \\
\text { hospitalisés, } \\
\text { appariés selon } \\
\text { I'âge, I'hôpital } \\
\text { d'admission, la } \\
\text { numération des } \\
\text { CD4, le stade } \\
\text { clinique de } \\
\text { I'infection à VIH }\end{array}$ & $\begin{array}{l}\text { Efficacité réelle du vaccin (ERV) : } 49 \% \\
\text { (IC à } 95 \% 12,70) \text { ajustée pour toutes les } \\
\text { variables, aucun terme d'interaction } \\
\text { ERV avec terme d'interaction race*statut } \\
\text { vaccinal : } \\
\text { Blancs : } 74 \%(\text { IC à } 95 \% 8,93) \\
\text { ERV chez les Noirs : } \\
8 \%(I C \text { à } 95 \% 112,60)\end{array}$ & Niveau II-2 & Bonne \\
\hline
\end{tabular}




\begin{tabular}{|c|c|c|c|c|c|c|}
\hline \multicolumn{7}{|c|}{ Données sur l'efficacité réelle } \\
\hline \multicolumn{5}{|c|}{ DÉTAIL DE L'ÉTUDE } & \multicolumn{2}{|c|}{ SOMMAIRE } \\
\hline Étude & Vaccin & Devis de l'étude & Participants & $\begin{array}{l}\text { Résumé des principales constatations } \\
\text { sous forme de texte ou de données }\end{array}$ & $\begin{array}{l}\text { Niveau de } \\
\text { preuve }\end{array}$ & Qualité \\
\hline $\begin{array}{l}\text { Hung, } 2004 \\
\text { (12) }\end{array}$ & $\begin{array}{l}\text { PNEU-P-23 } \\
\text { Voie : n.d. } \\
\text { Dose : n.d. } \\
\text { Calendrier: } \\
\text { n.d. }\end{array}$ & $\begin{array}{l}\text { Étude } \\
\text { d'observation } \\
\text { prospective } \\
\text { Durée du suivi : } \\
641 \text { jrs chez les } \\
\text { vaccinés } \\
500 \text { jrs chez les } \\
\text { non-vaccinés } \\
\text { Période : } \\
\begin{array}{l}\text { 1er juin } 2001 \text { - } \\
31 \text { octobre } 2002\end{array}\end{array}$ & $\begin{array}{l}\text { N1 = } 305 \text { sujets } \\
\text { infectés par le } \\
\text { VIH vaccinés } \\
\text { Âge moyen : } \\
37 \text { ans } \\
\text { H/F: 280/25 } \\
\text { Référence CD4+ } \\
<200: 54,6 \% \\
\text { Infection buccale } \\
\text { (IB) associée au } \\
\text { sida exigeant une } \\
\text { antibiothérapie: } \\
\text { 23,6\% } \\
\text { N2 = 203 sujets } \\
\text { infectés par le } \\
\text { VIH non vaccinés } \\
\text { Âge moyen : } 33 \\
\text { H/F: 183/20 } \\
\text { Valeurs de } \\
\text { référence CD4+ } \\
<200 \text { - 50,6\% } \\
\text { IB associée au } \\
\text { sida exigeant une } \\
\text { antibiothérapie : } \\
23,6 \% \\
\text { Lieu : National } \\
\text { Taiwan University } \\
\text { Hospital }\end{array}$ & 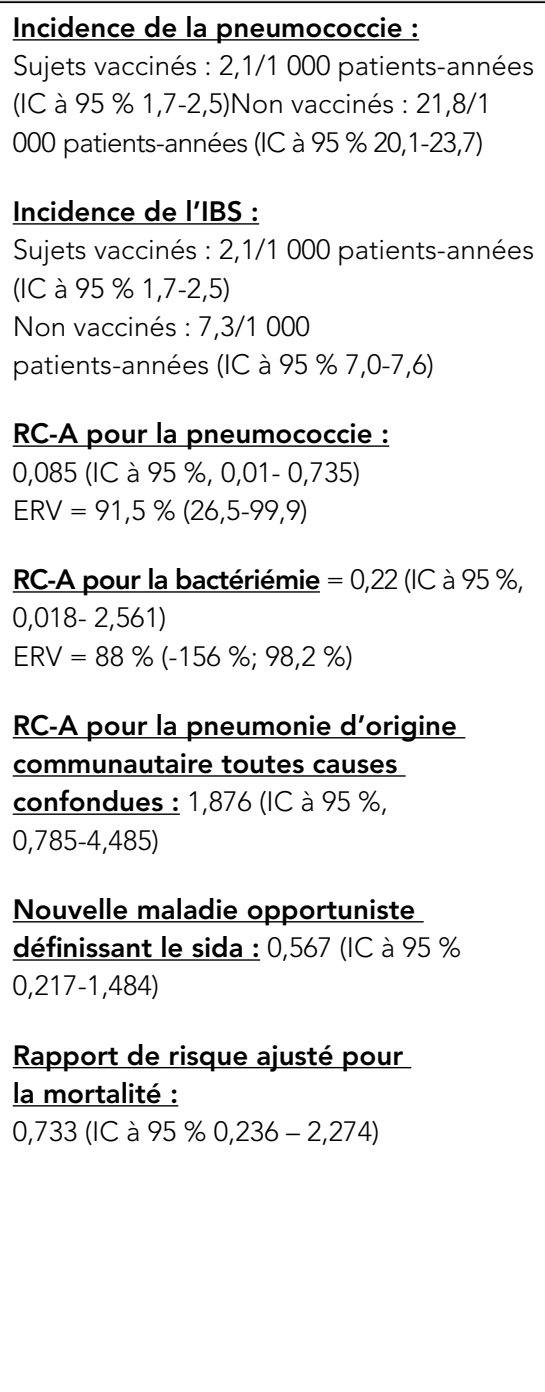 & Niveau II-2 & Bonne \\
\hline $\begin{array}{l}\text { French, } \\
2000(13)\end{array}$ & $\begin{array}{l}\text { PNEU-P-23 } \\
\text { vs placebo }\end{array}$ & $\begin{array}{l}\text { Essai comparatif } \\
\text { randomisé, avec } \\
\text { placebo }\end{array}$ & $\begin{array}{l}\mathrm{N}=1392 \\
\text { adultes infectés } \\
\text { par le VIH au } \\
\text { stade clinique } \\
\text { OMS 1, } 2 \text { ou } 3 \\
\text { répartis } \\
\text { aléatoirement } \\
\text { selon un ratio 1:1 }\end{array}$ & 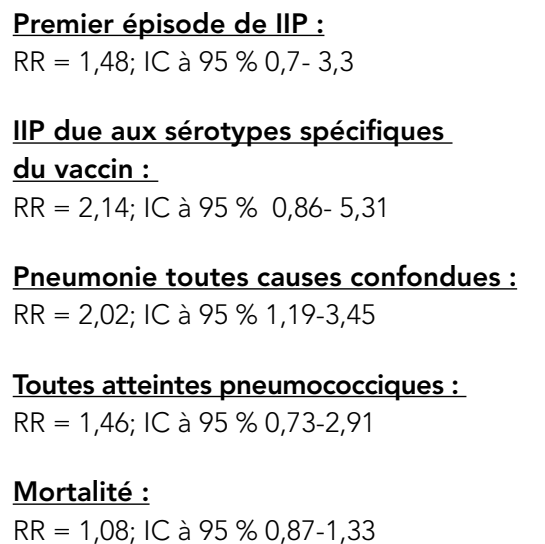 & Niveau I & Bonne \\
\hline
\end{tabular}




\begin{tabular}{|c|c|c|c|c|c|c|}
\hline \multicolumn{7}{|c|}{ Données sur l'efficacité réelle } \\
\hline \multicolumn{5}{|c|}{ DÉTAIL DE L'ÉTUDE } & \multicolumn{2}{|c|}{ SOMMAIRE } \\
\hline Étude & Vaccin & Devis de l'étude & Participants & $\begin{array}{l}\text { Résumé des principales constatations } \\
\text { sous forme de texte ou de données }\end{array}$ & $\begin{array}{l}\text { Niveau de } \\
\text { preuve }\end{array}$ & Qualité \\
\hline $\begin{array}{l}\text { Vila- } \\
\text { Corcoles, } \\
2005 \text { (14) }\end{array}$ & PNEU-P-23 & $\begin{array}{l}\text { Étude de cohorte } \\
\text { prospective } \\
\text { Durée du suivi : } \\
12 \text { mois } \\
\text { Cohorte de } \\
\text { patients suivis } \\
\text { dans des cliniques } \\
\text { données. } \\
\text { Résultats } \\
\text { déterminés à partir } \\
\text { des bases de } \\
\text { données } \\
\text { électroniques et } \\
\text { des dossiers de } \\
\text { patients }\end{array}$ & $\begin{array}{l}\text { N = } 11241 \\
\text { Sujets vaccinés } \\
\text { avant } \\
\text { l'inscription = } \\
4986 \\
\text { Non vaccinés } \\
\text { avant } \\
\text { inscription = } \\
6255 \\
\text { Vaccinés après } \\
\text { inscription }=720 \\
\text { Les } \\
\text { caractéristiques } \\
\text { de référence des } \\
\text { sujets résidant } \\
\text { dans la } \\
\text { collectivité } \geq 65 \\
\text { ans (vaccinés vs } \\
\text { non vaccinés } \\
\text { avant l'inscription) } \\
\text { différaient } \\
\text { significativement : } \\
\text { l'âge, la } \\
\text { comorbidité et le } \\
\text { statut d'immuno- } \\
\text { déficience } \\
\text { étaient } \\
\text { significativement } \\
\text { plus élevés dans } \\
\text { le groupe des } \\
\text { vaccinés que } \\
\text { dans le groupe } \\
\text { des non vaccinés. } \\
\text { Le pourcentage } \\
\text { de fumeurs était } \\
\text { significativement } \\
\text { plus élevé dans } \\
\text { le groupe des } \\
\text { non vaccinés. }\end{array}$ & 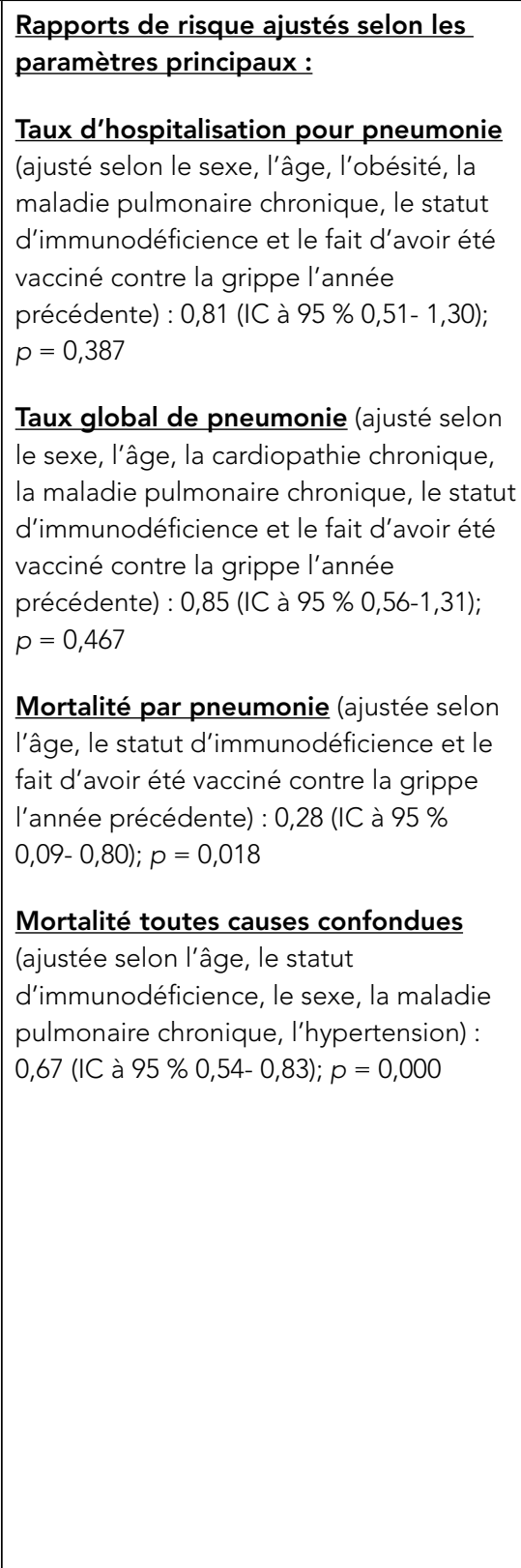 & Niveau II-2 & Moyenne \\
\hline
\end{tabular}




\begin{tabular}{|c|c|c|c|c|c|c|}
\hline \multicolumn{7}{|c|}{ Données sur l'efficacité réelle } \\
\hline \multicolumn{5}{|c|}{ DÉTAIL DE L'ÉTUDE } & \multicolumn{2}{|c|}{ SOMMAIRE } \\
\hline Étude & Vaccin & Devis de l'étude & Participants & $\begin{array}{l}\text { Résumé des principales constatations } \\
\text { sous forme de texte ou de données }\end{array}$ & $\begin{array}{l}\text { Niveau de } \\
\text { preuve }\end{array}$ & Qualité \\
\hline $\begin{array}{l}\text { Vila- } \\
\text { Corcoles, } \\
2006(15)\end{array}$ & $\begin{array}{l}\text { PNEU-P-23: } \\
\text { offert } \\
\text { gratuitement } \\
\text { aux } 65 \text { ans } \\
\text { ou plus, sans } \\
\text { campagne } \\
\text { spécifique } \\
\text { Vaccin: } \\
\text { variable } \\
\text { temporelle }\end{array}$ & 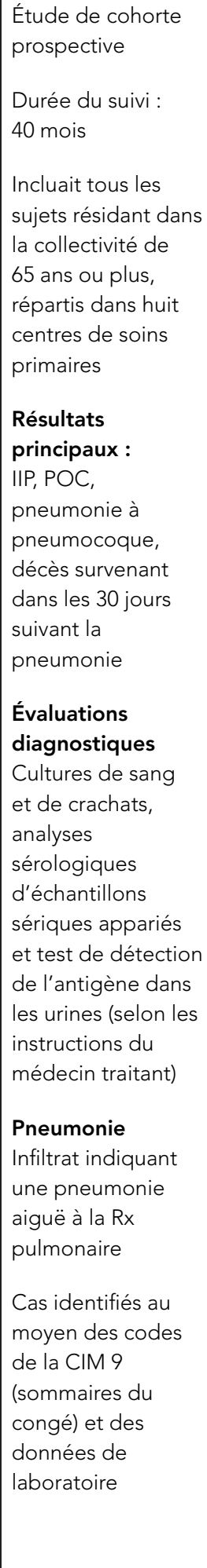 & 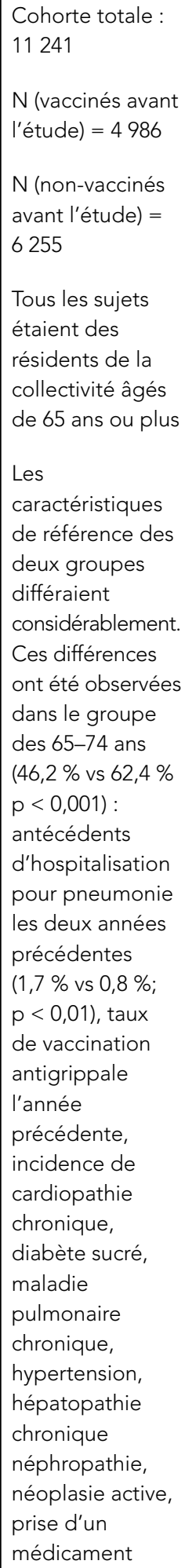 & 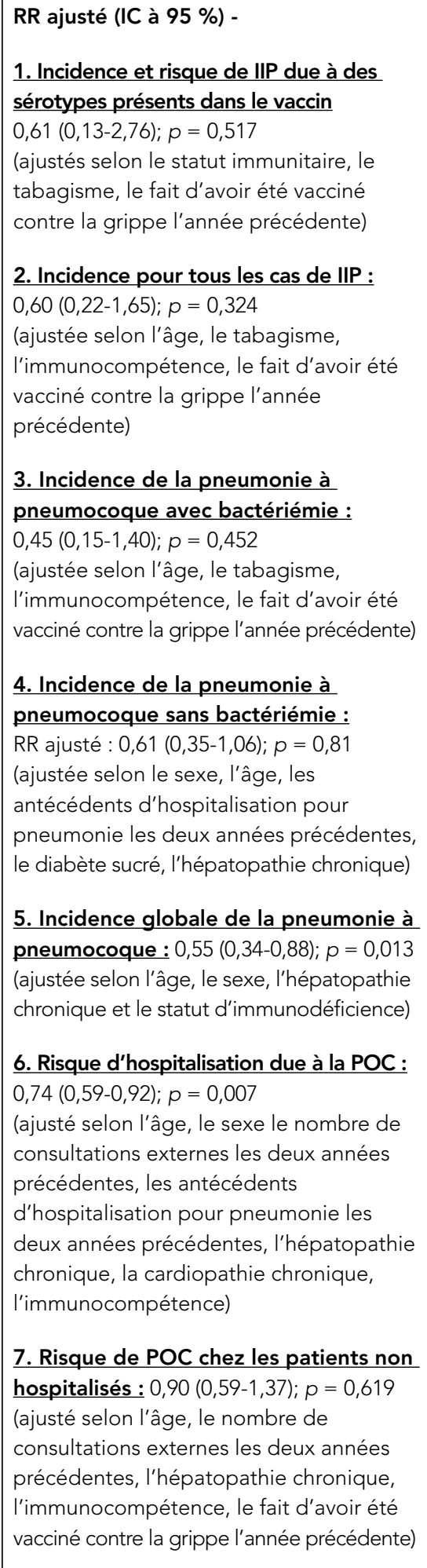 & Niveau II-2 & Bonne \\
\hline
\end{tabular}




\begin{tabular}{|c|c|c|c|c|c|c|}
\hline \multicolumn{7}{|c|}{ Données sur l'efficacité réelle } \\
\hline \multicolumn{5}{|c|}{ DÉTAIL DE L'ÉTUDE } & \multicolumn{2}{|c|}{ SOMMAIRE } \\
\hline Étude & Vaccin & Devis de l'étude & Participants & $\begin{array}{l}\text { Résumé des principales constatations } \\
\text { sous forme de texte ou de données }\end{array}$ & $\begin{array}{l}\text { Niveau de } \\
\text { preuve }\end{array}$ & Qualité \\
\hline & & & $\begin{array}{l}\text { immuno- } \\
\text { dépresseur et } \\
\text { statut d'immuno- } \\
\text { déficience } \\
\text { significativement } \\
\text { plus élevés dans } \\
\text { le groupe des } \\
\text { vaccinés que } \\
\text { chez les } \\
\text { non-vaccinés; } \\
\text { p < } 0,01 \text {. } \\
\text { En général, la } \\
\text { morbidité était } \\
\text { supérieure dans } \\
\text { la population des } \\
\text { vaccinés. }\end{array}$ & 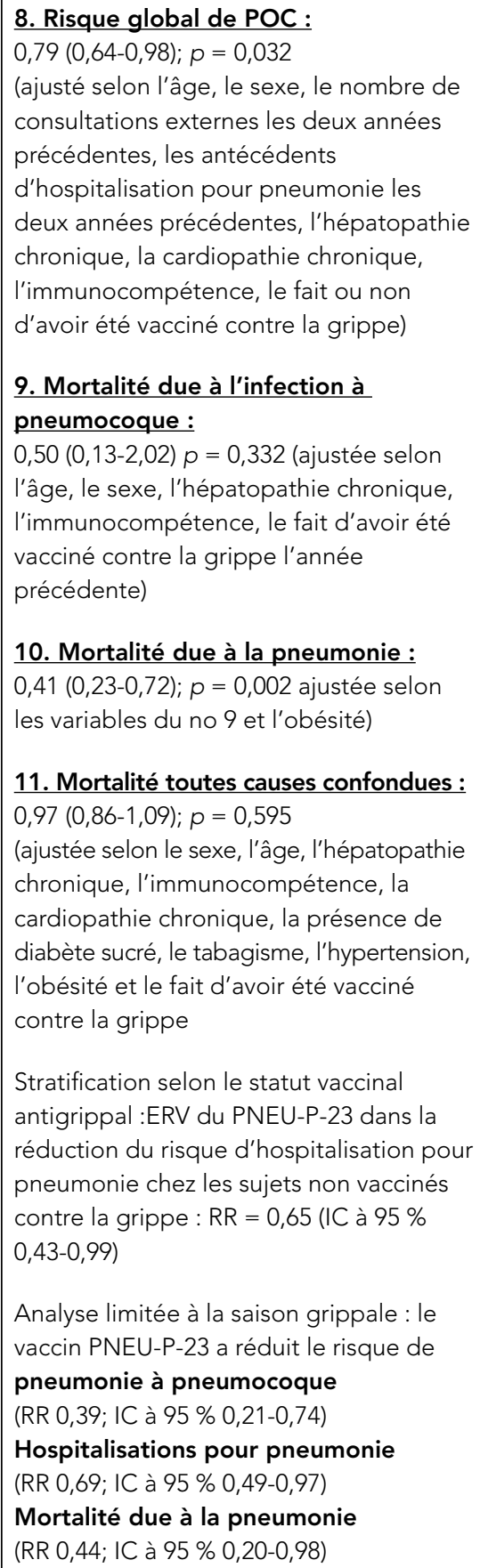 & & \\
\hline
\end{tabular}




\begin{tabular}{|c|c|c|c|c|c|c|}
\hline \multicolumn{7}{|c|}{ Données sur l'efficacité réelle } \\
\hline \multicolumn{5}{|c|}{ DÉTAIL DE L'ÉTUDE } & \multicolumn{2}{|c|}{ SOMMAIRE } \\
\hline Étude & Vaccin & Devis de l'étude & Participants & $\begin{array}{l}\text { Résumé des principales constatations } \\
\text { sous forme de texte ou de données }\end{array}$ & $\begin{array}{l}\text { Niveau de } \\
\text { preuve }\end{array}$ & Qualité \\
\hline $\begin{array}{l}\text { Mooney, } \\
2008(16)\end{array}$ & PNEU-P-23 & $\begin{array}{l}\text { Étude de cohorte } \\
\text { rétrospective } \\
\text { Résultat principal : } \\
\text { taux d'incidence de } \\
\text { la IIP durant I'hiver } \\
\text { 2003-2004 dans la } \\
\text { population visée } \\
\text { par le vaccin âgée } \\
\text { de } 65 \text { ans ou plus } \\
\text { Données extraites } \\
\text { de la base de } \\
\text { données nationale } \\
\text { de la SPLI pour les } \\
\text { cas de IIP } \\
\text { Taux de vaccination } \\
\text { par le PNEU-P-23 } \\
\text { estimé à l'aide du } \\
\text { réseau sentinelle } \\
\text { (échantillon } \\
\text { représentatif de } 7 \\
\% \text { de la population } \\
\text { écossaise) } \\
\text { Pour chaque cas de } \\
\text { IIP : examen du } \\
\text { dossier du patient } \\
\text { (soins primaires) et } \\
\text { questionnaire } \\
\text { postal }\end{array}$ & $\begin{array}{l}\text { N (cas de IIP) : } \\
396 \\
N \text { (IIP et } \geq 65 \text { ans) : } \\
170 \\
N \text { (IIP et } \geq 65 \text { ans + } \\
\text { statut vaccinal } \\
\text { connu) : } 145 \\
\text { N (IIP et } \geq 65 \text { ans } \\
\text { vaccinés) : } 63 \\
\text { Pas de différence } \\
\text { significative dans } \\
\text { I'incidence de IIP } \\
\text { chez les sujets } \\
\text { vaccinés de } \geq 65 \\
\text { ans avec ou sans } \\
\text { maladie } \\
\text { respiratoire, } \\
\text { maladie } \\
\text { cardiovasculaire } \\
\text { ou plus d'un } \\
\text { facteur de risque } \\
\% \text { hommes (tous } \\
\text { les cas de IIP) : } \\
51,4 \\
\% \text { femmes (tous } \\
\text { les cas de IIP): } \\
36,7 \\
\text { Taux de } \\
\text { vaccination } \\
\text { estimé : } \\
\text { hommes } 68,1 \% \\
\text { femmes } 65,5 \%\end{array}$ & 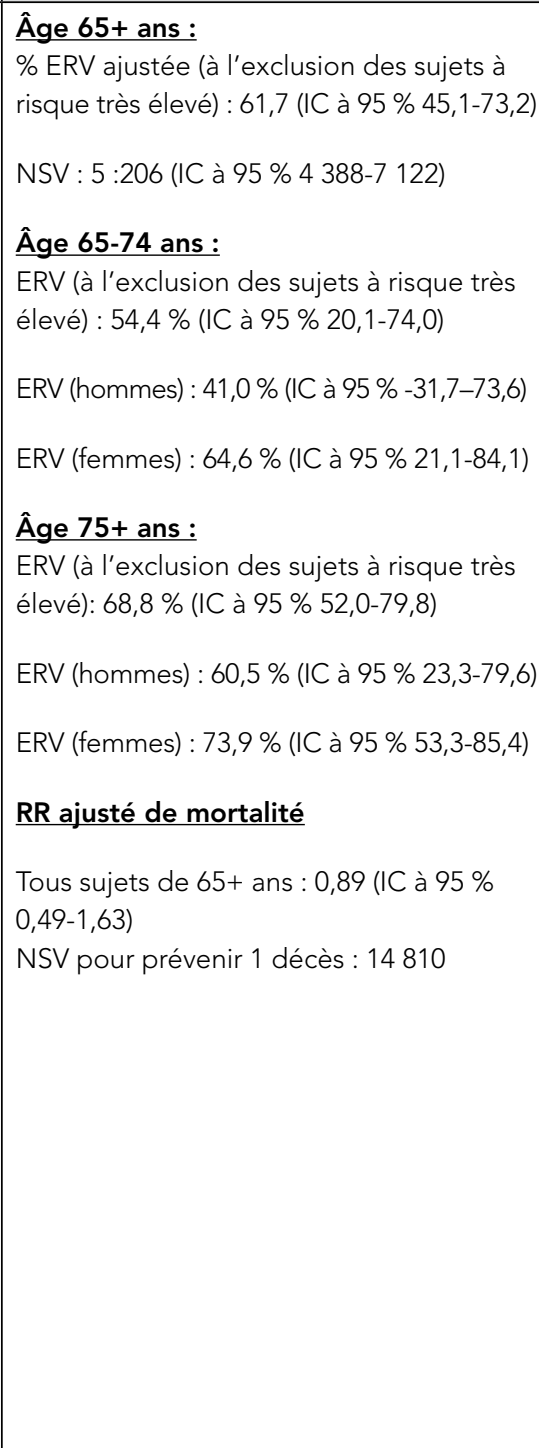 & Niveau II-2 & Bonne \\
\hline
\end{tabular}




\begin{tabular}{|c|c|c|c|c|c|c|}
\hline \multicolumn{7}{|c|}{ Données sur l'efficacité réelle } \\
\hline \multicolumn{5}{|c|}{ DÉTAIL DE L'ÉTUDE } & \multicolumn{2}{|c|}{ SOMMAIRE } \\
\hline Étude & Vaccin & Devis de l'étude & Participants & $\begin{array}{l}\text { Résumé des principales constatations } \\
\text { sous forme de texte ou de données }\end{array}$ & $\begin{array}{l}\text { Niveau de } \\
\text { preuve }\end{array}$ & Qualité \\
\hline $\begin{array}{l}\text { Melagaro, } \\
2004 \text { (17) }\end{array}$ & $\begin{array}{l}\text { PNEU-P-23 } \\
\text { vs placebo }\end{array}$ & $\begin{array}{l}\text { Méta analyse } \\
\text { Recherche dans } \\
\text { Medline et } \\
\text { PubMed pour } \\
\text { trouver des études } \\
\text { sur l'efficacité } \\
\text { potentielle du } \\
\text { PNEU-P-23 sans } \\
\text { restriction d'année } \\
\text { ou de langue } \\
\text { Résultats évalués : } \\
\text { pneumonie à } \\
\text { pneumocoque et IIP }\end{array}$ & $\begin{array}{l}\text { Études incluses: } \\
\text { ECR = } 6 \\
\text { Quasi } \\
\text { randomisés = } 3 \\
\text { Groupes à risque } \\
\text { élevé = } 4 \\
\text { Inclusion : } \\
\text { Essais } \\
\text { comparatifs } \\
\text { randomisés ou } \\
\text { quasi randomisés } \\
\text { avec processus } \\
\text { de randomisation } \\
\text { ou quasi- } \\
\text { randomisation } \\
\text { bien défini; } \\
\text { ciblant des sujets } \\
\text { âgés de plus de } \\
50 \text { ans immuno- } \\
\text { compétents ou } \\
\text { immunodéprimés, } \\
\text { et évaluant la } \\
\text { pneumonie à } \\
\text { pneumocoque } \\
\text { et/ou la IIP } \\
\text { Deux } \\
\text { examinateurs } \\
\text { indépendants; } \\
\text { utilisation des } \\
\text { scores de Jadad }\end{array}$ & $\begin{array}{l}\text { ERV contre la pneumonie à } \\
\text { pneumocoque } \\
\text { N d'études analysées en fonction de ce } \\
\text { paramètre : } 7 \\
\text { Estimations regroupées de l'ERV au } \\
\text { moyen d'un modèle à effets aléatoires } \\
\text { incluant des essais sur des groupes non à } \\
\text { risque élevé : } 16 \% \text { (IC à } 95 \%:-50-53 \% \text { ) } \\
\text { Estimations regroupées de l'ERV au } \\
\text { moyen d'un modèle à effets aléatoires } \\
\text { incluant des essais sur des groupes à } \\
\text { risque élevé (GRÉ) : -20 \% (-92-25\%) } \\
\text { Efficacité réelle du vaccin dans la } \\
\text { réduction de la IIP } \\
\text { Études incluses : } 6 \\
\text { Population générale : } 2 \\
\text { GRÉ - randomisées : } 4 \\
\text { GRÉ - quasi randomisées : } 2 \\
\text { Estimation regroupée de l'ERV dans la } \\
\text { réduction de la IIP chez les personnes } \\
\text { âgées en général : } 65 \% \text { (-42-92 \%) } \\
\text { Estimation regroupée de l'ERV dans la } \\
\text { réduction de la IIP dans les GRÉ à } \\
\text { l'exclusion des études quasi randomisées: } \\
20 \% \text { (-187-78 \%) } \\
\text { Estimation regroupée de l'ERV dans la } \\
\text { réduction de la IIP dans les GRÉ incluant } \\
\text { les études quasi randomisées : } 44 \% \\
\text { (-45-79\%) }\end{array}$ & Niveau I & Bonne \\
\hline
\end{tabular}




\begin{tabular}{|c|c|c|c|c|c|c|}
\hline \multicolumn{7}{|c|}{ Données sur l'immunogénicité } \\
\hline \multicolumn{5}{|c|}{ DÉTAIL DE L'ÉTUDE } & \multicolumn{2}{|c|}{ SOMMAIRE } \\
\hline Étude & Vaccin & Devis de l'étude & Participants & $\begin{array}{l}\text { Résumé des principales constatations sous } \\
\text { forme de texte ou de données }\end{array}$ & $\begin{array}{l}\text { Niveau } \\
\text { de preuve }\end{array}$ & Qualité \\
\hline $\begin{array}{l}\text { Kumar, } \\
2008 \text { (19) }\end{array}$ & $\begin{array}{l}\text { Placebo- } \\
\text { PNEU-P-23 } \\
\text { PNEU-C-7/ } \\
\text { PNEU-P-23 } \\
\text { Voie : IM } \\
\text { Calendrier : } \\
0 \text { semaine, } \\
8 \text { semaines } \\
\text { Dose : dose } \\
\text { unique de } \\
0,5 \mathrm{ml}\end{array}$ & 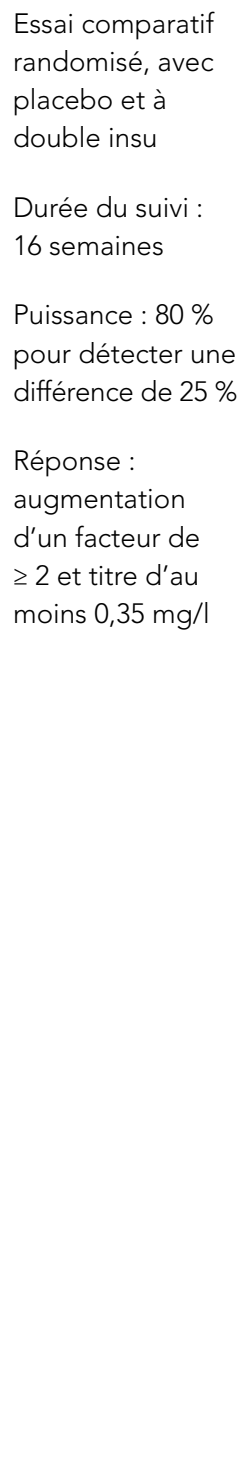 & $\begin{array}{l}\mathrm{N}=130 \\
\mathrm{~N} 1=65 \\
\mathrm{~N} 2=65 \\
\text { Caractéristiques } \\
\text { de référence - } \\
\text { patients ayant } \\
\text { subi une } \\
\text { transplantation } \\
\text { du foie } \geq 3 \text { mois } \\
\text { auparavant; } \\
\text { PNEU-P-23 } \\
\geq 5 \text { ans } \\
\text { auparavant } \\
\text { PNEU-P-23 } \\
\text { antérieur (\%) : } 8 \\
\%, 14 \% \text { p } 0,17 \\
\text { Prednisone (\%) } \\
\text { 28, 44 (p = 0,09) } \\
\text { Traitement } \\
\text { antérieur aux } \\
\text { anti- } \\
\text { thymoglobulines } \\
\text { p = 0,064 } \\
\text { Dans les analyses } \\
\text { multivariées et } \\
\text { univariées, } \\
\text { I'utilisation de } \\
\text { corticostéroïdes } \\
\text { a été associée } \\
\text { significativement } \\
\text { à une réponse } \\
\text { anticorps } \\
\text { inférieure } \\
\text { (RC = 5,0; IC à } \\
95 \% 1,29-19,6 ; \\
p=0,02 \text { ) }\end{array}$ & 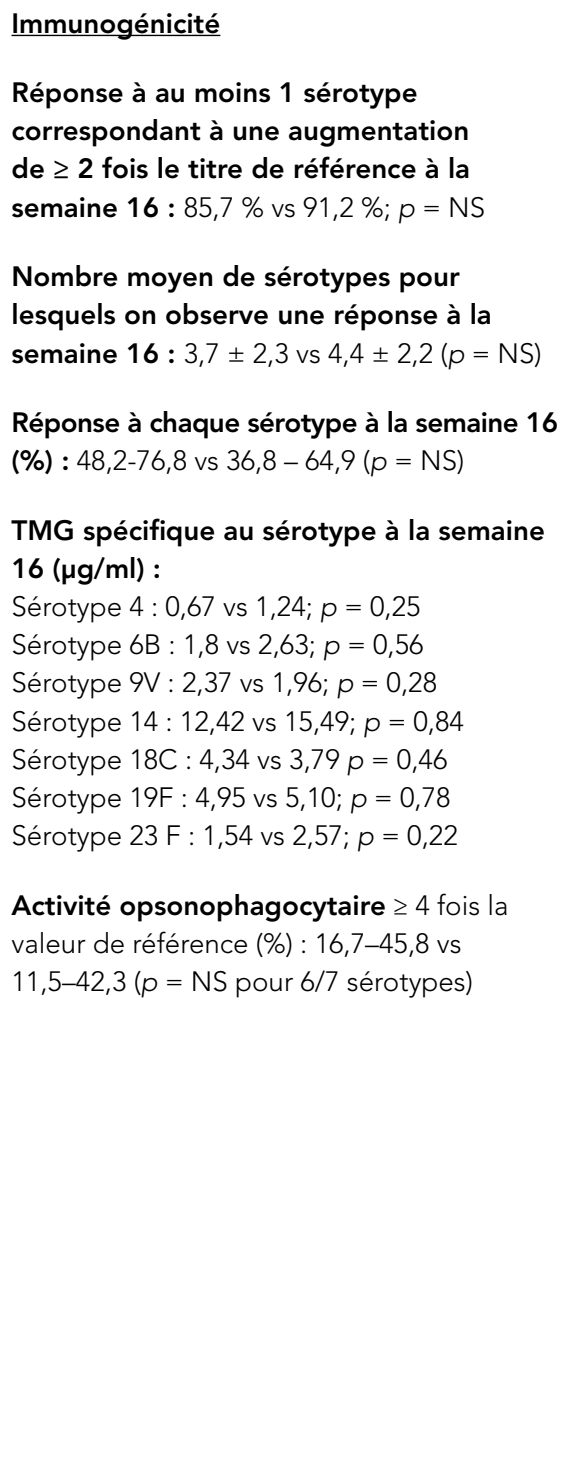 & Niveau I & Bonne \\
\hline
\end{tabular}




\begin{tabular}{|c|c|c|c|c|c|c|}
\hline \multicolumn{7}{|c|}{ Données sur l'immunogénicité } \\
\hline \multicolumn{5}{|c|}{ DÉTAIL DE L'ÉTUDE } & \multicolumn{2}{|c|}{ SOMMAIRE } \\
\hline Étude & Vaccin & Devis de l'étude & Participants & $\begin{array}{l}\text { Résumé des principales constatations sous } \\
\text { forme de texte ou de données }\end{array}$ & $\begin{array}{l}\text { Niveau } \\
\text { de preuve }\end{array}$ & Qualité \\
\hline $\begin{array}{l}\text { Kumar, } \\
2003(20)\end{array}$ & $\begin{array}{l}\text { PNEU-C-7 } \\
\text { PNEU-P-23 } \\
\text { Dose = 0,5 ml } \\
\text { Voie : IM } \\
\text { Période de } \\
\text { l'étude : } \\
\text { sept.-déc. } \\
2001\end{array}$ & $\begin{array}{l}\text { Essai comparatif } \\
\text { randomisé, avec } \\
\text { placebo et à } \\
\text { double insu } \\
\text { Durée du suivi : } \\
8 \text { semaines } \\
\text { Transplantation } \\
\text { rénale: } \\
3 \text { mois à } 3 \text { ans } \\
\text { après la } \\
\text { transplantation } \\
\text { Exclusions: } \\
\text { splénectomie ou } \\
\text { PNEU-P-23 dans } \\
\text { les } 5 \text { dernières } \\
\text { années }\end{array}$ & $\begin{array}{l}\mathrm{N}=60 \text { - } \\
\text { Transplantation } \\
\text { rénale } \\
\mathrm{N}=30 \\
\text { (PNEU-P-23) } \\
\mathrm{N}=30 \\
\text { (PNEU-C-7) } \\
\text { Caractéristiques } \\
\text { de référence: } \\
\text { deux groupes } \\
\text { présentant des } \\
\text { caractéristiques } \\
\text { démographiques } \\
\text { et cliniques } \\
\text { semblables, } \\
\text { notamment } \\
\text { sur le plan de } \\
\text { la fonction } \\
\text { rénale, du délai } \\
\text { depuis la } \\
\text { transplantation } \\
\text { et de l'immuno- } \\
\text { dépression } \\
\text { Réponse : } \\
\text { ELISA : } \\
\text { augmentation } \\
\text { d'un facteur } \\
\text { de } \geq 2 \text {, avec titre } \\
\text { absolu d'au } \\
\text { moins } 1 \mu \text { g/ml } \\
\text { OPA : } \\
\text { augmentation } \\
\text { d'un facteur } \\
\text { de } \geq 4 \text {, avec titre } \\
\text { absolu }>1: 8\end{array}$ & $\begin{array}{l}\text { Immunogénicité (lgG): } \\
\text { Facteur d'augmentation moyen des TMG } \\
\text { spécifiques au sérotype à } 8 \text { semaines } \\
\text { comparativement aux valeurs de référence } \\
\text { (PNEU-C-7 vs PNEU-P-23): } \\
\text { Sérotype 4, 6B, 14, 18C, 19F; } p=N S \\
\text { Sérotype } 23 F: 16,8 \text { (intervalle } 0,8-160 \text { ) vs } \\
2,2 \text { (intervalle } 0,4-23,5) ; p=0,046 \\
\text { Sérotype } 9: 17 \text { vs } 2,6, p=0,09 \\
\text { Proportion de sujets qui ont présenté } \\
\text { une réponse (PNEU-C-7 vs PNEU-P-23): } \\
\text { Sérotypes } 4,9 V, 18 C, 19 F: \text { PNEU-C-7 }> \\
\text { PNEU-P-23; } p=N S \\
\text { Sérotype } 23 F \text { (\%) : } 40 \text { vs } 16,7 ; p=0,046 \\
\text { Sérotype } 6 B: 33,7 \text { vs } 13,3 ; p=0,067 \\
\geq 1 \text { sérotype (\%) : } 53,3 \text { vs } 73,3 \\
\text { Nombre médian de sérotypes pour lesquels } \\
\text { on a observé une réponse : } 1,0 \text { vs } 2,5 ; p=0,069 \\
\text { Facteur d'augmentation des titres d'OPA } \\
\text { spécifiques au sérotype : } \\
\text { Pas de différence significative entre les deux } \\
\text { groupes pour l'ensemble des } 7 \text { sérotypes } \\
\text { Taux de réponses OPA spécifiques au } \\
\text { sérotype : } 83,3 \text { vs } 80 ; p=N S \\
\text { Nombre médian de réponses OPA } \\
\text { spécifiques au sérotype : } 2,0 \text { vs } 3,0 ; p=N S\end{array}$ & Niveau I & Bonne \\
\hline
\end{tabular}




\begin{tabular}{|c|c|c|c|c|c|c|}
\hline \multicolumn{7}{|c|}{ Données sur l'immunogénicité } \\
\hline \multicolumn{5}{|c|}{ DÉTAIL DE L'ÉTUDE } & \multicolumn{2}{|c|}{ SOMMAIRE } \\
\hline Étude & Vaccin & Devis de l'étude & Participants & $\begin{array}{l}\text { Résumé des principales constatations sous } \\
\text { forme de texte ou de données }\end{array}$ & $\begin{array}{l}\text { Niveau } \\
\text { de preuve }\end{array}$ & Qualité \\
\hline $\begin{array}{l}\text { Kumar, } \\
2007 \text { (21) }\end{array}$ & $\begin{array}{l}\text { PNEU-C-7 } \\
\text { PNEU-P- } 23 \\
\text { Dose de } \\
\text { départ: } \\
0,5 \mathrm{ml}\end{array}$ & $\begin{array}{l}\text { Étude de cohorte } \\
\text { prospective } \\
\text { constituant un } \\
\text { suivi de trois ans } \\
\text { d'un ECR auprès } \\
\text { de patients } \\
\text { ayant subi une } \\
\text { transplantation } \\
\text { rénale } \\
\text { À } 3 \text { ans, la } \\
\text { majorité des } \\
\text { patients } \\
\text { recevaient } \\
\text { des inhibiteurs } \\
\text { de la calcineurine } \\
\text { (95,7 \%) et du } \\
\text { MMF (78, } 7 \% \text { ) }\end{array}$ & $\begin{array}{l}60 \text { cas } \\
\text { sélectionnés } \\
\text { aléatoirement } \\
\text { Transplantation } \\
\text { rénale } \\
47 \text { sujets } \\
\text { analysés = } \\
\text { PNEU-C-7 = 23 } \\
\text { PNEU-P-23 = 24 } \\
\text { 14 : échappés } \\
\text { au suivi pour les } \\
\text { raisons suivantes: } \\
\text { refus de } \\
\text { donner leur } \\
\text { consentement (7), } \\
\text { décès (1), } \\
\text { impossibles à } \\
\text { joindre (5) } \\
\text { l'étude. } \\
\text { Les caractéristiques } \\
\text { de référence des } \\
\text { deux groupes } \\
\text { étaient semblables } \\
\text { sur le plan de l'âge } \\
\text { moyen, du sexe, } \\
\text { du délai depuis la } \\
\text { transplantation, } \\
\text { de l'immuno- } \\
\text { dépression, de la } \\
\text { perte du greffon, } \\
\text { de la créatinine } \\
\text { sériet } \\
\text { dant la }\end{array}$ & 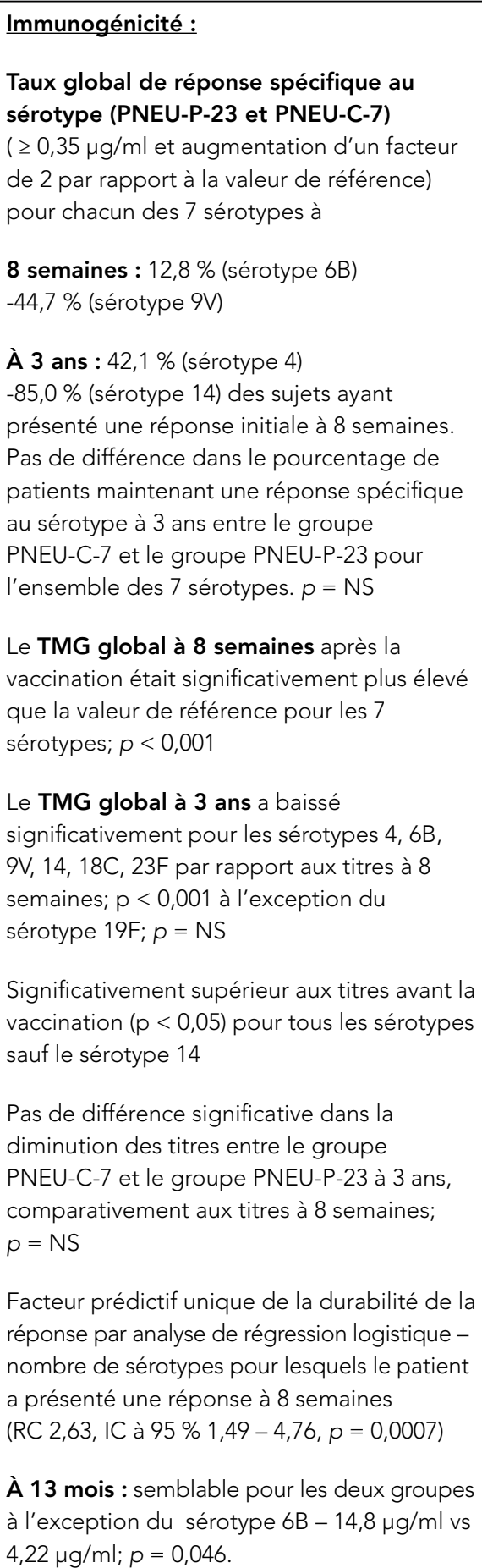 & Niveau I & Bonne \\
\hline
\end{tabular}




\begin{tabular}{|c|c|c|c|c|c|c|}
\hline \multicolumn{7}{|c|}{ Données sur l'immunogénicité } \\
\hline \multicolumn{5}{|c|}{ DÉTAIL DE L'ÉTUDE } & \multicolumn{2}{|c|}{ SOMMAIRE } \\
\hline Étude & Vaccin & Devis de l'étude & Participants & $\begin{array}{l}\text { Résumé des principales constatations sous } \\
\text { forme de texte ou de données }\end{array}$ & $\begin{array}{l}\text { Niveau } \\
\text { de preuve }\end{array}$ & Qualité \\
\hline $\begin{array}{l}\text { Tobudic } \\
\text { et al. (22) }\end{array}$ & $\begin{array}{l}\text { PNEU-C-7 } \\
\text { PNEU-P-23 }\end{array}$ & $\begin{array}{l}\text { Essai comparatif } \\
\text { randomisé, à } \\
\text { simple insu, } \\
\text { mené dans un } \\
\text { seul centre }\end{array}$ & $\begin{array}{l}\mathrm{N}=80 \text { (receveurs } \\
\text { de transplantation } \\
\text { rénale) } \\
9 \text { se sont retirés; } \\
9 \text { ont été perdus } \\
\text { de vue; } \\
62 \text { ont été analysés }\end{array}$ & $\begin{array}{l}\text { Immunogénicité } \\
\text { Taux de réponse (TMG à } 8 \text { semaines après } \\
\text { dose de PNEU-C-7 vs PNEU-P-23) : dans } \\
\text { tous les cas, augmentation significative } \\
\text { par rapport à la valeur de référence, à } \\
\text { l'exception des sérotypes 6B et 19F dans } \\
\text { le cas du PNEU-P-23 } \\
\text { Taux de réponse - un an après la vaccination } \\
\text { initiale : (TMG) diminution pour tous les } \\
\text { sérotypes dans le cas des deux vaccins } \\
\text { Taux de réponse - } 8 \text { semaines après le } \\
\text { rappel avec le PNEU-P-23 (TMG) } \\
\text { Les sérotypes (4, 6B, } 14,18 C, 23 F) \text { étaient } \\
\text { associés à une réponse supérieure à celle } \\
\text { observée avec une dose de PNEU-P-23 } \\
\text { Réponse au vaccin : augmentation du titre } \\
\text { d'anticorps d'un facteur de } \geq 2 \text { et valeur } \\
\text { absolue > 1ug/ml. } \\
\text { - Réponse à > } 1 \text { sérotype après un vaccin : } \\
\text { 77,1 \% PNEU-C-7 } \\
\text { 93,1 \% PNEU-P-23 ( } p=0,046 \text { ) } \\
\text { - Réponse à >1 sérotype après } \\
\text { rappel avec le PNEU-P-23: } \\
87,5 \% \text { PNEU-C-7/PNEU-P-23 } \\
87,1 \% \text { PNEU-P-23/PNEU-P-23 } \\
\text { (non significatif) } \\
\text { 3,5 pour le PNEU-C-7/PNEU-P-23 } \\
5 \text { pour le PNEU-P-23 }\end{array}$ & Niveau I & Bonne \\
\hline
\end{tabular}




\begin{tabular}{|c|c|c|c|c|c|c|}
\hline \multicolumn{7}{|c|}{ Données sur l'immunogénicité } \\
\hline \multicolumn{5}{|c|}{ DÉTAIL DE L'ÉTUDE } & \multicolumn{2}{|c|}{ SOMMAIRE } \\
\hline Étude & Vaccin & Devis de l'étude & Participants & $\begin{array}{l}\text { Résumé des principales constatations sous } \\
\text { forme de texte ou de données }\end{array}$ & $\begin{array}{l}\text { Niveau } \\
\text { de preuve }\end{array}$ & Qualité \\
\hline $\begin{array}{l}\text { Cordonnier } \\
2009 \text { (23) }\end{array}$ & $\begin{array}{l}\text { PNEU-C-7 } \\
\text { PNEU-P-23 } \\
\text { Calendrier : } \\
3 \text { doses de } \\
\text { PNEU-C-7 } \\
\text { administrées } \\
\text { à } 1 \text { mois } \\
\text { d'intervalle: } \\
3 \text { mois } \\
\text { (groupe de } \\
\text { vaccination } \\
\text { précoce) } \\
\text { ou } 9 \text { mois } \\
\text { (groupe de } \\
\text { vaccination } \\
\text { tardive) } \\
\text { après la } \\
\text { greffe } \\
\text { PNEU-P-23 à } \\
12 \text { mois } \\
\text { (groupe de } \\
\text { vaccination } \\
\text { précoce) } \\
\text { ou } 18 \text { mois } \\
\text { (groupe de } \\
\text { vaccination } \\
\text { tardive) } \\
\text { après la } \\
\text { greffe }\end{array}$ & $\begin{array}{l}\text { Étude de } \\
\text { non-infériorité } \\
\text { randomisée } \\
\text { multicentrique } \\
\text { Marge de non } \\
\text { infériorité = -20\% } \\
\text { Durée du suivi : } \\
24 \text { mois } \\
\text { Réponse = titre } \\
\text { d'au moins } 0,15 \\
\text { mg/l } 1 \text { mois après } \\
\text { 3e dose de } \\
\text { PNEU-C-7 }\end{array}$ & 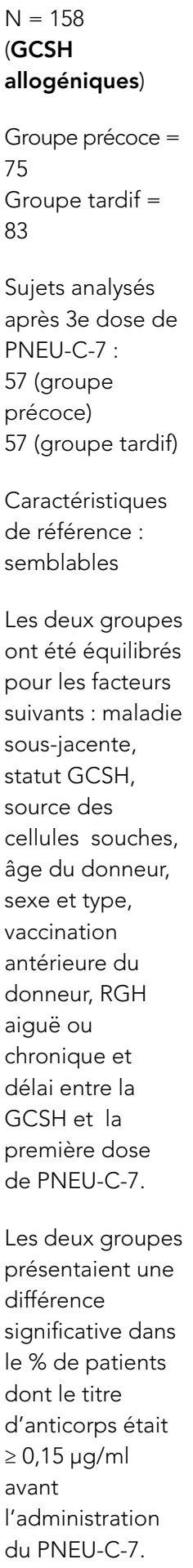 & 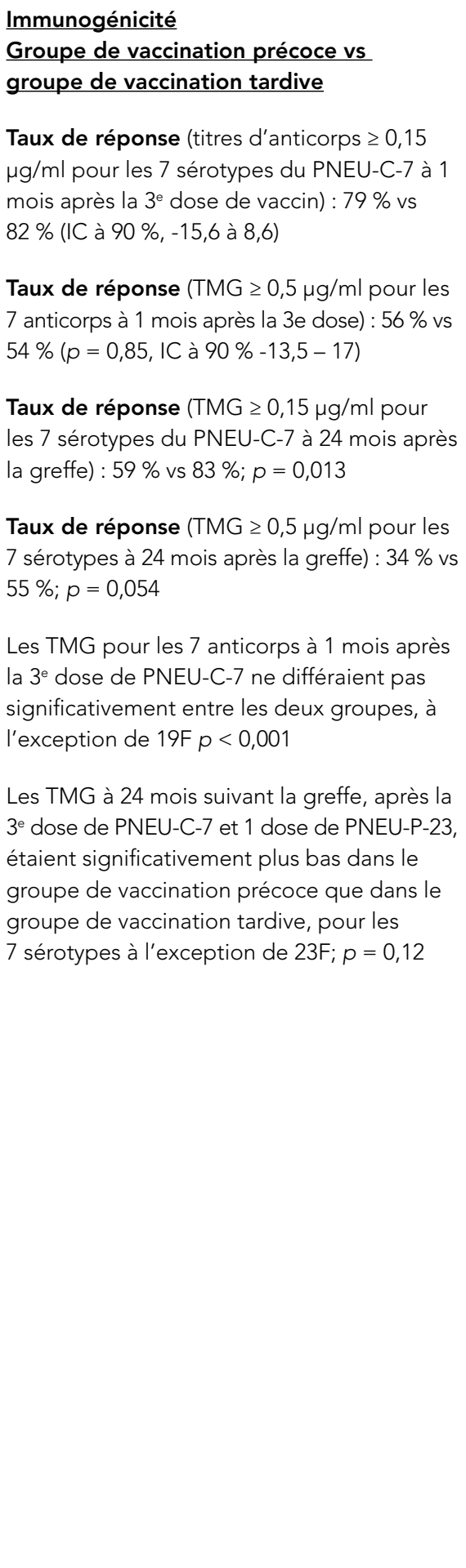 & Niveau I & Bonne \\
\hline
\end{tabular}




\begin{tabular}{|c|c|c|c|c|c|c|}
\hline \multicolumn{7}{|c|}{ Données sur l'immunogénicité } \\
\hline \multicolumn{5}{|c|}{ DÉTAIL DE L'ÉTUDE } & \multicolumn{2}{|c|}{ SOMMAIRE } \\
\hline Étude & Vaccin & Devis de l'étude & Participants & $\begin{array}{l}\text { Résumé des principales constatations sous } \\
\text { forme de texte ou de données }\end{array}$ & $\begin{array}{l}\text { Niveau } \\
\text { de preuve }\end{array}$ & Qualité \\
\hline $\begin{array}{l}\text { Molrine, } \\
2003 \text { (24) }\end{array}$ & 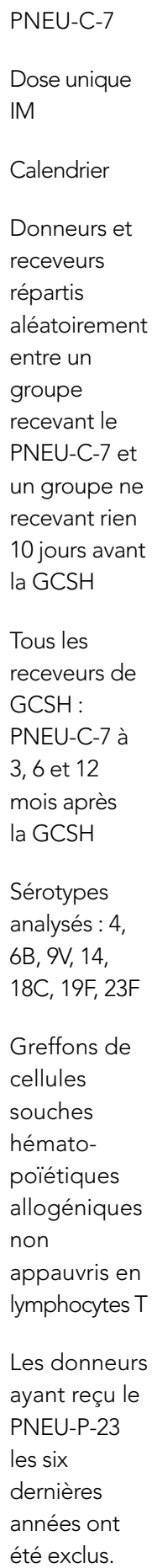 & $\begin{array}{l}\text { Essai comparatif } \\
\text { randomisé } \\
\text { Durée du suivi : } \\
13 \text { mois } \\
\text { *comparaison } \\
\text { établie avec le } \\
\text { TMG de patients } \\
\text { d'une autre étude } \\
\text { présentant des } \\
\text { caractéristiques } \\
\text { cliniques de } \\
\text { référence } \\
\text { semblables, qui } \\
\text { avaient reçu le } \\
\text { PNEU-P-23 à } \\
\text { 12 mois } \\
\text { Randomisation } \\
\text { par strates selon } \\
\text { l'âge } \\
\text { Sujets } \geq 2 \text { ans }\end{array}$ & 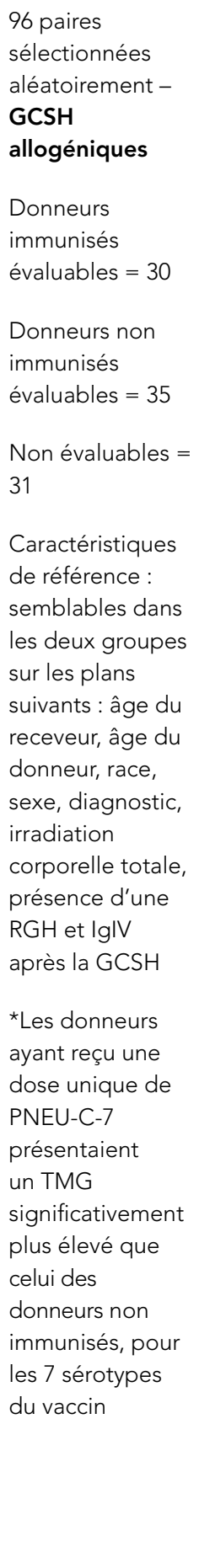 & 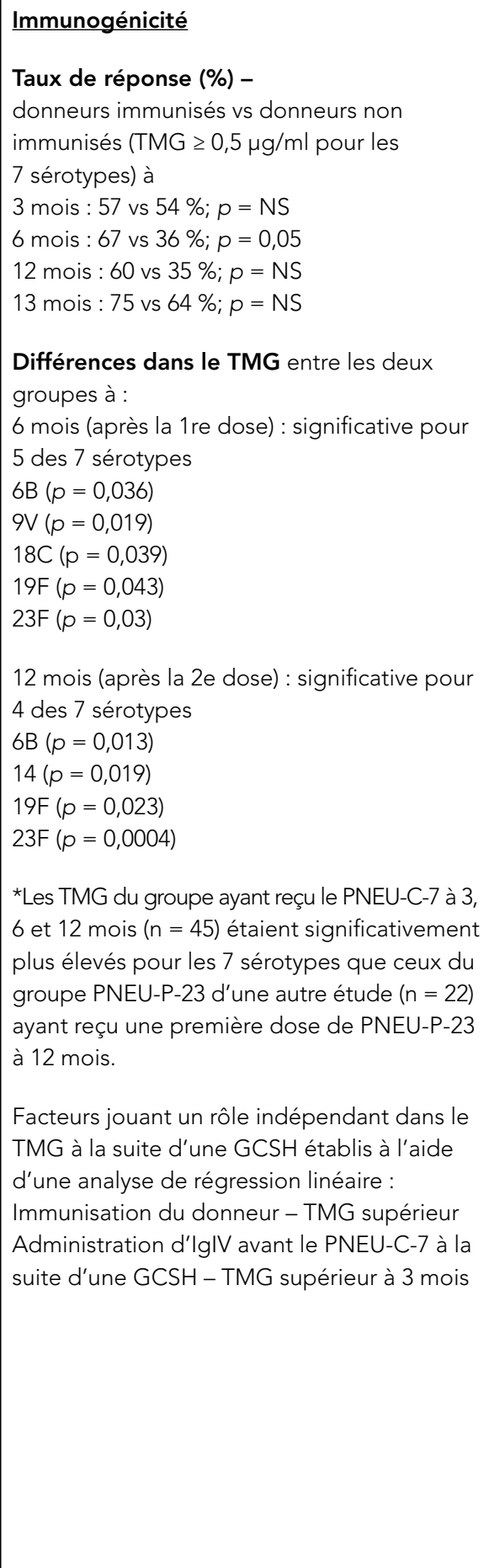 & Niveau I & Moyenne \\
\hline
\end{tabular}




\begin{tabular}{|c|c|c|c|c|c|c|}
\hline \multicolumn{7}{|c|}{ Données sur l'immunogénicité } \\
\hline \multicolumn{5}{|c|}{ DÉTAIL DE L'ÉTUDE } & \multicolumn{2}{|c|}{ SOMMAIRE } \\
\hline Étude & Vaccin & Devis de l'étude & Participants & $\begin{array}{l}\text { Résumé des principales constatations sous } \\
\text { forme de texte ou de données }\end{array}$ & $\begin{array}{l}\text { Niveau } \\
\text { de preuve }\end{array}$ & Qualité \\
\hline $\begin{array}{l}\text { Kumar, } \\
2007(25)\end{array}$ & $\begin{array}{l}\text { PNEU-P-23 } \\
\text { PNEU-C-7 } \\
\text { Dose : 0,5 ml } \\
\text { Paires de } \\
\text { donneurs et } \\
\text { receveurs } \\
\text { Donneurs: } \\
\text { 1 dose de } \\
\text { l'un ou } \\
\text { I'autre des } \\
\text { vaccins } \\
\geq 2 \text { semaines } \\
\text { avant le } \\
\text { prélèvement } \\
\text { de cellules } \\
\text { Receveurs : } \\
1 \text { dose de } \\
\text { I'un ou } \\
\text { l'autre des } \\
\text { vaccins } \\
6 \text { mois après } \\
\text { la GCSH } \\
\text { Voie : IM } \\
\text { Sérotypes } \\
\text { analysés: } 4, \\
6 B, 14,18 C, \\
19 F, 23 F\end{array}$ & $\begin{array}{l}\text { Essai comparatif } \\
\text { randomisé, à } \\
\text { double insu } \\
\text { Paires } \\
\text { sélectionnées } \\
\text { aléatoirement } \\
\text { Durée du suivi : } \\
12 \text { mois après la } \\
\text { GCSH } \\
\text { Réponse : } \\
\text { augmentation } \\
\text { d'un facteur de } 2 \\
\text { du TMG et titre } \\
\text { absolu } \geq 0,35 \mu / \mathrm{ml}\end{array}$ & $\begin{array}{l}\mathrm{N}=64 \text { paires } \\
\text { donneurs- } \\
\text { receveurs } \\
\text { (GCSH } \\
\text { allogéniques) } \\
\text { Paires recevant le } \\
\text { PNEU-C-7 = } 32 \\
\text { Paires recevant le } \\
\text { PNEU-P-23 = } 32 \\
\text { Caractéristiques } \\
\text { de référence : } \\
\text { semblables chez } \\
\text { les donneurs et } \\
\text { les receveurs }\end{array}$ & 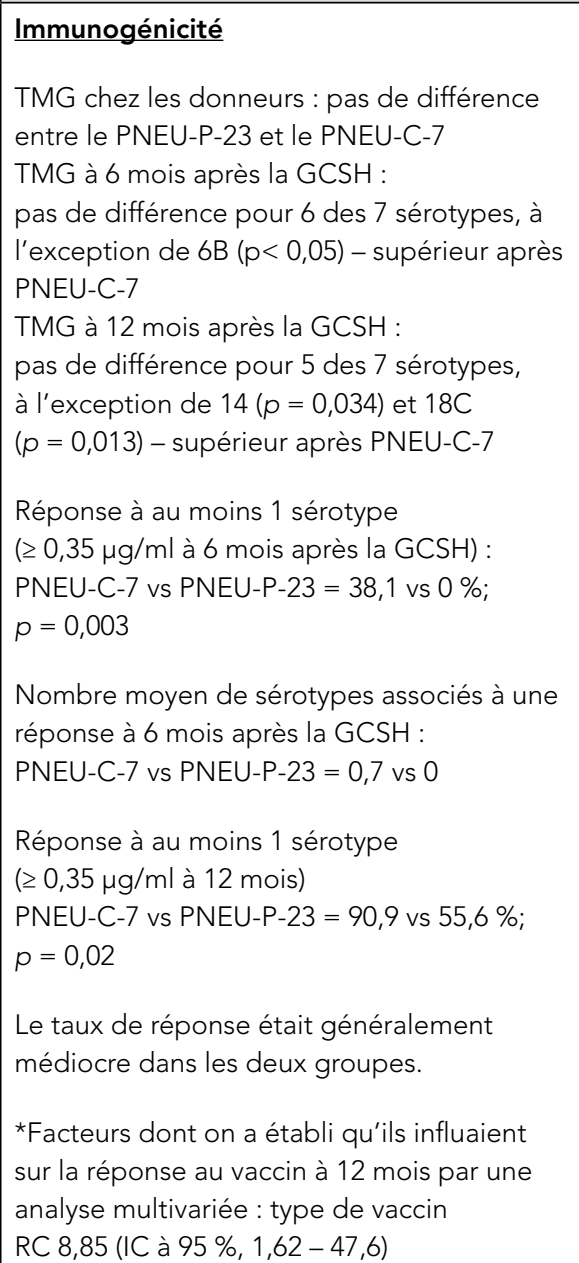 & Niveau I & Bonne \\
\hline
\end{tabular}




\begin{tabular}{|c|c|c|c|c|c|c|}
\hline \multicolumn{7}{|c|}{ Données sur l'immunogénicité } \\
\hline \multicolumn{5}{|c|}{ DÉTAIL DE L'ÉTUDE } & \multicolumn{2}{|c|}{ SOMMAIRE } \\
\hline Étude & Vaccin & Devis de l'étude & Participants & $\begin{array}{l}\text { Résumé des principales constatations sous } \\
\text { forme de texte ou de données }\end{array}$ & $\begin{array}{l}\text { Niveau } \\
\text { de preuve }\end{array}$ & Qualité \\
\hline $\begin{array}{l}\text { Feikin, } 2002 \\
(26)\end{array}$ & $\begin{array}{l}\text { Combinaison } \\
\text { du PNEU-C-7, } \\
\text { PNEU-P-23 } \\
\text { ou placebo } \\
\text { PNEU-C-7/ } \\
\text { PNEU-C-7 } \\
\text { PNEU-C-7/ } \\
\text { PNEU-P-23 } \\
\text { Placebo/ } \\
\text { PNEU-P-23 } \\
\text { Placebo/ } \\
\text { placebo } \\
\text { Voie : IM } \\
\text { (deltoïde) } \\
\text { Calendrier: } \\
\text { 0, } 8 \text { semaines }\end{array}$ & $\begin{array}{l}\text { Essai comparatif } \\
\text { randomisé } \\
\text { Durée du suivi : } \\
24 \text { semaines } \\
\text { Sérotypes } \\
\text { analysés : } \\
\text { 4, 6B, 9V, 14, 23F } \\
\text { CMG (IgG) } \\
\text { TMG (OPA) }\end{array}$ & $\begin{array}{l}\mathrm{N}=90 \\
\mathrm{~N}=67 \\
\text { (étude terminée) } \\
\\
\text { Des adultes } \\
\text { infectés par le } \\
\text { VIH avec } \\
\text { numération } \\
\text { lymphocytaire } \\
\mathrm{CD} 4 \geq 200 / \mu \text { ont } \\
\text { reçu } 2 \text { doses } \\
\text { d'une combinaison } \\
\text { de vaccins }\end{array}$ & 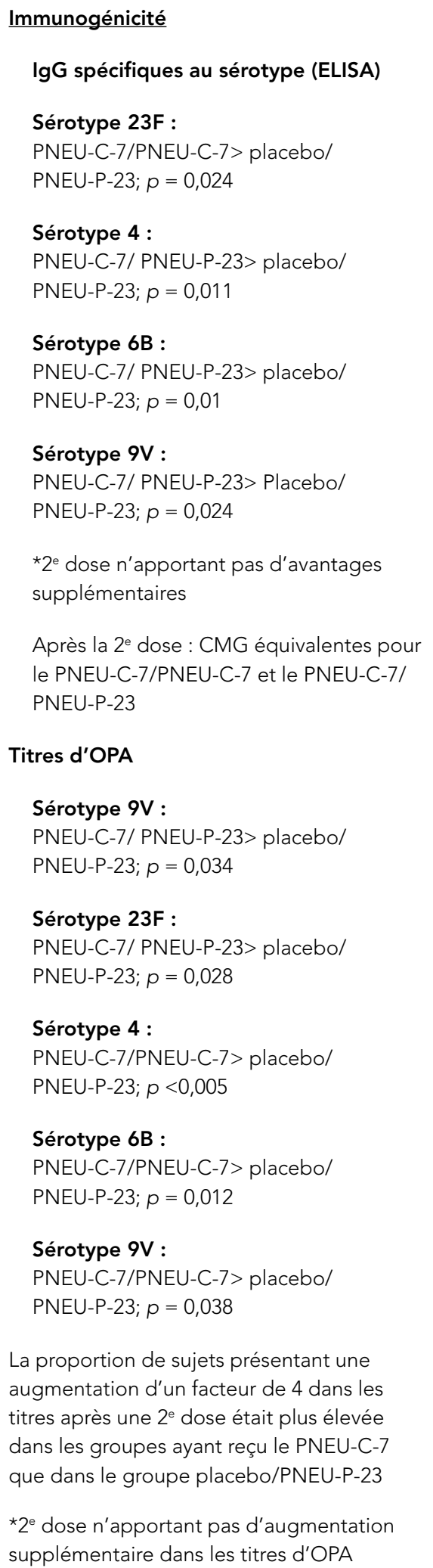 & Niveau I & Bonne \\
\hline
\end{tabular}




\begin{tabular}{|c|c|c|c|c|c|c|}
\hline \multicolumn{7}{|c|}{ Données sur l'immunogénicité } \\
\hline \multicolumn{5}{|c|}{ DÉTAIL DE L'ÉTUDE } & \multicolumn{2}{|c|}{ SOMMAIRE } \\
\hline Étude & Vaccin & Devis de l'étude & Participants & $\begin{array}{l}\text { Résumé des principales constatations sous } \\
\text { forme de texte ou de données }\end{array}$ & $\begin{array}{l}\text { Niveau } \\
\text { de preuve }\end{array}$ & Qualité \\
\hline $\begin{array}{l}\text { Penaranda } \\
2010 \text { (27) }\end{array}$ & $\begin{array}{l}\text { PNEU-C-7 } \\
\text { PNEU-P-23 } \\
\text { Calendrier } \\
\text { Groupe 1: } \\
\text { Dose unique } \\
\text { de PNEU-C-7 } \\
\text { à } 0 \text { semaine } \\
\text { suivie d'une } \\
\text { dose unique } \\
\text { de PNEU-P-23 } \\
\text { à } 4 \text { semaines } \\
\text { Groupe 2: } \\
\text { PNEU-P-23 } \\
\text { à } 0 \text { semaine }\end{array}$ & 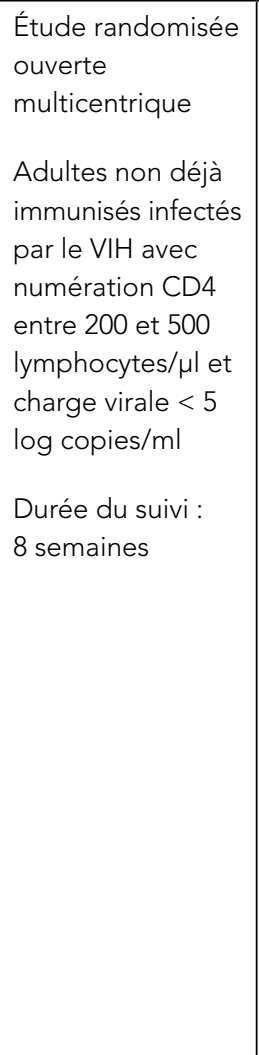 & $\begin{array}{l}\text { N=220 (110 dans } \\
\text { chaque groupe) } \\
\text { Répartis } \\
\text { aléatoirement } \\
\text { entre deux } \\
\text { groupes : } \\
\text { combinaison de } \\
\text { PNEU-C-7/ } \\
\text { PNEU-P-23 (4 } \\
\text { semaines plus } \\
\text { tard) } \\
\text { OU uniquement } \\
\text { PNEU-P-23 } \\
\text { Caractéristiques } \\
\text { des patients : } \\
\text { semblables au } \\
\text { départ, à } \\
\text { l'exception de la } \\
\text { proportion de } \\
\text { patients recevant } \\
\text { le traitement } \\
\text { HAART : } \\
98 \% \text { dans le } \\
\text { groupe } 1 \text { vs } 91 \% \\
\text { dans le groupe } 2\end{array}$ & $\begin{array}{l}\text { Paramètres principaux } \\
\text { 1) Augmentation des IgG spécifiques d'un } \\
\text { facteur de } \geq 2 \\
\text { 2) Augmentation des IgG spécifiques d'un } \\
\text { facteur de } 2 \text { ET atteignant } 1 \mu \mathrm{g} / \mathrm{ml} \\
\text { Pourcentage de répondeurs à } 8 \text { semaines } \\
\text { selon les critères } 1 \text { et } 2 \text { : } \\
\text { Pas de différence entre les deux groupes, à } \\
\text { l'exception du sérotype } 23 \mathrm{~F}: 26 \% \text { de } \\
\text { répondeurs (combinaison des } 2 \text { vaccins) vs } \\
14 \% \text { de répondeurs (uniquement PNEU-P-23) } \\
\text { RC = 2,2; IC à } 95 \% 1,07-4,56 \\
\text { Pas de différence sur le plan de l'avidité }\end{array}$ & Niveau I & Bonne \\
\hline
\end{tabular}




\begin{tabular}{|c|c|c|c|c|c|c|}
\hline \multicolumn{7}{|c|}{ Données sur l'immunogénicité } \\
\hline \multicolumn{5}{|c|}{ DÉTAIL DE L'ÉTUDE } & \multicolumn{2}{|c|}{ SOMMAIRE } \\
\hline Étude & Vaccin & Devis de l'étude & Participants & $\begin{array}{l}\text { Résumé des principales constatations sous } \\
\text { forme de texte ou de données }\end{array}$ & $\begin{array}{l}\text { Niveau } \\
\text { de preuve }\end{array}$ & Qualité \\
\hline $\begin{array}{l}\text { Crum- } \\
\text { Cianflone, } \\
2010 \text { (28) }\end{array}$ & $\begin{array}{l}\text { Revaccination } \\
\text { avec le } \\
\text { PNEU-C-7 ou } \\
\text { le PNEU-P-23 } \\
\text { Dose unique } \\
3 \text { à } 8 \text { années } \\
\text { après } \\
\text { administration } \\
\text { antérieure du } \\
\text { PNEU-P-23 }\end{array}$ & $\begin{array}{l}\text { Essai comparatif } \\
\text { randomisé } \\
\text { Sujets infectés par } \\
\text { le VIH répartis } \\
\text { aléatoirement } \\
\text { selon un ratio 2:1 } \\
\text { (PNEU-C-7: } \\
\text { PNEU-P-23) } \\
\text { Sujets non infectés } \\
\text { par le VIH : } \\
1 \text { dose de } \\
\text { PNEU-C-7 } \\
\text { Patients : } \\
18-60 \text { ans } \\
\text { Durée du suivi : } \\
180 \text { jours } \\
\text { Durée de l'étude : } \\
\text { févr. } 2006 \text { - } \\
\text { sept. } 2008\end{array}$ & $\begin{array}{l}\mathrm{N}=131 \\
\text { (PNEU-C-7) } \\
\mathrm{N}=73 \\
\text { (PNEU-P-23) } \\
\text { Adultes infectés } \\
\text { par le VIH ayant } \\
\text { reçu le PNEU-P-23 } \\
\text { de } 3 \text { à } 8 \text { ans } \\
\text { auparavant } \\
\mathrm{N}=25 \text { dans le } \\
\text { groupe non } \\
\text { infecté par le } \\
\text { VIH au départ } \\
\text { Caractéristiques } \\
\text { de référence : } \\
\text { semblables } \\
\text { (nombre médian } \\
\text { de CD4 > 500/ } \\
\text { mm3) à l'exception } \\
\text { des sujets recevant } \\
\text { le traitement } \\
\text { HAART (\%) = } \\
84,7,56\end{array}$ & 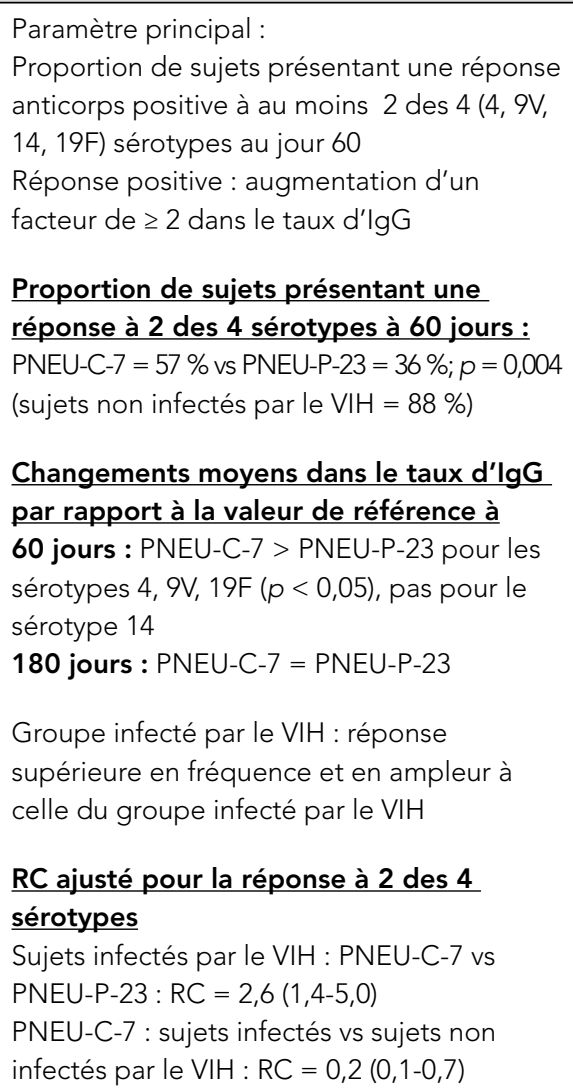 & Niveau I & Bonne \\
\hline
\end{tabular}




\begin{tabular}{|c|c|c|c|c|c|c|}
\hline \multicolumn{7}{|c|}{ Données sur l'immunogénicité } \\
\hline \multicolumn{5}{|c|}{ DÉTAIL DE L'ÉTUDE } & \multicolumn{2}{|c|}{ SOMMAIRE } \\
\hline Étude & Vaccin & Devis de l'étude & Participants & $\begin{array}{l}\text { Résumé des principales constatations sous } \\
\text { forme de texte ou de données }\end{array}$ & $\begin{array}{l}\text { Niveau } \\
\text { de preuve }\end{array}$ & Qualité \\
\hline $\begin{array}{l}\text { Lesprit, } \\
2007 \text { (29) }\end{array}$ & $\begin{array}{l}\text { PNEU-C-7/ } \\
\text { PNEU-P-23 } \\
\text { (4 semaines } \\
\text { plus tard) } \\
\text { OU } \\
\text { PNEU-P-23 à } \\
4 \text { semaines } \\
\text { Dose - n.d. } \\
\text { Voie }- \text { n.d. }\end{array}$ & $\begin{array}{l}\text { Essai comparatif } \\
\text { randomisé - } \\
\text { stratifié selon la } \\
\text { numération CD4 } \\
\text { de référence et } \\
\text { prise antérieure } \\
\text { d'ARV } \\
\text { Durée du suivi : } \\
24 \text { semaines } \\
\text { Sujets inclus: } \\
\text { infectés par le } \\
\text { VIH1 avec } \\
\text { numération CD4 } \\
\text { de } 200-500 ; \\
\text { CV: } 50 \text { 000 } \\
\text { copies/ml; } n^{\prime} \text { ayant } \\
\text { jamais pris d'ARV } \\
\text { ou schéma stable } \\
\text { x au moins } 3 \text { mois; } \\
\text { pas de } \\
\text { pneumococcie les } \\
5 \text { dernières } \\
\text { années } \\
\text { Patients } \\
\text { sélectionnés entre } \\
\text { décembre } 2002 \text { et } \\
\text { décembre } 2003\end{array}$ & $\begin{array}{l}\mathrm{N}=212 \text { (patients } \\
\text { infectés par le } \\
\text { VIH) } \\
\text { Répartis } \\
\text { aléatoirement } \\
\text { entre deux } \\
\text { groupes : } \\
\text { PNEU-C-7/ } \\
\text { PNEU-P-23 (106) } \\
\text { OU uniquement } \\
\text { PNEU-P-23 (106) } \\
\text { Caractéristiques } \\
\text { de référence: } \\
\text { Pas de différence } \\
\text { entre les deux } \\
\text { groupes }\end{array}$ & $\begin{array}{l}\text { Résultats sur le plan de l'immunogénicité } \\
\text { a) augmentation d'un facteur de } 2 \text { dans le } \\
\text { taux d'IgG spécifiques au sérotype } \\
\text { b) augmentation d'un facteur de } 2 \text { ET taux } \\
\text { d'au moins } 1 \text { mg/l } \\
\text { Valeurs de référence : titres d'lgG } \\
\text { semblables dans les deux groupes } \\
\text { À } 8 \text { semaines (4 semaines après l'administration } \\
\text { du PNEU-P-23 dans les deux groupes) : } \\
\text { mêmes titres d'IgG dans les deux groupes, à } \\
\text { l'exception de } 18 C \text { et } 23 F \text { (supérieur avec } \\
\text { calendrier d'administration combinée) } \\
\text { À } 24 \text { semaines : mêmes titres d'IgG dans les } \\
\text { deux groupes, à l'exception de } 18 C \text {, } 23 F \text {, } 14 \\
\text { et } 19 F \\
\text { Proportion de sujets répondant au critère } \\
\text { b ci-dessus : } \\
\text { Pas de différence entre les deux groupes à } \\
8 \text { semaines, à l'exception de la réponse à } \\
5 \text { des } 7 \text { sérotypes ( } 59 \% \text { pour l'administration } \\
\text { combinée vs } 40 \% \text { pour le PNEU-P-23, } \\
\text { p = } 0,005 \text { ) et identique pour les taux à } \\
24 \text { semaines, à l'exception de la réponse à } \\
5 \text { des } 7 \text { sérotypes ( } 30 \% \text { pour l'administration } \\
\text { combinée vs } 10 \% \text { pour le PNEU-P-23, } \\
\text { p = } 0,003 \text { ). }\end{array}$ & Niveau I & Bonne \\
\hline
\end{tabular}




\begin{tabular}{|c|c|c|c|c|c|c|}
\hline \multicolumn{7}{|c|}{ Données sur l'immunogénicité } \\
\hline \multicolumn{5}{|c|}{ DÉTAIL DE L'ÉTUDE } & \multicolumn{2}{|c|}{ SOMMAIRE } \\
\hline Étude & Vaccin & Devis de l'étude & Participants & $\begin{array}{l}\text { Résumé des principales constatations sous } \\
\text { forme de texte ou de données }\end{array}$ & $\begin{array}{l}\text { Niveau } \\
\text { de preuve }\end{array}$ & Qualité \\
\hline $\begin{array}{l}\text { Frenck, } \\
2012(30)\end{array}$ & $\begin{array}{l}\text { PNEU-C-13/ } \\
\text { VTG - } \\
\text { placebo } \\
\text { (1 mois plus } \\
\text { tard) } \\
\text { vsplaceboNTG- } \\
\text { PNEU-C-13 } \\
\text { (1 mois plus } \\
\text { tard) } \\
0,5 \text { ml IM }\end{array}$ & $\begin{array}{l}\text { Essai comparatif } \\
\text { randomisé } \\
\text { Population : sujets } \\
\text { sains de } 50-59 \text { ans, } \\
\text { n'ayant reçu pas } \\
\text { déjà le vaccin } \\
\text { contre le } \\
\text { pneumocoque }\end{array}$ & $\begin{array}{l}\text { Multicentrique - } \\
\text { É.-U. } \\
\mathrm{N}=1158 \text { sujets } \\
\text { inscrits } \\
\mathrm{N}=1116 \text { sujets } \\
\text { répartis } \\
\text { aléatoirement } \\
\mathrm{N} 1=554 \\
\text { (PNEU-C-13/NTG) } \\
\text { N2 = 562 (VTG } \\
\text { puis PNEU-C-13) }\end{array}$ & $\begin{array}{l}\text { Réponse au PNEU-C-13 mesurée par les lgG } \\
\text { spécifiques au sérotype (ELISA) } 1 \text { mois après } \\
\text { la vaccination antipneumococcique } \\
\text { OPA : réponse spécifique au sérotype } \\
\text { 1. CMG entre } 1,15 \text { (sérotype } 3 \text { ) et } 16,80 \\
\text { (19A) } \mu \mathrm{g} / \mathrm{ml} \text { dans le groupe } \\
\text { d'administration concomitante et entre } \\
\text { 1,46 (3) et } 18,84 \text { (19A) } \mu \mathrm{g} / \mathrm{ml} \text { dans le } \\
\text { groupe PNEU-C-13 } \\
\text { 2. TMG mesurés par l'OPA entre } 61 \\
\text { (sérotype } 3 \text { ) et } 2421 \text { (6B) dans le groupe } \\
\text { d'administration concomitante et entre } \\
\text { 78 (3) et } 3215 \text { (6B) dans le groupe } \\
\text { PNEU-C-13 } \\
\text { 3. Réponse au VTG : semblable dans les } \\
\text { deux groupes } \\
\text { 4. Réponse au PNEU-C-13: } \\
\text { a) Les CMG étaient généralement } \\
\text { inférieures dans le groupe } \\
\text { d'administration concomitante, } \\
\text { se situant entre } 0,69 \text { et } 0,89 \text { - dans } \\
\text { aucun cas, le critère d'infériorité } \\
\text { n'a été atteint; } \\
\text { b) Les TMG mesurés par l'OPA étaient } \\
\text { aussi généralement inférieurs dans le } \\
\text { groupe d'administration concomitante, } \\
\text { se situant entre } 0,5 \text { et } 0,8 \text { - les } \\
\text { sérotypes } 1,5,7 F, 9 V \text { et } 19 F \text { ont } \\
\text { atteint le critère d'infériorité (limite } \\
\text { inférieure de l'IC à } 95 \% \text { < } 0,5 \text { ) }\end{array}$ & Niveau I & Bonne \\
\hline
\end{tabular}




\begin{tabular}{|c|c|c|c|c|c|c|}
\hline \multicolumn{7}{|c|}{ Données sur l'immunogénicité } \\
\hline \multicolumn{5}{|c|}{ DÉTAIL DE L'ÉTUDE } & \multicolumn{2}{|c|}{ SOMMAIRE } \\
\hline Étude & Vaccin & Devis de l'étude & Participants & $\begin{array}{l}\text { Résumé des principales constatations sous } \\
\text { forme de texte ou de données }\end{array}$ & $\begin{array}{l}\text { Niveau } \\
\text { de preuve }\end{array}$ & Qualité \\
\hline $\begin{array}{l}\text { Schwarz, } \\
2011(31)\end{array}$ & $\begin{array}{l}\text { PNEU-C-13/ } \\
\text { VTG - } \\
\text { placebo } \\
\text { (1 mois } \\
\text { plus tard) } \\
\text { vs } \\
\text { placebo/NTG- } \\
\text { PNEU-C-13 } \\
\text { (1 mois plus } \\
\text { tard 0,5 ml IM) }\end{array}$ & $\begin{array}{l}\text { Essai comparatif } \\
\text { randomisé } \\
\text { Tous les sérotypes } \\
\text { du PNEU-C-13 ont } \\
\text { été analysés } \\
\text { Sujets sains de } \\
65 \text { ans ou plus, } \\
\text { n'ayant pas déjà } \\
\text { reçu le vaccin } \\
\text { contre le } \\
\text { pneumocoque } \\
\text { Suivi jusqu'à } \\
1 \text { mois après la } \\
\text { dernière } \\
\text { administration } \\
\text { de vaccin }\end{array}$ & $\begin{array}{l}\text { Multicentrique - } \\
\text { Europe } \\
\mathrm{N}=1190 \\
\text { parti-cipants } \\
\text { inscrits; } 1160 \\
\text { répartis } \\
\text { aléatoirement - } \\
580 \text { dans chaque } \\
\text { groupe } \\
1 \text { 096 évaluables }\end{array}$ & 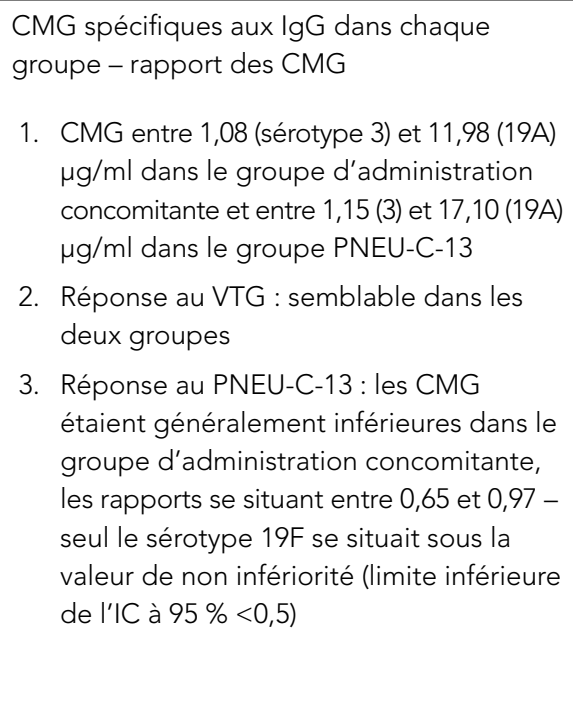 & Niveau I & Bonne \\
\hline
\end{tabular}




\begin{tabular}{|c|c|c|c|c|c|c|}
\hline \multicolumn{7}{|c|}{ Données sur l'immunogénicité } \\
\hline \multicolumn{5}{|c|}{ DÉTAIL DE L'ÉTUDE } & \multicolumn{2}{|c|}{ SOMMAIRE } \\
\hline Étude & Vaccin & Devis de l'étude & Participants & $\begin{array}{l}\text { Résumé des principales constatations sous } \\
\text { forme de texte ou de données }\end{array}$ & $\begin{array}{l}\text { Niveau } \\
\text { de preuve }\end{array}$ & Qualité \\
\hline $\begin{array}{l}\text { Jackson, } \\
2007 \text { (32) }\end{array}$ & $\begin{array}{l}\text { PNEU-C-7 } \\
\text { PNEU-P-23 } \\
\text { Dose } \\
\text { (PNEU-C-7) : } \\
0,1 \mathrm{ml} \text { ou } \\
0,5 \mathrm{ml} \text { ou } \\
1 \mathrm{ml} \text { ou } \\
2 \mathrm{ml} \\
\text { *PNEU-C-7 } \\
\text { homologué à } \\
\text { la dose de } \\
0,5 \mathrm{ml} \text { chez } \\
\text { les enfants } \\
\text { Dose } \\
\text { (PNEU-P-23) : } \\
\text { 0,5 ml IM } \\
\text { Test de } \\
\text { provocation } \\
\text { de } 0,1 \mathrm{ml} \\
\text { avec la dose } \\
\text { de PNEU-P-23 } \\
\text { à } 1 \text { an }\end{array}$ & 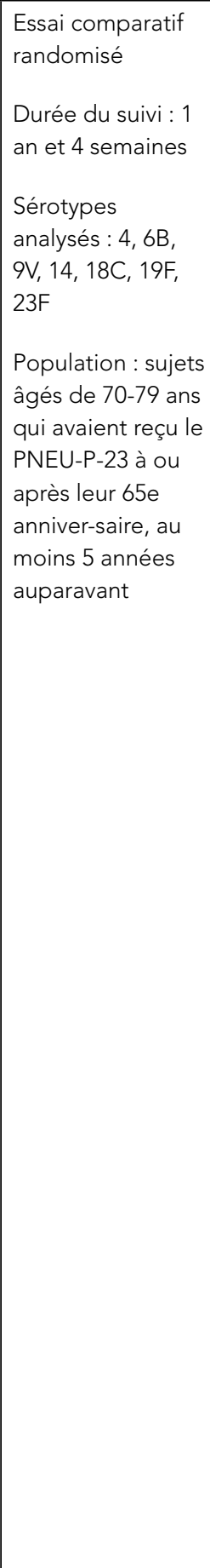 & $\begin{array}{l}\mathrm{N}=220 \\
\text { sujets sélectionnés } \\
\text { aléatoirement } \\
\text { selon un ratio } 4: 1 \\
\text { par groupe de } 55 \\
\text { pour recevoir le } \\
\text { PNEU-C-7 à des } \\
\text { doses de 0,1,0,5, } \\
\text { 1, et } 2 \text { ml vs le } \\
\text { PNEU-P-23 } \\
\mathrm{N}=219 \text { (sujets } \\
\text { analysés après la } \\
\text { 1re vaccination) } \\
\mathrm{N}=208 \text { (avant } \\
\text { le test de } \\
\text { provocation } \\
\text { du vaccin } \\
\text { PNEU-P-23) } \\
\mathrm{N}=203 \text { (sujets } \\
\text { analysés après } \\
\text { le test de } \\
\text { provocation du } \\
\text { vaccin) }\end{array}$ & $\begin{array}{l}\text { Immunogénicité } \\
\text { CMG spécifiques au sérotype après la } \\
\text { vaccination à l'inscription (0,5 } \mathrm{ml} \text { vs } 1 \mathrm{ml} \\
\text { et } 2 \mathrm{ml} \text {; IC à } 95 \%) \\
\text { Les titres post-vaccination correspondant } \\
\text { aux doses de } 1 \text { et } 2 \mathrm{ml} \text { étaient supérieurs } \\
\text { pour tous les sérotypes, à l'exception du } \\
\text { sérotype } 14 \text { : } \\
0,5 \mathrm{ml}-8,8(5,8-13,2) \text { vs } \\
1 \text { ml - 7,3 }(4,7-11,3) \text { vs } \\
2 \mathrm{ml}-8,9(5,5-14,8) \\
\text { Les titres post-vaccination étaient } \\
\text { significativement plus élevés à la dose de } \\
2 \mathrm{ml} \text { qu'à la dose de } 0,5 \mathrm{ml} \text { pour : } \\
\text { Sérotype } 6 \mathrm{~B} ; \mathrm{p}<0,05 \\
\text { À } 0,5 \mathrm{ml}-2,6(1,6-4,2) \\
2 \mathrm{ml}-4,7(2,9-7,6) \\
\text { Sérotype } 9 \mathrm{~V} ; \mathrm{p}<0,05 \\
0,5 \mathrm{ml}-3,2(2,0-4,9) \\
2 \mathrm{ml}-6,4(4,2-9,2) \\
\text { Après } 1 \text { an (avant le test de provocation) } \\
\text { les CMG évaluées par ELISA étaient } \\
\text { semblables à celles antérieures à la } \\
\text { vaccination, peu importe le vaccin et la } \\
\text { dose administrés }\end{array}$ & Niveau I & Bonne \\
\hline
\end{tabular}




\begin{tabular}{|c|c|c|c|c|c|c|}
\hline \multicolumn{7}{|c|}{ Données sur l'immunogénicité } \\
\hline \multicolumn{5}{|c|}{ DÉTAIL DE L'ÉTUDE } & \multicolumn{2}{|c|}{ SOMMAIRE } \\
\hline Étude & Vaccin & Devis de l'étude & Participants & $\begin{array}{l}\text { Résumé des principales constatations sous } \\
\text { forme de texte ou de données }\end{array}$ & $\begin{array}{l}\text { Niveau } \\
\text { de preuve }\end{array}$ & Qualité \\
\hline & & & & 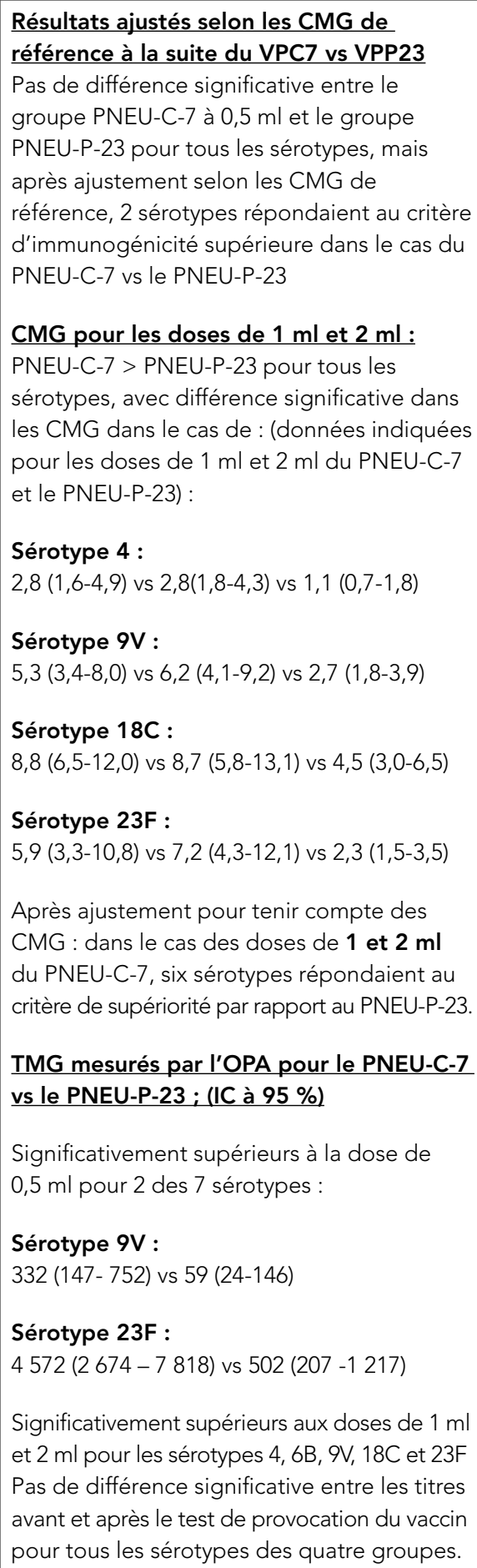 & & \\
\hline
\end{tabular}




\begin{tabular}{|c|c|c|c|c|c|c|}
\hline \multicolumn{7}{|c|}{ Données sur l'immunogénicité } \\
\hline \multicolumn{5}{|c|}{ DÉTAIL DE L'ÉTUDE } & \multicolumn{2}{|c|}{ SOMMAIRE } \\
\hline Étude & Vaccin & Devis de l'étude & Participants & $\begin{array}{l}\text { Résumé des principales constatations sous } \\
\text { forme de texte ou de données }\end{array}$ & $\begin{array}{l}\text { Niveau } \\
\text { de preuve }\end{array}$ & Qualité \\
\hline $\begin{array}{l}\text { De Roux, } \\
2008 \text { (33) }\end{array}$ & $\begin{array}{l}\text { PNEU-C-7 } \\
\text { suivi du } \\
\text { PNEU-C-7 } \\
\text { OU du } \\
\text { PNEU-P-23 } \\
\text { (un an plus } \\
\text { tard } \\
\text { OU } \\
\text { PNEU-P-23 } \\
\text { suivi du } \\
\text { PNEU-C-7 } \\
\text { (un an plus } \\
\text { tard) }\end{array}$ & $\begin{array}{l}\text { Essai comparatif } \\
\text { randomisé ouvert, } \\
\text { de phase } 2 \\
\text { Durée du suivi : } \\
13 \text { mois } \\
\text { Population : sujets } \\
\text { de } 70 \text { ans ou plus, } \\
\text { n'ayant PAS déjà } \\
\text { reçu le vaccin } \\
\text { contre le } \\
\text { pneumocoque }\end{array}$ & $\begin{array}{l}\mathrm{N}=219 \text { sujets de } \\
\geq 70 \text { années, } \\
\text { ambulatoires } \\
\text { 1re dose de } \\
\text { PNEU-C-7 = } 110 \\
\text { 1re dose de } \\
\text { PNEU-P-23 = } 109 \\
\text { PNEU-C-7/ } \\
\text { PNEU-C-7 = 43 } \\
\text { PNEU-C-7/ } \\
\text { PNEU-P-23 = 38 } \\
\text { PNEU-P-23/ } \\
\text { PNEU-C-7 = 78 } \\
\text { Caractéristiques } \\
\text { de référence : les } \\
\text { titres d'anticorps } \\
\text { pré-immunisation } \\
\text { étaient semblables } \\
\text { dans les deux } \\
\text { groupes initiaux. } \\
\text { L'âge moyen à } \\
\text { I'inscription était } \\
\text { de } 75 \text { ans. }\end{array}$ & 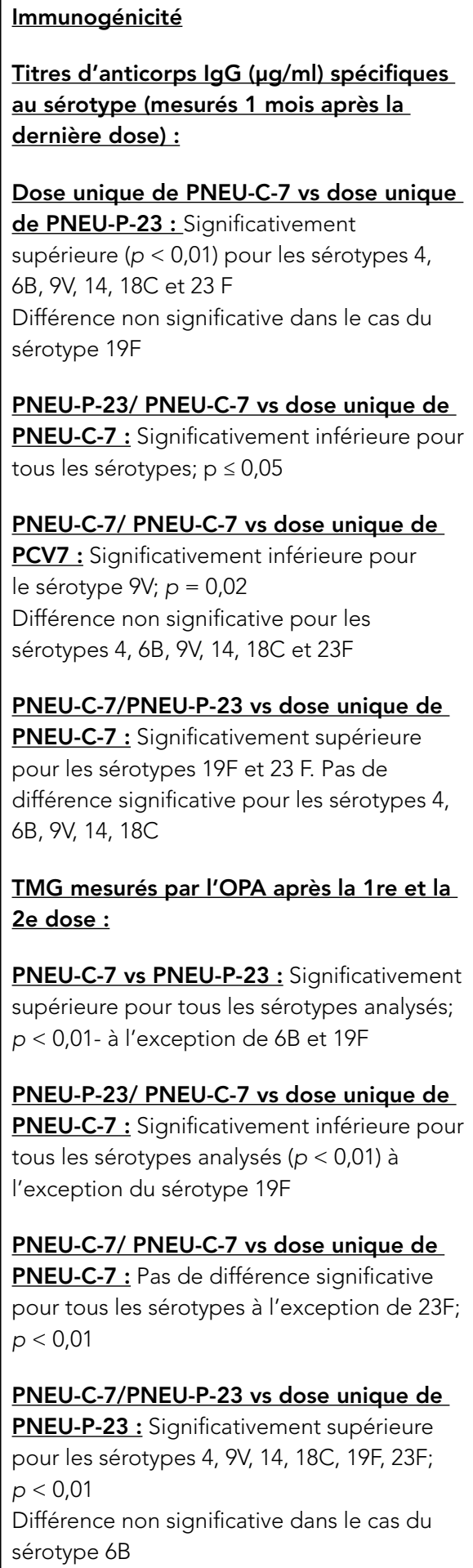 & Niveau I & Bonne \\
\hline
\end{tabular}




\begin{tabular}{|c|c|c|c|c|c|c|}
\hline \multicolumn{7}{|c|}{ Données sur l'immunogénicité } \\
\hline \multicolumn{5}{|c|}{ DÉTAIL DE L'ÉTUDE } & \multicolumn{2}{|c|}{ SOMMAIRE } \\
\hline Étude & Vaccin & Devis de l'étude & Participants & $\begin{array}{l}\text { Résumé des principales constatations sous } \\
\text { forme de texte ou de données }\end{array}$ & $\begin{array}{l}\text { Niveau } \\
\text { de preuve }\end{array}$ & Qualité \\
\hline $\begin{array}{l}\text { Miernyk, } \\
2009 \text { (34) }\end{array}$ & $\begin{array}{l}\text { PNEU-P-23 } \\
\text { PNEU-C-7 } \\
\text { Dose : 0,5ml } \\
\text { IM } \\
\text { Groupe 1: } \\
\text { PNEU-P- 23 } \\
\text { Groupe 2: } \\
\text { PNEU-C-7/ } \\
\text { PNEU-P-23 } \\
\text { (2 mois plus } \\
\text { tard) } \\
\text { Groupe 3: } \\
\text { PNEU-C-7/ } \\
\text { PNEU-P-23 } \\
\text { (6 mois plus } \\
\text { tard) } \\
\text { Sérotypes } \\
\text { analysés : 1, } \\
\text { 4, 6B, 14, 19F }\end{array}$ & $\begin{array}{l}\text { Essai comparatif } \\
\text { randomisé } \\
\text { Population: } \\
\text { Autochtones de } \\
\text { l'Alaska de } 55-70 \\
\text { ans, n'ayant pas } \\
\text { déjà reçu le vaccin } \\
\text { contre le } \\
\text { pneumocoque }\end{array}$ & $\begin{array}{l}\text { PNEU-P-23 = } 28 \\
\text { PNEU-C-7/ } \\
\text { PNEU-P-23 } \\
\text { (2 mois plus } \\
\text { tard) = } 29 \\
\text { PNEU-C-7/ } \\
\text { PNEU-P-23 } \\
\text { (6 mois plus } \\
\text { tard) = } 29 \\
\text { Caractéristiques } \\
\text { de référence : } \\
\text { pas de différence } \\
\text { significative entre } \\
\text { les groupes } \\
\text { d'étude sur le } \\
\text { plan de l'âge et } \\
\text { du sexe }\end{array}$ & 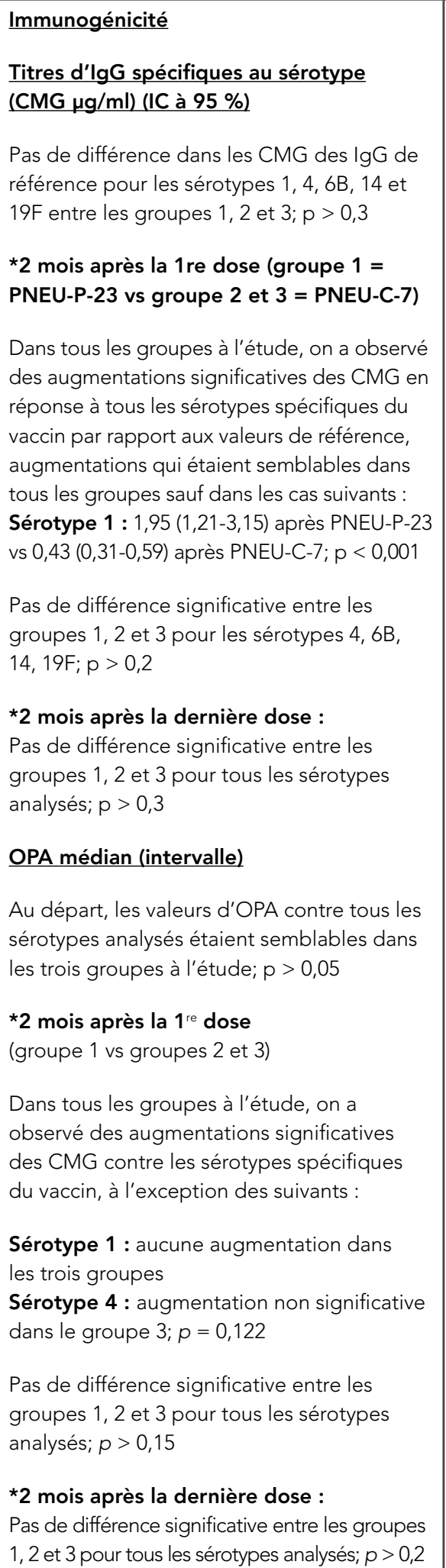 & Niveau I & Bonne \\
\hline
\end{tabular}




\begin{tabular}{|c|c|c|c|c|c|c|}
\hline \multicolumn{7}{|c|}{ Données sur l'immunogénicité } \\
\hline \multicolumn{5}{|c|}{ DÉTAIL DE L'ÉTUDE } & \multicolumn{2}{|c|}{ SOMMAIRE } \\
\hline Étude & Vaccin & Devis de l'étude & Participants & $\begin{array}{l}\text { Résumé des principales constatations sous } \\
\text { forme de texte ou de données }\end{array}$ & $\begin{array}{l}\text { Niveau } \\
\text { de preuve }\end{array}$ & Qualité \\
\hline $\begin{array}{l}\text { Goldblatt, } \\
2009 \text { (35) }\end{array}$ & $\begin{array}{l}\text { PNEU-C-7 } \\
\text { PNEU-P-23 } \\
\text { Groupe 1: } \\
\text { PNEU-C-7/ } \\
\text { PNEU-C-7 } \\
\text { (6 mois plus } \\
\text { tard) } \\
\text { Groupe 2: } \\
\text { PNEU-C-7/ } \\
\text { PNEU-P-23 } \\
\text { (6 mois plus } \\
\text { tard) } \\
\text { Groupe } 3 \text { : } \\
\text { PNEU-P-23 } \\
\text { Groupe } 4 \text { : } \\
\text { PNEU-C-7 }\end{array}$ & $\begin{array}{l}\text { Essai comparatif } \\
\text { randomisé, ouvert } \\
\text { Durée du suivi : } \\
12 \text { mois } \\
\text { Seuil pour les } \\
\text { titres d'lgG : } \\
0,35 \mathrm{ug} / \mathrm{ml}\end{array}$ & $\begin{array}{l}\text { Groupe } 1=133 \\
\text { Groupe } 2=171 \\
\text { Groupe } 3=159 \\
\text { Groupe } 4=136 \\
\text { Sujets âgés de } \\
50-80 \text { ans, } \\
\text { n'ayant reçu } \\
\text { aucun des } \\
\text { vaccins contre le } \\
\text { pneumocoque } \\
\text { dans les } 3 \text { à } \\
5 \text { années } \\
\text { précédant le } \\
\text { recrutement } \\
\text { Même nombre } \\
\text { de sujets dans } \\
\text { chaque groupe } \\
\text { d'âge, soit 50-59, } \\
\text { 60-69, 70-79 } \\
\text { Caractéristiques } \\
\text { de référence non } \\
\text { fournies }\end{array}$ & 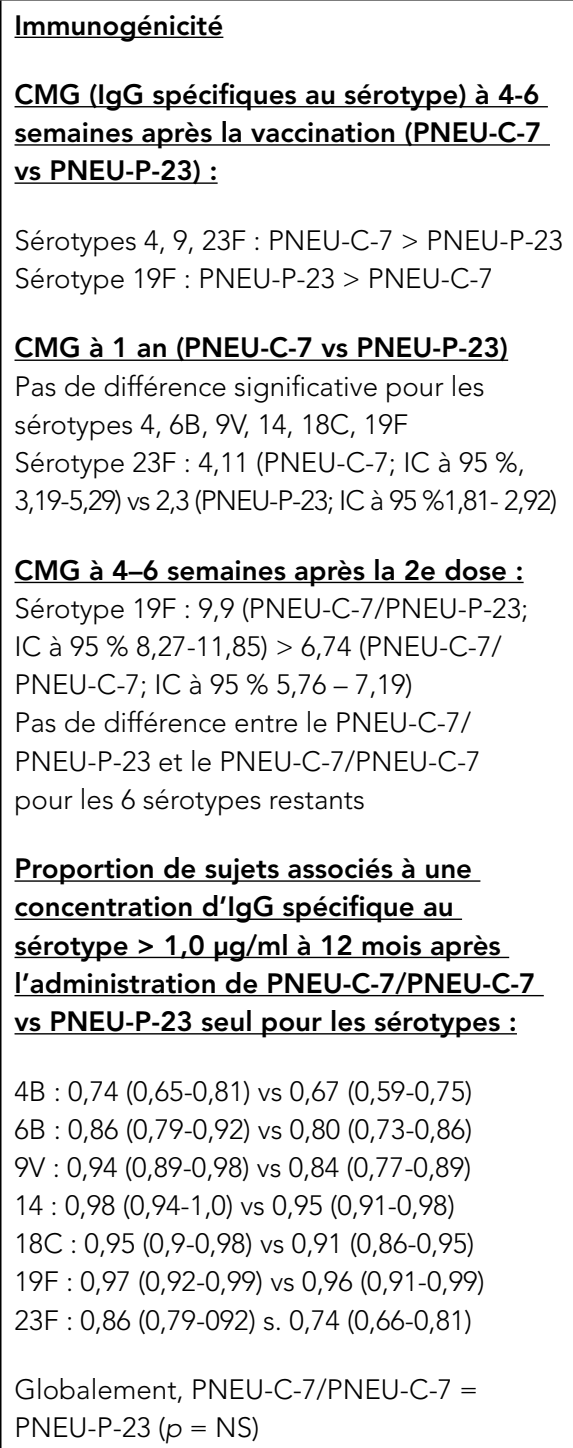 & Niveau I & Bonne \\
\hline
\end{tabular}




\begin{tabular}{|c|c|c|c|c|c|c|}
\hline \multicolumn{7}{|c|}{ Données sur l'immunogénicité } \\
\hline \multicolumn{5}{|c|}{ DÉTAIL DE L'ÉTUDE } & \multicolumn{2}{|c|}{ SOMMAIRE } \\
\hline Étude & Vaccin & Devis de l'étude & Participants & $\begin{array}{l}\text { Résumé des principales constatations sous } \\
\text { forme de texte ou de données }\end{array}$ & $\begin{array}{l}\text { Niveau } \\
\text { de preuve }\end{array}$ & Qualité \\
\hline $\begin{array}{l}\text { Schenkein, } \\
2008 \text { (36) }\end{array}$ & $\begin{array}{l}\text { PNEU-P-23 } \\
0,5 \mathrm{ml} \times 1 \\
\mathrm{IM} \\
\text { Sérotypes } \\
\text { analysés : 4, } \\
6 \mathrm{~B}, 9 \mathrm{~V}, 14, \\
18 \mathrm{C}, 19 \mathrm{~F}, \\
23 \mathrm{~F}, \text { analysés } \\
28 \text { jours } \\
\text { après la } \\
\text { vaccination }\end{array}$ & $\begin{array}{l}\text { Essai comparatif } \\
\text { randomisé } \\
\text { Étude comparative } \\
\text { de la réponse } \\
\text { immunitaire chez } \\
\text { des sujets âgés de } \\
65 \text { ans ou plus vs } \\
\text { sujets âgés de } \\
45 \text { ans et moins }\end{array}$ & $\begin{array}{l}<45 \text { ans }=45 \\
\geq 65 \text { ans }=58 \\
\text { Les adultes âgés } \\
\text { étaient des } \\
\text { résidents de la } \\
\text { collectivité } \\
\text { venant d'un } \\
\text { groupe témoin } \\
\text { d'une étude déjà } \\
\text { publiée, soit un } \\
\text { essai comparatif } \\
\text { contre placebo, } \\
\text { randomisé et à } \\
\text { double insu } \\
\text { Les sujets jeunes } \\
\text { étaient des } \\
\text { volontaires en } \\
\text { santé recrutés } \\
\text { parmi le } \\
\text { personnel de } \\
\text { recherche d'un } \\
\text { laboratoire } \\
\text { rattaché à un } \\
\text { grand centre } \\
\text { médical } \\
\text { universitaire }\end{array}$ & 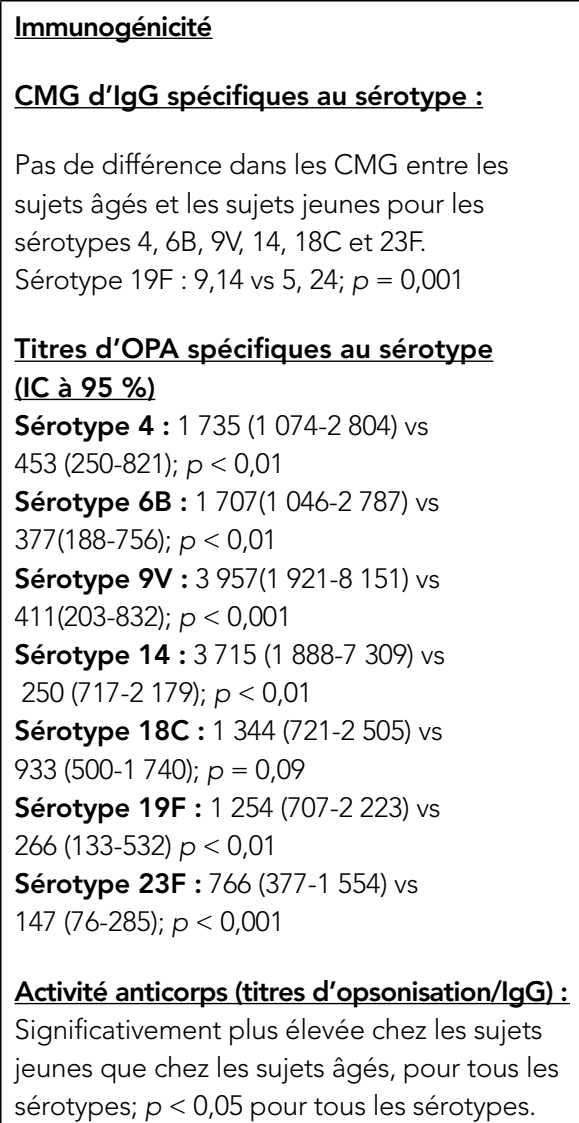 & Niveau I & Bonne \\
\hline
\end{tabular}




\begin{tabular}{|c|c|c|c|c|c|c|}
\hline \multicolumn{7}{|c|}{ Données sur l'immunogénicité } \\
\hline \multicolumn{5}{|c|}{ DÉTAIL DE L'ÉTUDE } & \multicolumn{2}{|c|}{ SOMMAIRE } \\
\hline Étude & Vaccin & Devis de l'étude & Participants & $\begin{array}{l}\text { Résumé des principales constatations sous } \\
\text { forme de texte ou de données }\end{array}$ & $\begin{array}{l}\text { Niveau } \\
\text { de preuve }\end{array}$ & Qualité \\
\hline $\begin{array}{l}\text { Musher, } \\
2010 \text { (37) }\end{array}$ & $\begin{array}{l}\text { PNEU-P-23 } \\
\text { Placebo } \\
\text { Suivi } 30 \text { jours } \\
\text { plus tard par } \\
\text { l'administra- } \\
\text { tion d'un } \\
\text { autre produit } \\
\text { dans l'autre } \\
\text { groupe } \\
\text { d'étude } \\
\text { Voie : IM } \\
\text { Suivi : } \\
5 \text { ans - } \\
\text { prélèvements } \\
\text { sanguins } \\
\text { annuels par } \\
\text { la suite }\end{array}$ & $\begin{array}{l}\text { Essai comparatif } \\
\text { randomisé } \\
\text { Exclusion : IIP } \\
\text { antérieure, } \\
\text { splénectomie, } \\
\text { déficit immunitaire } \\
\text { Groupe stratifié } \\
\text { selon l'âge et les } \\
\text { antécédents de } \\
\text { vaccination } \\
\text { antipneumo- } \\
\text { coccique (au moins } \\
3 \text { ans auparavant } \\
\text { pour les sujets de } \\
50 \text {-64 ans et de } \\
3 \text { à } 5 \text { ans auparavant } \\
\text { pour ceux de } \\
65 \text { ans ou plus) }\end{array}$ & 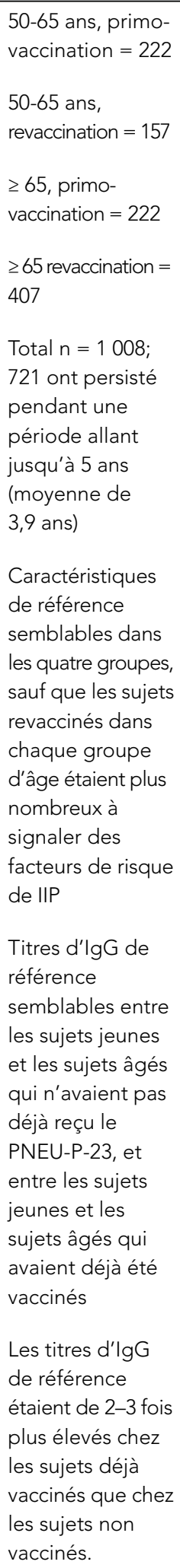 & 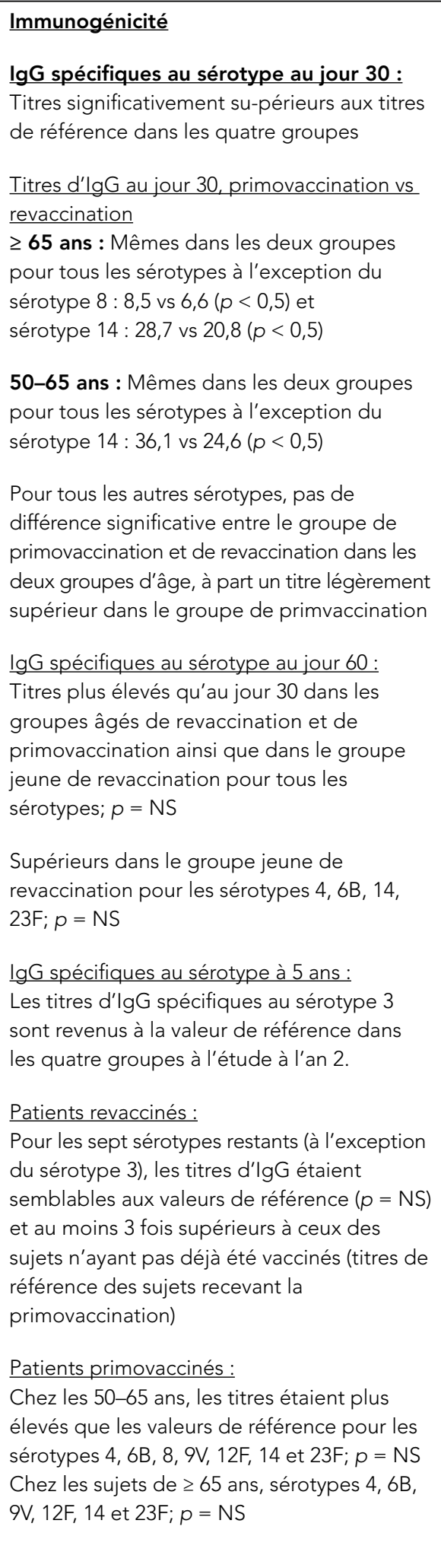 & Niveau I & Bonne \\
\hline
\end{tabular}




\begin{tabular}{|c|c|c|c|c|c|c|}
\hline \multicolumn{7}{|c|}{ Données sur l'innocuité } \\
\hline \multicolumn{5}{|c|}{ DÉTAIL DE L'ÉTUDE } & \multicolumn{2}{|c|}{ SOMMAIRE } \\
\hline Étude & Vaccin & $\begin{array}{l}\text { Devis de } \\
\text { l'étude }\end{array}$ & $\begin{array}{l}\text { Nombres de } \\
\text { participants }\end{array}$ & $\begin{array}{l}\text { Résumé des principales constatations } \\
\text { sous forme de texte ou de données }\end{array}$ & $\begin{array}{l}\text { Niveau } \\
\text { de preuve }\end{array}$ & Qualité \\
\hline $\begin{array}{l}\text { Frenck, } 2012 \\
\text { (30) }\end{array}$ & $\begin{array}{l}\text { PNEU-C-13/ } \\
\text { VTG - placebo } \\
\text { (1 mois plus } \\
\text { tard) } \\
\text { vs } \\
\text { placebo/NTG - } \\
\text { PNEU-C-13 } \\
(1 \text { mois plus } \\
\text { tard) } \\
0,5 \mathrm{ml} \mathrm{IM}\end{array}$ & $\begin{array}{l}\text { Essai } \\
\text { comparatif } \\
\text { randomisé } \\
\text { Population : } \\
\text { Sujets sains } \\
\text { de } 50-59 \text { ans, } \\
\text { n'ayant pas } \\
\text { déjà reçu le } \\
\text { vaccin } \\
\text { contre le } \\
\text { pneumocoque }\end{array}$ & $\begin{array}{l}\text { Multicentrique - } \\
\text { É.-U. } \\
\mathrm{N}=1158 \text { sujets } \\
\text { inscrits } \\
\mathrm{N}=1116 \text { sujets } \\
\text { répartis } \\
\text { aléatoirement } \\
\mathrm{N} 1=554 \\
\text { (PNEU-C-13/NTG) } \\
\text { N2 = 562 (VTG } \\
\text { puis PNEU-C-13) }\end{array}$ & $\begin{array}{l}\text { Innocuité : } \\
\text { a) Réactions locales : taux significativement } \\
\text { supérieur dans le groupe d'administration } \\
\text { concomitante vs VTG seul mais pas de } \\
\text { différence vs PNEU-C-13 seul } \\
\text { b) Réactions systémiques : taux accru de } \\
\text { participants présentant n'importe quel } \\
\text { effet systémique, céphalées, frissons, } \\
\text { éruption cutanée, perte d'appétit, } \\
\text { vomissements, douleurs articulaires } \\
\text { et musculaires dans le groupe } \\
\text { d'administration concomitante vs } \\
\text { VTG seul, mais comparativement au } \\
\text { PNEU-C-13 seul, uniquement taux } \\
\text { accru de participants présentant } \\
\text { n'importe quel effet systémique et } \\
\text { céphalées }\end{array}$ & Niveau I & Bonne \\
\hline $\begin{array}{l}\text { Schwarz, } \\
2011(31)\end{array}$ & $\begin{array}{l}\text { PNEU-C-13/ } \\
\text { VTG - placebo } \\
\text { (1 mois } \\
\text { plus tard) } \\
\text { vs } \\
\text { placebo/ VTG - } \\
\text { PNEU-C-13 } \\
\text { (1 mois plus } \\
\text { tard) } \\
0,5 \mathrm{ml} \mathrm{IM}\end{array}$ & $\begin{array}{l}\text { Essai } \\
\text { comparatif } \\
\text { randomisé } \\
\text { Tous les } \\
\text { sérotypes du } \\
\text { PNEU-C-13 } \\
\text { analysés } \\
\text { Sujets sains } \\
\text { de } 65 \text { ans ou } \\
\text { plus, n'ayant } \\
\text { pas déjà reçu } \\
\text { le vaccin } \\
\text { contre le } \\
\text { pneumocoque } \\
\text { Suivi jusqu'à } \\
1 \text { mois après } \\
\text { la dernière } \\
\text { administration } \\
\text { de vaccin }\end{array}$ & $\begin{array}{l}\text { Multicentrique - } \\
\text { Europe } \\
\mathrm{N}=1190 \text { sujets } \\
\text { inscrits; } 1160 \text { sujets } \\
\text { répartis } \\
\text { aléatoirement - } \\
580 \text { dans chaque } \\
\text { groupe } \\
1 \text { 096 sujets } \\
\text { évaluables }\end{array}$ & $\begin{array}{l}\text { Innocuité : } \\
\text { a) Réactions locales : semblables dans les } \\
\text { deux groupes } \\
\text { b) Réactions systémiques : taux accru de } \\
\text { participants présentant des frissons, } \\
\text { une éruption cutanée, des douleurs } \\
\text { musculaires, n'importe quel effet } \\
\text { systémique dans le groupe } \\
\text { d'administration concomitante vs VTG } \\
\text { seul } \\
\text { c) Taux accru de participants présentant } \\
\text { une fatigue, des céphalées, des } \\
\text { frissons, une perte d'appétit, des } \\
\text { douleurs articulaires, n'importe quel } \\
\text { effet systémique même dans le groupe } \\
\text { d'administration concomitante vs } \\
\text { PNEU-C-13 seul }\end{array}$ & Niveau I & Bonne \\
\hline
\end{tabular}




\section{TABLEAU 6. Niveaux de preuve fondés sur la méthodologie de la recherche}

\begin{tabular}{l|l}
\hline I & Données probantes provenant d'un ou de plusieurs essais cliniques comparatifs randomisés. \\
\hline II-1 & Données probantes provenant d'un ou de plusieurs essais cliniques comparatifs sans randomisation. \\
\hline II-2 & $\begin{array}{l}\text { Données probantes provenant d'études analytiques de cohortes ou cas/témoins, de préférence de plus d'un centre ou } \\
\text { groupe de recherche utilisant des indicateurs cliniques de résultats de l'efficacité d'un vaccin. }\end{array}$ \\
\hline II-3 & $\begin{array}{l}\text { Données probantes provenant d'études de plusieurs séries chronologiques avec ou sans intervention. Les résultats } \\
\text { spectaculaires obtenus dans un contexte non contrôlé (comme les résultats de l'introduction de la pénicilline dans les } \\
\text { années 1940) pourraient aussi être considérés comme faisant partie de ce type de données probantes. }\end{array}$ \\
\hline III & $\begin{array}{l}\text { Opinions d'experts reconnus se basant sur des expériences cliniques, des études descriptives et des études de cas ou des } \\
\text { rapports de comités d'experts. }\end{array}$ \\
\hline
\end{tabular}

\section{TABLEAU 7. Qualité des preuves (validité interne)}

\begin{tabular}{l|l}
\hline Bonne & $\begin{array}{l}\text { Étude (notamment les méta-analyses ou les recensions systématiques) répondant bien à tous les critères propres à la } \\
\text { méthodologie*. }\end{array}$ \\
\hline Moyenne & $\begin{array}{l}\text { Étude (notamment les méta-analyses ou les recensions systématiques) ne répondant pas (ou du moins pas clairement) à au } \\
\text { moins un critère propre à la méthodologie*, mais n'ayant pas de «lacune majeure » connue. }\end{array}$ \\
\hline Mauvaise & $\begin{array}{l}\text { Étude (notamment les méta-analyses ou les recensions systématiques) ayant au moins une « lacune majeure » propre à la } \\
\text { méthodologie* ou une accumulation de lacunes moins importantes ne permettant pas de formuler des recommandations à } \\
\text { partir des résultats de l'étude. }\end{array}$ \\
\hline
\end{tabular}

* Les critères spécifiques de la méthodologie générale sont décrits dans Haris et coll., $2001^{1}$.

\section{TABLEAU 8. Recommandation du CCNI concernant l'immunisation - Catégories}

\begin{tabular}{|c|c|}
\hline A & Le CCNI a conclu qu'il existait des données probantes suffisantes pour recommander l'immunisation. \\
\hline B & Le CCNI a conclu qu'il existait des données probantes acceptables pour recommander l'immunisation. \\
\hline C & $\begin{array}{l}\text { Le CCNI a conclu qu'il existait des données probantes contradictoires qui ne permettent pas de faire une recommandation } \\
\text { pour ou contre l'immunisation; cependant, d'autres facteurs peuvent influer sur la prise de décisions. }\end{array}$ \\
\hline D & Le CCNI a conclu qu'il existait des données probantes acceptables pour déconseiller l'immunisation. \\
\hline E & Le CCNI a conclu qu'il existait des données probantes suffisantes pour déconseiller l'immunisation. \\
\hline I & $\begin{array}{l}\text { Le CCNI a conclu qu'il existait des données probantes insuffisantes (en quantité ou en qualité) pour formuler une } \\
\text { recommandation; cependant, d'autres facteurs peuvent influer sur la prise de décisions. }\end{array}$ \\
\hline
\end{tabular}




\section{Liste des abréviations}

ABRÉVIATIONS

ARV

CMG

ECR

ERV

GCSH

GRÉ

HAART

IB

IIP

IM

LNM

LSPQ

MMF

OP

OPA

PNEU-C-13

PNEU-P-23

POC

RC

RR

SCSMDO

TIBDN

TMG

VTG

\section{TERME}

Antirétroviraux (traitement antirétroviral)

Concentration moyenne géométrique

Essai comparatif randomisé

Efficacité réelle du vaccin

Greffe de cellules souches hématopoḯtiques

Groupe à risque élevé

Traitement antirétroviral hautement actif

Infection buccale

Infection invasive à pneumocoque

Intramusculaire (voie)

Laboratoire national de microbiologie

Laboratoire de santé publique du Québec

Mofétilmycophénolate

Organe plein (greffe $d^{\prime}$ )

Activité opsonophagocytaire

Vaccin conjugué contre le pneumocoque - 13-valent

Vaccin polysaccharidique contre le pneumocoque - 23-valent

Pneumonie d'origine communautaire

Rapport de cotes

Rapport de risque

Système canadien de surveillance des maladies à déclaration obligatoire

Toronto Invasive Bacterial Disease Network

Titre moyen géométrique

Vaccin trivalent contre la grippe 


\section{Références}

(1) An Advisory Committee Statement (ACS). National Advisory Committee on Immunization (NACl). Statement on recommended use of pneumococcal conjugate vaccine. Can Commun Dis Rep. Jan 15 2002;28(ACS-2):1-32.

(2) Update on the recommendations for the routine use of pneumococcal conjugate vaccine for infants. An Advisory Committee Statement (ACS). Can Commun Dis Rep. May 1 2006;32(ACS-4):1-6.

(3) National Advisory Committee on Immunization (NACl). Update on the Use of Pneumococcal Vaccines in Childhood. Can Commun Dis Rep. 2010;36(ACS-12):1-21.

(4) Evidence-based recommendations for immunization-methods of the National Advisory Committee on Immunization. An Advisory Committee Statement (ACS). Can Commun Dis Rep. Jan 2009;35(ACS-1):1-10.

(5) World Health Organization. Pneumococcal Disease. 2012; www.who.int/ith/diseases/pneumococcal/en/ index.html.

(6) Demczuk WH, Martin I, Griffith A, et al. Serotype distribution of invasive Streptococcus pneumoniae in Canada during the introduction of the 13-valent pneumococcal conjugate vaccine, 2010. Can J Microbiol. Aug 2012;58(8):1008-1017.

(7) National Microbiology Laboratory. National Laboratory Surveillance of Streptococcus pneumoniae and Streptococcus pyogenes in Canada: Annual Summary 2010, 2010.

(8) National Microbiology Laboratory. National Laboratory Surveillance of Streptococcus pneumoniae and Streptococcus pyogenes in Canada: Annual Summary 2011, 2011.

(9) French N, Gordon SB, Mwalukomo T, et al. A trial of a 7-valent pneumococcal conjugate vaccine in HIV-infected adults. N Engl J Med. Mar 4 2010;362(9):812-822.

(10) Siemieniuk RA, Gregson DB, Gill MJ. The persisting burden of invasive pneumococcal disease in HIV patients: an observational cohort study. BMC Infect Dis. 2011;11:314.
(11) Breiman RF, Keller DW, Phelan MA, et al. Evaluation of effectiveness of the 23-valent pneumococcal capsular polysaccharide vaccine for HIV-infected patients. Arch Intern Med. Sep 25 2000;160(17):2633-2638.

(12) Hung CC, Chen MY, Hsieh SM, Hsiao CF, Sheng WH, Chang SC. Clinical experience of the 23-valent capsular polysaccharide pneumococcal vaccination in HIV-1-infected patients receiving highly active antiretroviral therapy: a prospective observational study. Vaccine. May 7 2004;22(15-16):2006-2012.

(13) French N, Nakiyingi J, Carpenter LM, et al. 23-valent pneumococcal polysaccharide vaccine in HIV-1-infected Ugandan adults: double-blind, randomised and placebo controlled trial. Lancet. Jun 17 2000;355(9221):2106-2111.

(14) Vila-Corcoles A, Ochoa-Gondar O, Llor C, Hospital I, Rodriguez T, Gomez A. Protective effect of pneumococcal vaccine against death by pneumonia in elderly subjects. Eur Respir J. Dec 2005;26(6):1086-1091.

(15) Vila-Corcoles A, Ochoa-Gondar O, Hospital I, et al. Protective effects of the 23-valent pneumococcal polysaccharide vaccine in the elderly population: the EVAN-65 study. Clin Infect Dis. Oct 1 2006;43(7):860-868.

(16) Mooney JD, Weir A, McMenamin J, et al. The impact and effectiveness of pneumococcal vaccination in Scotland for those aged 65 and over during winter 2003/2004. BMC Infect Dis. 2008;8:53.

(17) Melegaro A, Edmunds WJ. The 23-valent pneumococcal polysaccharide vaccine. Part I. Efficacy of PPV in the elderly: a comparison of meta-analyses. Eur J Epidemiol. 2004;19(4):353-363.

(18) Nahm MH, Romero-Steiner S. Functional Assays for Pneumococcal Antibody. In: Siber G, Klugman KP, Makela PH, eds. Pneumococcal Vaccines - The Impact of Conjugate Vacine. Washington, DC: ASM Press; 2008:449.

(19) Kumar D, Chen MH, Wong G, et al. A randomized, double-blind, placebo-controlled trial to evaluate the prime-boost strategy for pneumococcal vaccination in adult liver transplant recipients. Clin Infect Dis. Oct 1 2008;47(7):885-892. 
(20) Kumar D, Rotstein C, Miyata G, Arlen D, Humar A. Randomized, double-blind, controlled trial of pneumococcal vaccination in renal transplant recipients. J Infect Dis. May 15 2003;187(10):1639-1645.

(21) Kumar D, Welsh B, Siegal D, Chen MH, Humar A. Immunogenicity of pneumococcal vaccine in renal transplant recipients--three year follow-up of a randomized trial. Am J Transplant. Mar 2007;7(3):633-638.

(22) Tobudic S, Plunger V, Sunder-Plassmann G, Riegersperger M, Burgmann $\mathrm{H}$. Randomized, single blind, controlled trial to evaluate the prime-boost strategy for pneumococcal vaccination in renal transplant recipients. PLoS One. 2012;7(9):e46133.

(23) Cordonnier C, Labopin M, Chesnel V, et al. Randomized study of early versus late immunization with pneumococcal conjugate vaccine after allogeneic stem cell transplantation. Clin Infect Dis. May 15 2009;48(10):1392-1401.

(24) Molrine DC, Antin JH, Guinan EC, et al. Donor immunization with pneumococcal conjugate vaccine and early protective antibody responses following allogeneic hematopoietic cell transplantation. Blood. Feb 1 2003;101(3):831-836.

(25) Kumar D, Chen MH, Welsh B, et al. A randomized, double-blind trial of pneumococcal vaccination in adult allogeneic stem cell transplant donors and recipients. Clin Infect Dis. Dec 15 2007;45(12):1576-1582.

(26) Feikin DR, Elie CM, Goetz MB, et al. Randomized trial of the quantitative and functional antibody responses to a 7-valent pneumococcal conjugate vaccine and/or 23-valent polysaccharide vaccine among HIV-infected adults. Vaccine. Nov 12 2001;20(3-4):545-553.

(27) Penaranda M, Payeras A, Cambra A, Mila J, Riera M. Conjugate and polysaccharide pneumococcal vaccines do not improve initial response of the polysaccharide vaccine in HIV-infected adults. Aids. May 15 2010;24(8):1226-1228.

(28) Crum-Cianflone NF, Huppler Hullsiek K, Roediger M, et al. A randomized clinical trial comparing revaccination with pneumococcal conjugate vaccine to polysaccharide vaccine among HIV-infected adults. J Infect Dis. Oct 1 2010;202(7):1114-1125.

(29) Lesprit P, Pedrono G, Molina JM, et al. Immunological efficacy of a prime-boost pneumococcal vaccination in HIV-infected adults. Aids. Nov 30 2007;21(18):2425-2434.
(30) Frenck RW, Jr., Gurtman A, Rubino J, et al. Randomized, controlled trial of a 13-valent pneumococcal conjugate vaccine administered concomitantly with an influenza vaccine in healthy adults. Clin Vaccine Immunol. Aug 2012;19(8):1296-1303.

(31) Schwarz TF, Flamaing J, Rumke HC, et al. A randomized, double-blind trial to evaluate immunogenicity and safety of 13-valent pneumococcal conjugate vaccine given concomitantly with trivalent influenza vaccine in adults aged $>/=65$ years. Vaccine. Jul 18 2011; 29(32):5195-5202.

(32) Jackson LA, Neuzil KM, Nahm MH, et al. Immunogenicity of varying dosages of 7-valent pneumococcal polysaccharide-protein conjugate vaccine in seniors previously vaccinated with 23 -valent pneumococcal polysaccharide vaccine. Vaccine. May 16 2007;25(20):4029-4037.

(33) de Roux A, Schmole-Thoma B, Siber GR, et al. Comparison of pneumococcal conjugate polysaccharide and free polysaccharide vaccines in elderly adults: conjugate vaccine elicits improved antibacterial immune responses and immunological memory. Clin Infect Dis. Apr 1 2008;46(7):1015-1023.

(34) Miernyk KM, Butler JC, Bulkow LR, et al. Immunogenicity and reactogenicity of pneumococcal polysaccharide and conjugate vaccines in alaska native adults $55-70$ years of age. Clin Infect Dis. Jul 15 2009;49(2):241-248.

(35) Goldblatt D, Southern J, Andrews N, et al. The immunogenicity of 7-valent pneumococcal conjugate vaccine versus 23 -valent polysaccharide vaccine in adults aged 50-80 years. Clin Infect Dis. Nov 1 2009; 49(9):1318-1325.

(36) Schenkein JG, Park S, Nahm MH. Pneumococcal vaccination in older adults induces antibodies with low opsonic capacity and reduced antibody potency. Vaccine. Oct 9 2008;26(43):5521-5526.

(37) Musher DM, Manoff SB, Liss C, McFetridge RD, Marchese RD, Bushneil B, Alvarez F, Painter C, Blum $M D$, Silber JL. Safety and antibody response, including antibody persistence for 5 years, after primary vaccination or revaccination with pneumococcal Polysaccharide vaccine in middle-aged and older adults. J Infect Dis. Oct 1 2010;201(4):516-524.

(38) Pfizer Canada. Product Monograph - Prevnar 13. 2012; www.pfizer.ca/en/our_products/products/monograph/232. Accessed 2012-08-28. 
(39) Vanderkooi OG, Scheifele DW, Girgenti D, et al. Safety and immunogenicity of a 13-valent pneumococcal conjugate vaccine in healthy infants and toddlers given with routine pediatric vaccinations in Canada.

Pediatr Infect Dis J. Jan 2012;31(1):72-77. 